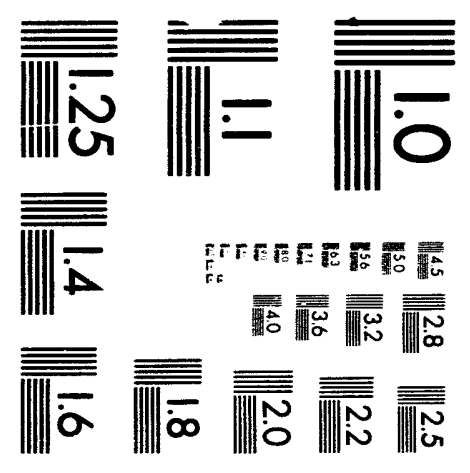



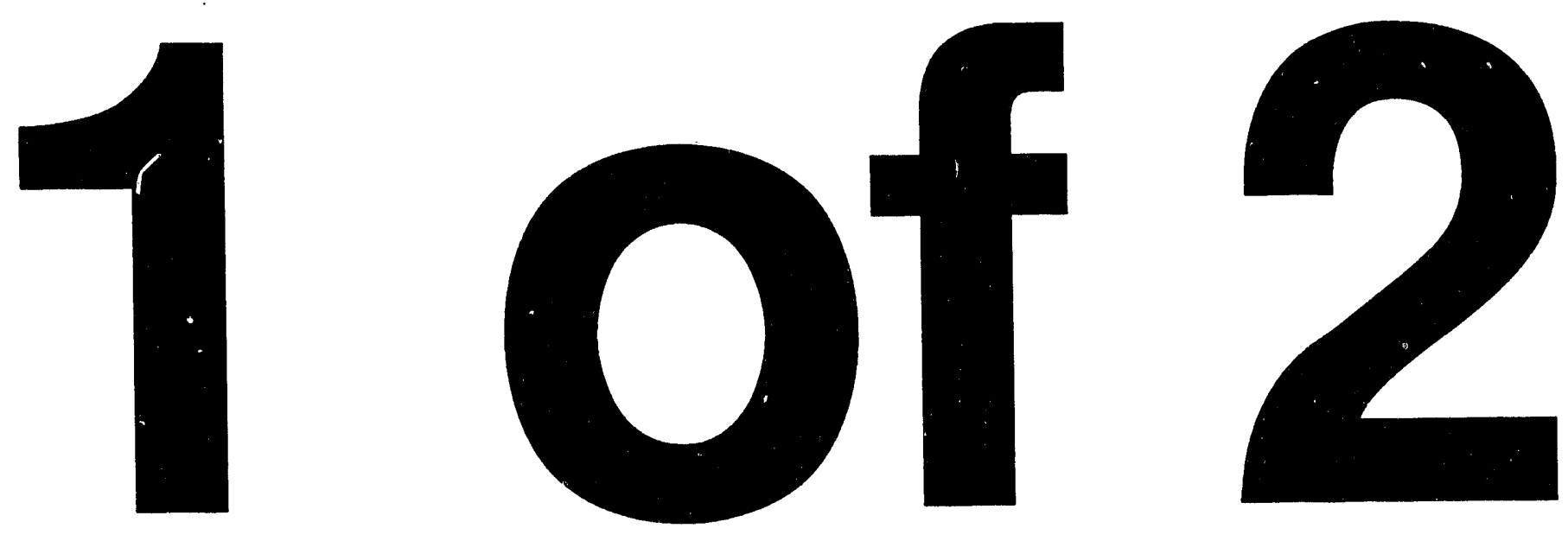


\section{CONTENTS:}

Purpose of Program

Student List

Seminar Speakers

Projects 


\section{SUMMER UNDERGRADUATE RESEARCH PROGRAM: ENUIRONMENTAL STUDIES}

The purpose of the summer undergraduate internship program for research in environmental studies is to provide an opportunity for well-qualified students to undertake an original research project as an apprentice to an active research scientist in basic environmental research. The students are offered research topics in the areas of toxicology, risk assessment, environmental microbiology and marine sciences. During the ten week period that the students are on campus, several seminars are presented by participating faculty and invited lecturers highlighting aspects of research in the areas of environmental scierce. At the end of their ten week internship the students are required to give an oral presentation of their research and to turn in a written report on the project. By undertaking an independent research project the students will gain an understanding and appreciation of the process whereby scientific theory is developed, tested, and documented.

The program was very fortunate in this, its year of inception, to have attracted the interest of many qualified applicants. Ten well-qualified students from throughout the midwestern and eastern areas of the country were accepted into the program. These students selected projects in the areas of marine sciences, biostatistics and epidemiology, and toxicology. The research experience for all these students and their mentors was very positive. The seminars were well-attended and the students showed their interest in the presentations and environmental sciences as a whole by presenting the speakers with thoughtful and intuitive questions. The oral presentations and written reports by the students were well done and were approached with enthusiasm. Several students have stated that the introduction to and experience in research they gained from this program has provided them with the option of pursuing research in environmental sciences as a career goal. This summer program has shown itself to be a valuable educational tool. 


\title{
SUMMER UNDERGRADUATE RESEARCH PROgRAM: ENUIRONMENTIIL STUDIES
}

\author{
Summer 1993
}

\section{$\underline{\text { Student List }}$}

\section{Student: SaraJane Carlson}

College/University: University of Michigan

Major: Biology

Ann Arbor, MI

Mentor: Karen Burnett, Ph.D.

Marine Biomedical and Environmental Sciences

Project Title: Assays of immune response in the red drum, Sciaenops acellatus, as tools for monitoring "environmental health" in estuarine systems.

Student: Kimberly Frampton

College/University: Presbyterian College

Major: Biology

Clinton, SC

Mentor. Susan Morrison, Ph.D.

Biology Department, University of Charleston

Project Title: Fit to eat? The effects of microwaving on the bacterial counts in oysters.

\section{Student: Jill Huntington}

College/University: State University of New York - Buffalo

Major: Undeclaired

Buffalo, NY

Mentor: Peter Moeller, Ph.D.

National Marine Fisheries Service and

Marine Biomedical and Environmental Sciences

Project Title: Isolation and purification of marine biotoxins produced by $a$ Caribbean strain of Gambierdiscus toxicus.

Student: Lisa Johnson

College/University: Long Island University - Southampton

Major: Marine Science/Biology

Mentor. Donald DiBona, Ph.D.

Marine Biomedical and Environmental Sciences

Project Title: Sister chromatid exchange as an indicator of environmental stress. 
Student: Rachel Levine

College/University: Wesleyan University

Middletown, CT

Major: Earth Science/Environmental Science

Mentor. Donald DiBona, Ph.D.

Marine Biomedical and Environmental Sciences

Project Title: Use of diatom distributions to monitor environmental health.

Student: Katherine Maze

College/University: Georgetown College

Georgetown, KY

Major: Biology/Environmental Science

Mentor: Greg Doucette, Ph.D.

Marine Biotoxin Program, National Marine Fisheries Service and

Marine Biomedical and Environmental Sciences

Project Title: Bacterial production of PSP toxins.

Student: R. Blaine McClesky

College/University: College of Charleston

Major: Biochemistry Charleston, SC

Mentor. Fran Van Dolah, Ph.D.

Marine Biotoxin Program, National Marine Fisheries Service and Marine Biomedical and Environmental Sciences

Project Title: Growth inhibition in GH4Cl cells: effects of MTX and TGFa.

Student: Matthew Mitchell

College/University: Cedarville College

Major: Biology

Cedarville, $\mathrm{OH}$

Mentor. Daniel Lackland, Ph.D.

Department of Biostatistcs, Epidemiology and System Sciences

Project Title: An epidemiological study of leukemia in South Carolina:

Student: B. Charlotte Smith

College/University: College of Charleston

Major: Applied Mathematics

Charleston, SC

Mentor: Zhen Zhang, Ph.D.

Department of Biostatistics, Epidemiology and System Sciences

Project Title: Pharmacokinetics - physiological vs mathematical, a systems science approach.

Student: Amy Weaver

College/University: College of Charleston

Major: Mathematics

Charleston, SC

Mentor. JoEllyn McMillan, Ph.D.

Department of Cell and Molecular Pharmacology and Experimental Therapeutics

Project Title: Toluene toxicity: metabolism by isolated rat hepatocytes. 


\title{
SUMMER UNDERGRADURTE RESEARCH PROGRAM: ENUIRONMENTAL STUDIES
}

Summer 1993

\section{Seminar Speakers}

\author{
Dr. Fred Holland \\ Director \\ South Carolina Wildlife and Marine Resources Research Institute \\ Title: Overview of Coastal Environmental Issues \\ Dr. Michael Schmidt \\ Assistant Professor \\ Department of Microbiology and Immunology \\ Medical University of South Carolina \\ Title: Environmental Microbiology \\ Dr. Daniel Lackland \\ Assistant Professor \\ Department of Biostatistics, Epidemiology and Systems Science \\ Medical University of South Carolina \\ Title: Epidemiological Assessments of Environmental Hazards
}


Assays of Immune Response in the Red Drum. Sciaenops ocellatus. as Tools for Monitoring "Environmental Health" in Estuarine Systems.

Researcher:

SaraJane V. Carlson

University of Michigan

Summer Undergraduate Research Program, 1993

Medical University of South Carolina

Funded by:

United States Department of Energy

Mentor:

Karen G. Burnett, Ph.D.

Associate Professor

Department of Marine Biomedical and Environmental Sciences

Medical University of South Carolina

221 Fort Johnson Road

Charleston, South Carolina 29412 
Assays of Immune Response in the Red Drum. Sciaenops ocellatus. as Tools for Monitoring "Environmental Health" in Estuarine Systems.

\section{INTRODUCTION}

The quality of a habitat greatly impacts the health of the organisms which are found within it. Animal health itself can be measured in many ways, and the selection of an assay which might be diagnostic for habitat quality must be validated for this particular application. Teleost fish have a sophisticated immune system similar to that of other vertebrates which may be sufficiently sensitive to reflect environmental quality. In one early study, Goncharov and Mikryakov (1970) found a correlation between the concentrations of phenols and antibody production in carp and subsequently proposed that the immune systems of fish might be useful in monitoring the levels of toxins in their environment. Additional studies have shown immunosuppression of the humoral responses of fish due to other pollutants such as polycyclic aromatic hydrocarbons (Spitsbergen et al., 1986: Payne and Fancey, 1989.) In light of these date, it may be possible to determine the environmental health of an area by monitoring immune responses of the indigenous fish.

Fish normally carry and are exposed to an array of bacteria with which they live commensally" (Bullock and Snieszko, 1969). Healthy, immunocompetent fish might be expected to produce humoral responses against their co-occurring bacteria. The present studies utilized Sciaenops ocellatus, commonly known as the red drum or spot-tail bass, which is a teleost fish native to the estuaries and near shore waters of the Southeastern United States. Two populations of red drum, one of apparently healthy and one of suspected unhealthy animals were sampled in an attempt to determine whether the health of individuals could actually be monitored by assays for humoral response against indigenous bacteria.

\section{Materials and Methods:}

Experimental Sites: Our study focused on two estuarine systems, the first in Charleston Harbor (Grice Cove), Charleston, South Carolina, and the second in Winyah Bay (Mother Norton Shoals), Georgetown, South Carolina. These fish populations were selected based on previous animal health observations by the staff of the South 
Carolina Wildlife and Marine Resources Department during January and February, 1993. These workers noted generally healthy individuals in the Grice Cove area, while almost half of the individuals in Winyah Bay displayed open reddish sores on their flanks. For the present study, specimens were collected by stop net on May 10, 1993 and June 17, 1993 from Grice Cove, as well as by trammel net from Winyah Bay on May 19, 1993. In an additional netting attempt on July 14, 1993, no red drum were captured.

Specimen Collection: After capturing fish, we visually assessed the health of each individual and coded them according to the criteria in Table 1. About $4 \mathrm{ml}$ of blood was obtained from all captured red drum of "2" or "3" health and from approximately ten fish of "1" health during each collection. The blood was placed in non-activated clot tubes and left on ice for at least 30 minutes before centrifugation at $1800 \mathrm{rpm}$ for 10 minutes. The separated sera was aliquotted into microcentrifuge tubes, then stored at $-20^{\circ} \mathrm{C}$. We also swabbed the flanks of some red drum to collect mucosal slime with which we inoculated Trypticase Soy Agar (TSA) plates to promote growth of the harbored bacteria. The plates were incubated at $25^{\circ} \mathrm{C}$ for up to 72 hours.

Isolation and Identification of Bacteria: We picked isolated colonies of bacteria from the inoculated TSA plates to re-isolate them on TSA. Each originally picked colony was re-plated on TSA two to four times to ensure isolation. We distinguished isolates by morphological observations and labeled each with a type number. Backup vials of each isolate were stored in a freezing solution of $10 \%$ glycerol in phosphate buffered saline (PBS) by washing cultures from TSA slants after 48 hour growth and storing those suspensions at $-70^{\circ} \mathrm{C}$. We stored working slants of each isolate at $4^{\circ} \mathrm{C}$. For use in identifying the bacteria, we gram stained all bacteria, then tested each isolate using O/F Dextrose tubed media, motility media, tubed, Triple Sugar Iron slants, and novobiocine disks which we obtained through BBL and using Pseudomonas F agar obtained from Difco Laboratories. Each isolate was also tested using selected biochemical tests in the Becton and Dickinson Minitech system for differentiation of bacteria in addition to cytochrome oxidase and indole spot test reagents. Some isolates $(t 1,9,12,16,17,18,19)$ were also tested on the api 20E System. Both systems were tested for equivalent results at temperatures of $25^{\circ} \mathrm{C}$ and $37^{\circ} \mathrm{C}$. 
Bacterial Antigen Preparation: To prepare antigens for use in ELISAs (enzyme-linked immunosorbent assays) we inoculated $5 \mathrm{ml}$ of Trypticase Soy Broth (TSB) in a culture tube and incubated them at room temperature (RT) with agitation. After growth to maximal densities (between 8 to 36 hours depending on the growth rate of individual isolates) we inoculated $100 \mathrm{ml}$ culture bottles containing $50 \mathrm{ml}$ of TSB with $100 \mathrm{ul}$ or $250 \mathrm{ul}$ (volume was dependent on growth rate) of the $5 \mathrm{ml}$ cultures. We incubated the $50 \mathrm{ml}$ cultures at $\mathrm{RT}$ for 18 hours, or until they reached an optical density of 0.3 or greater at $660 \mathrm{~nm}$. We then transferred the cultures and centrifuged them at $3500 \mathrm{rpm}$ for 20 minutes. (Some variation in centrifugation occurred due to use of different centrifuges and because some species such as t7, were unable to be recovered from the supernatant after such high speeds of centrifugation.) We washed the bacteria twice by resuspending them in PBS and centrifuging at $3500 \mathrm{rpm}$ for 20 minutes. After the second wash we resuspended the bacteria to an O.D. of between 0.25 and 0.34 to correspond to a density of about $5 \mathrm{x}$ $10^{8}$ cells $/ \mathrm{ml}$, as estimated using the McFarland Standard no. 0.5. We heated-killed the standardized bacterin preparations in a boiling water bath for 30 minutes, then froze $5 \mathrm{ml}$ aliquots of these bacterin preparations at $-20^{\circ} \mathrm{C}$.

ELISAs: ELISAs were run using the standard method with the following modification of volumes. We coated the wells by adding $50 u l$ of the bacterins and letting the plates dry overnight in a $37^{\circ} \mathrm{C}$ incubator. We blocked the plates for 2 to 4 hours with Blotto Blocker in PBS obtained from Pierce which was also used for all subsequent antigen dilutions. Between coats, we washed the plate three times using PBS containing $0.1 \%$ Tween. For general screening we used the collected sera as the primary antigen at a 1:30 dilution (50 ul), the mouse-anti-red drum monoclonal antibody (previously develcped in our laboratory) for the secondary antigen at a 1:5000 dilution (100ul), and a 1:500 dilution of goat-anti-mouse horseradish peroxidase conjugate (HRP) as the tertiary antigen (100 ul.) Tle color was developed using the Peroxidase Substrate Kit ABTS obtained from Bio-Rad, then the plates were read on a Molecular Devices spectrophotometer at $405 \mathrm{~nm}$. We ran blanks for each antigen ( $1^{\circ}$ coat Blotto Blocker) and subtracted these values from the appropriate wells. We ran positive controls to ensure working procedures by coating some wells with HSA/DNP and using serum from an HSA/DNP immunized fish which showed previous reactivity as the primary antigen. All other steps in the assay were conserved in the control wells. 
Results:

Identification of Bacteria: All isolates were gram-negative short rods as observed through magnification of the gram-stained slides under oil-immersion. An identification scheme for bacterial fish pathogens and additional identification charts provided the basis for identifying the bacterial isolates (MacFaddin, 1980, Austin, B. and D. A. Austin, 1987). The Minitech and api 20E differentiation systems, both developed for use with human pathogens and designed for incubation at $37^{\circ} \mathrm{C}$, showed varying results at the $25^{\circ} \mathrm{C}$ and $37^{\circ} \mathrm{C}$ incubations, therefore diminishing the reliability of the results. It was noted in the bacterial profiles of the estuaries, that Pseudomonas species were evident in Winyah Bay, but no Aeromonas species were found. In contrast, some Aeromonas species, but no Pseudomonas species were isolated from Grice Cove.

Serum Reactivities: The antibody reactivity profiles generated by the ELISA showed a striking difference between the immune responses of the two populations of fish. The optical densities of each serum reactivity against all isolates are listed in Table 3 . In analyzing these data it is apparent that the " 1 " rated animals from Grice Cove show a wide range of reactivities against the isolates from Grice Cove (Figure 1) and Winyah Bay (Figure 2,) as well as against those from the recirculating tanks (not shown.) In the ELISAs, most sera from the Grice Cove red drum generated O.D.s greater than 0.500 . In contrast, the sera from Winyah Bay red drum generated very low $(<0.500)$ O.D. readings.

It appears that the immune responses elicited by each bacterium varies greatly. Those species which mounted the greatest responses were the Aeromonads and Pseudomonads (excepting Pseudomonas fluorescens.) In general the sera all seem to show the lowest immune responses to the Enterobacter species.

A comparison of serum responses of the "1" and "2" rated fish from Grice Cove (Figure 3) shows no apparent differences in the magnitude of reactivities, or in the pattern of responses across the entire panel of bacteria. In making the same comparison on Winyah Bay animals (Figure 4), once again the pattern and magnitude of the ELISA responses between the "1," "2" and " 3 " health categories were not strikingly different. But, when comparing Figures 4 and 5, the difference between antibody responses in the two populations are visible. 


\section{Discussion:}

The fish health assessment data does indicate that there may be a higher incidence of fish with external physical damage in the population at Winyah Bay, although, due to the small number of specimens captured in this area we are unable to make conclusions on the comparative visual health of the populations in these estuaries. From comparison of the immune responses measured in the different health categories within each population (Figures 3 and 4), we are able to infer that simple visual assessments are not sensitive indicators of the immunocompetence of a fish, and so it follows, would not be sensitive tools for the assessment of the environmental health of estuaries.

From these primary screenings of sera, it seems that the information from the ELISAs that could be most useful in indicating the health of individuals may be the magnitude of the optical densities when tested against a variety of bacterins. There is a wide range of individual responses even between two apparently healthy animals from the same area, as shown by the profiles of two animals from Grice Cove in Figure 5. The variable responses to a single bacteria across a population of healthy fish may be due to the degree of individual exposure to that bacteria. Even an immunocompetent fish will not show antibodies against bacteria that have not been introduced into their immune system, unless that bacteria has similar epitopes to another species which the fish has seen, causing cross-reactivity of an antibody. However, Figure 5 also suggests that it may be possible to select a panel of bacteria against which most immunocompetent animals show significant ELISA reactivity. It is interesting to note that Winyah Bay animals show a similarly high variance in response when ELISA readings are plotted on a log scale. This is evidence that the Winyah Bay animals may be eliciting very small responses to bacteria they are exposed to, but that because of their probable immunosuppression, their responses are very small. Alternatively, it is possible that this variation is due to reduced sensitivity of the ELISA at low levels of antibody.

For further use of the ELISA as a diagnostic tool in assessing animal and environmental health, it may be necessary to study animals with defined immunocompetence and immunosuppression. This data could be used to establish an optical density as a "cut-off" point between a true humoral response and background signals due 
to the physical insensitivities of the assay. In previous studies involving purified protein antigens, 0.100 O.D. has been the "cut-off" point, above which animals were considered to show antibody response to the antigen. In the current study, though, it is not known how the bacterial antigens non-specifically react and affect the background signals.

Overall, the data show that populations of apparently healthy red druni are capable of mounting humoral immune responses against indigenous bacteria. The population of suspected unhealthy red drum studied failed to show humoral immune responses to these bacteria, leading to the conclusion that assays for the immune responses of the red drum may be useful indicators of environmental health. Additional work must be done to narrow the panel of bacteria for further screening, creating one to which most immunocompetent fish will show at least one antibody response and which will be useful in testing additional estuaries and microhabitats within the previously studied estuaries. It is also necessary to continue sampling at time points throughout the year in order to monitor possible seasonal fluctuations in antibody response due to temperature variations.

In the process of identification of the bacteria, the Minitech and api $20 \mathrm{E}$ systems showed variable responses at the $25^{\circ} \mathrm{C}$ and $37^{\circ} \mathrm{C}$ incubations. This may be due to the suppressed or inhibited growth of the fish bacteria at the higher temperature. Variable results in replicates run at $25^{\circ} \mathrm{C}$ in the Minitech system indicate that this system may be unreliable when used for bacteria with maximum growth rates at $25^{\circ} \mathrm{C}$. It is possible, though, that this variance is due to differences in techniques or true variability in the biochemical reactions within the strain of bacteria. Duplicates were not tested in the api $20 \mathrm{E}$ system, so further tests need to be run to test this system for reliability and reproducibility at $25^{\circ} \mathrm{C}$.

\section{Acknowledgements:}

I would like to thank Dr. Karen Burnett, my mentor, for her insight and drive in creating this project, and her valuable knowledge and support which she imparted to me throughout the project. I would also like to thank Leslie Schwarz and Kent MacDougal for their technical assistance in the laboratory, Bill Roumillat and George Reikerk for their invaluable knowledge of red drum and for 
collection of specimens, and $\mathrm{M}$. Yvonne Bobo for assisting in microbiological techniques. I must also thank the United States Department of Energy for making my research possible through funding this research program.

References:

Austin, B. and D.A Austin. Bacterial Fish Pathogens: disease in farmed and wild fish. Ellis Horwood Limited, Chichester, England. 1987.

Bullock, G. L. and S. F. Sniesko. 1969. Bacteria in blood and kidney of apparently healthy hatchery trout. Trans. Am. Fish. Soc. 98: $268-71$.

Goncharov, G. D. and V. R. Mikryakov. 1970. The effect of low concentrations of phenol on antibody formation in carp, Cyprinus carpio L. Problems of Aquatic Toxicology, published by "Nauka" Moscow. Translated by : Bur. of Sport Fisheries \& Wildlife, Div. of Fish. Research. 1971. 7 p.

Mac Faddin, J. F. Biochemical Tests for Identification of Medical Bacteria, 2nd ed. Wiliams \&Wilkins, Baltimore, Maryland 1980.

Spitsbergen, J. M., Schat, K. A., Kleeman, J. M. and R. E. Peterson. 1986. Interactions of 2, 3, 7, 8-tetrachorodibenzo-p-dioxin (TCDD) with the immune response of reinbow trout. Vet. Immun. Immunopath 12: 263-80.

Payne, J.F. and L. F. Fancey. 1989. Effect of polycyclic aromatic hydrocarbons on immune responses in fish: change in melanomacrophage centers in flounder (Pseudopleuronectes americanus) exposed to hydrocarbon-contaminated sediments. Mar. Environ. Res. 28: 431-35. 

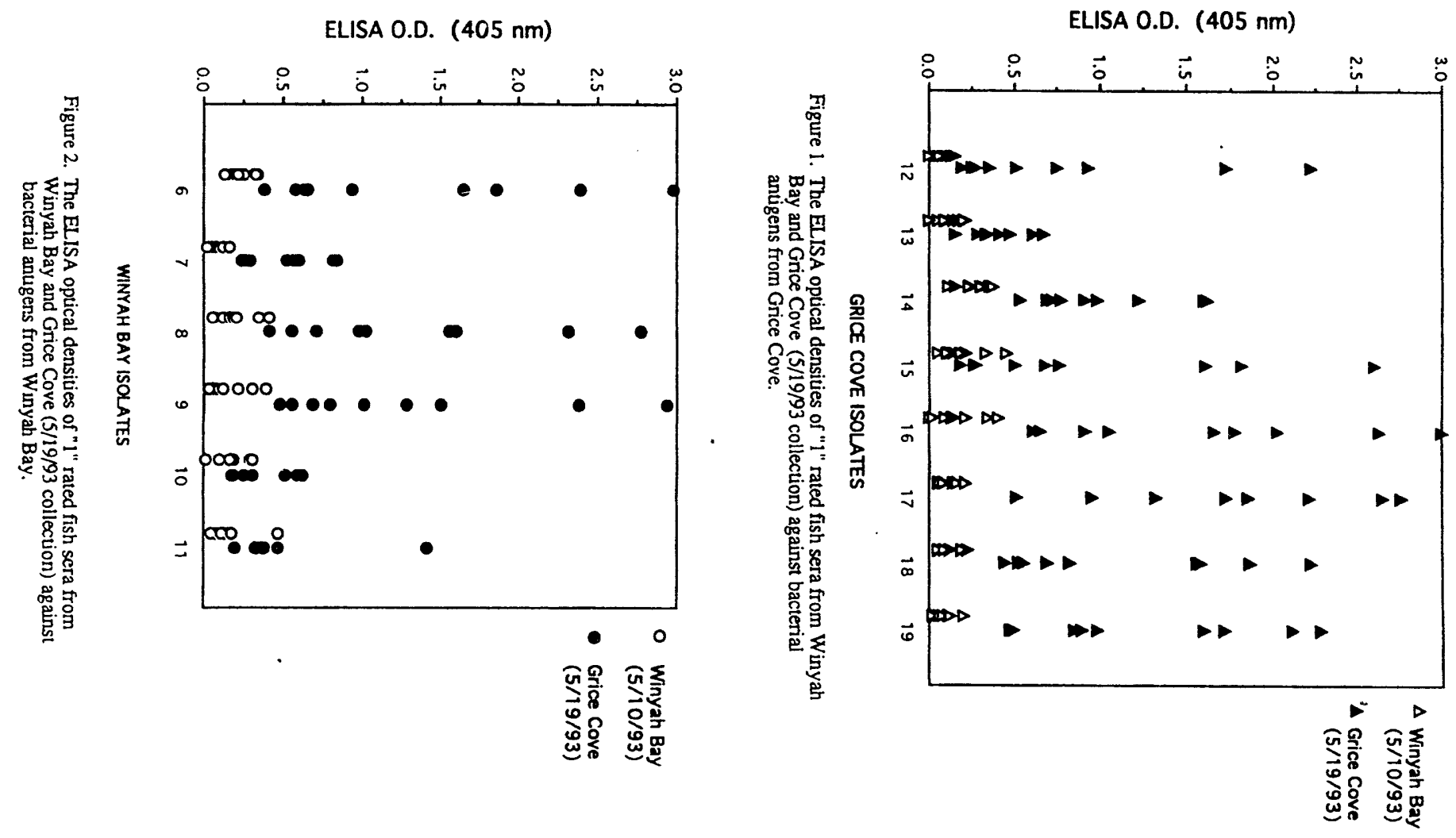

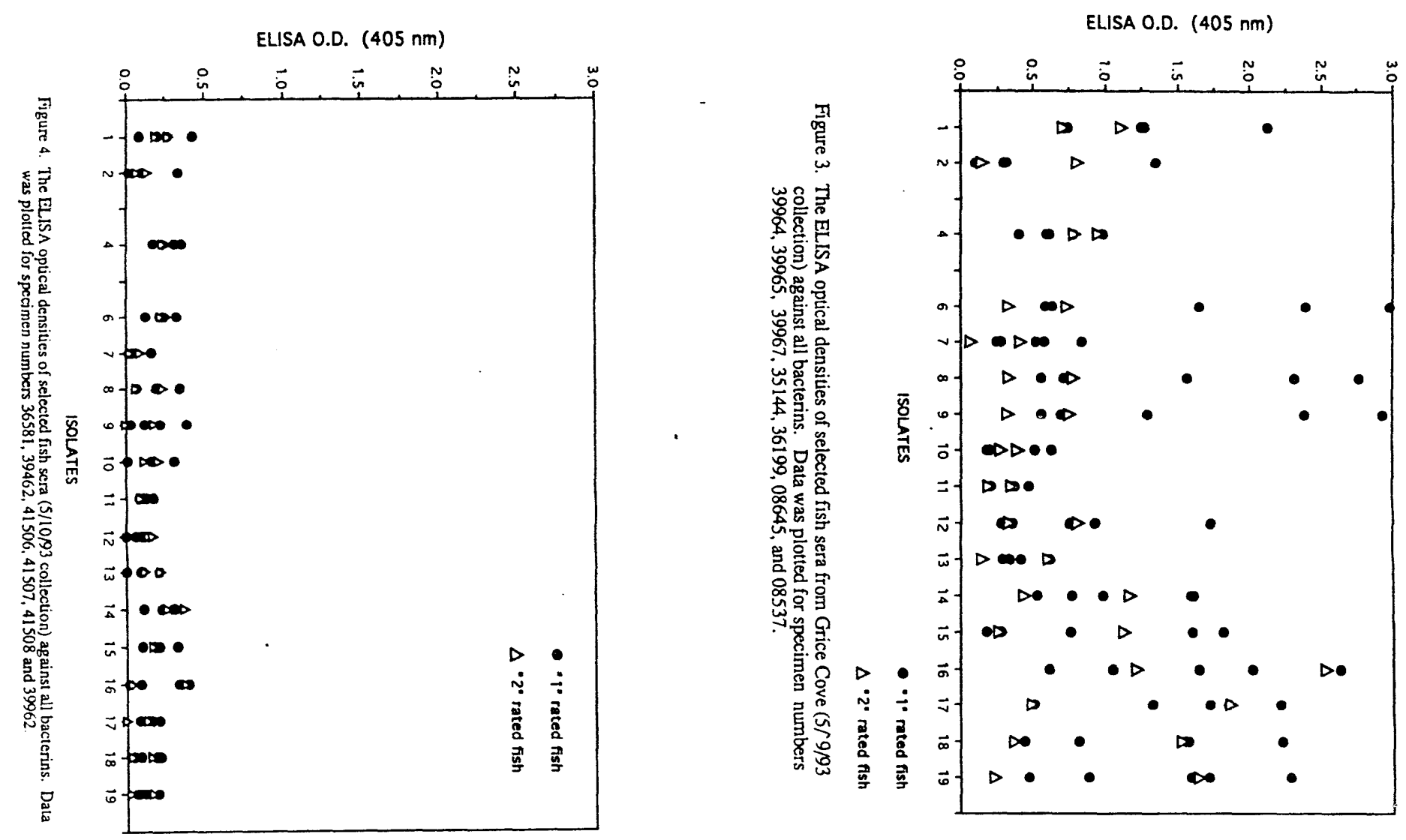


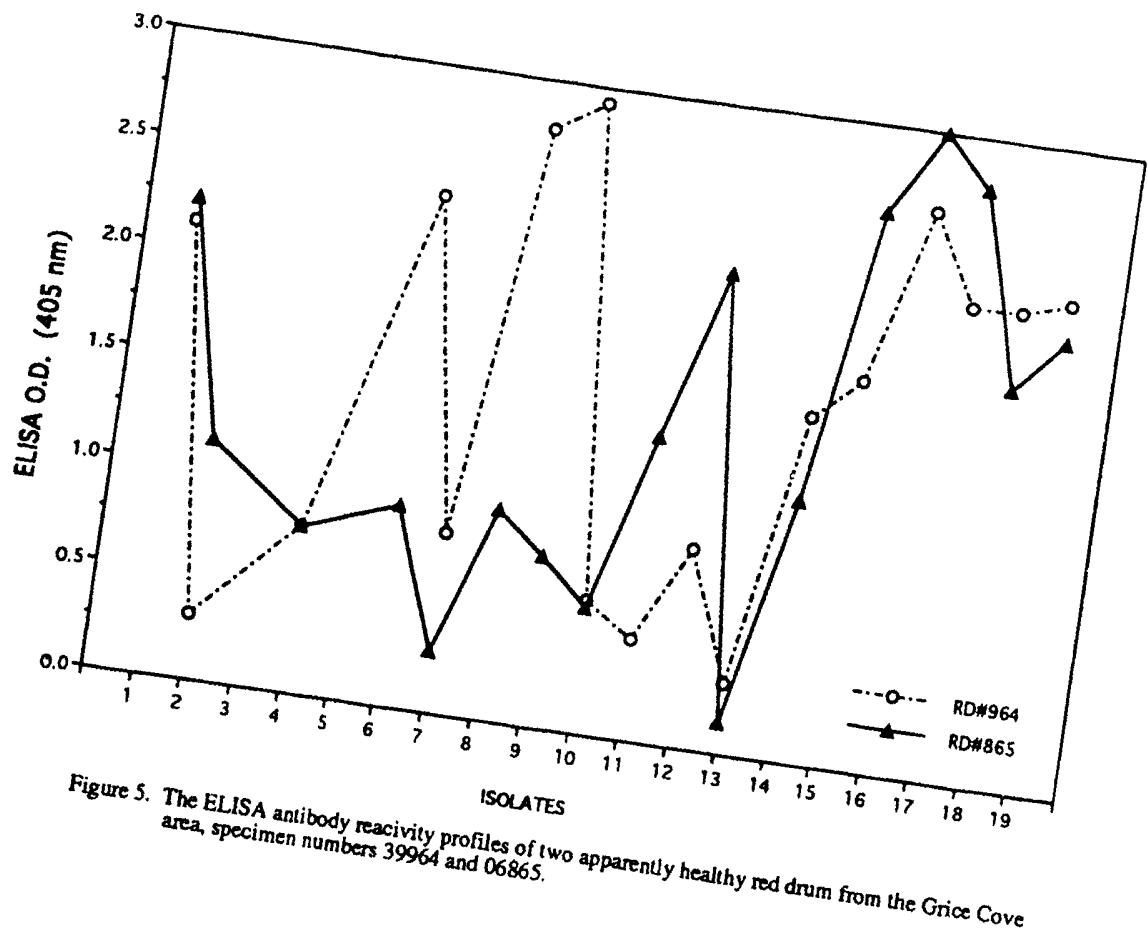


Table 1. Visual health assessment of feral red drum. Health categories were defined as follows: 1 = no external lesions or damage, 2 = some undefined external lesions or parasite, $3=$ open reddish sore, $4=$ hemorrhagic lesion (none found).

\begin{tabular}{|c|c|c|c|} 
Health Code & $\begin{array}{c}\text { Grice Cove } \\
(5 / 19 / 93)\end{array}$ & $\begin{array}{c}\text { Grice Cove } \\
(6 / 17 / 93)\end{array}$ & $\begin{array}{c}\text { Winyah Bay } \\
(5 / 10 / 93)\end{array}$ \\
\hline "1" & $36 / 41$ & $27 / 30$ & $9 / 15$ \\
"2" & $5 / 41$ & $3 / 30$ & $5 / 15$ \\
"3" & $0 / 41$ & $0 / 30$ & $1 / 15$
\end{tabular}

Table 2. Identifications of bacteria isolated and identified from both estuaries and from fish in mariculture tanks.

\begin{tabular}{|l|c|c|c|} 
Bacterial Identification & Grice Cove & Winyah Bay & Mariculture \\
\hline $\begin{array}{l}\text { Acinetobacter calcoaceticus } \\
\text { Aeromonas hydrophila }\end{array}$ & $\mathrm{t} 16$ & $\mathrm{t} 7$ & \\
Aeromonas salmonicida & $\mathrm{t} 17, \mathrm{t} 18, \mathrm{t} 19$ & & $\mathrm{t}$ \\
Aeromonas spp. & $\mathrm{t} 15$ & & \\
Edwardsiella spp. & $\mathrm{t} 13$ & $\mathrm{t} 11$ & $\mathrm{t}$ \\
Enterobacter spp. & $\mathrm{t} 14$ & & $\mathrm{t} 2$ \\
Flavobacterium spp. & $\mathrm{t} 12$ & $\mathrm{t} 10$ & \\
Pasteurella piscidia & & $\mathrm{t} 6, \mathrm{t} 8$ & \\
Pseudomonas fluorescens & & $\mathrm{t} 9$ & \\
Pseudomonas spp. & & &
\end{tabular}


Table 3. Individual red drum specimens and their lengths, health code, and ELISA O.D. of sera tested against all bacterial isolates. *indicates that the ELISA $3^{\circ}$ antibody used was 1:360 concentration instead of 1:500, so these data are not directly comparable to other O.D.s.

\begin{tabular}{|c|c|c|c|c|c|c|c|c|c|c|c|c|c|c|c|c|c|c|c|c|}
\hline \multirow[t]{2}{*}{ Collection } & \multirow{2}{*}{$\frac{\text { Spocimen }}{\text { (1ag \#) }}$} & \multicolumn{2}{|c|}{\begin{tabular}{|l|l|l|} 
Health Length \\
\end{tabular}} & \multicolumn{17}{|c|}{ Serum Reactlvity against Isolates (ELISA O.D.) } \\
\hline & & $\operatorname{cod} \theta$ & $(\mathrm{mm})$ & $t 1$ & 12 & 14 & 16 & 17 & 18 & 19 & 110 & 111 & 112 & 113 & 114 & 115 & $t 16$ & 117 & 118 & 119 \\
\hline Winyah Bay & 41501 & $\overline{1}$ & 405 & 0.45 & 0.2 & 0.21 & 0.34 & 0.05 & 0.07 & 0.08 & 0.29 & 0.12 & 0.08 & 0.17 & 0.24 & 0.12 & 0.14 & 0.06 & 0.06 & 0.04 \\
\hline $5 / 10 / 93$ & 39960 & 1 & 680 & 0.33 & 0.13 & 0.35 & 0.18 & 0.08 & 0.12 & 0.06 & 0.19 & 0.15 & 0.13 & 0.14 & 0.35 & 0.45 & 0.13 & 0.05 & 0.05 & 0.02 \\
\hline \multirow[t]{4}{*}{ Ist netting } & 36581 & 1 & 562 & 0.26 & 0.34 & 0.36 & 0.25 & 0.04 & 0.06 & 0.03 & 0.31 & 0.13 & 0.15 & 0.21 & 0.31 & \begin{tabular}{|l|}
0.21 \\
\end{tabular} & 0.34 & 0.14 & 0.05 & 0.06 \\
\hline & 39959 & 2 & 597 & 0.21 & 0.08 & 0.14 & 0.14 & 0.03 & 0.1 & 0.02 & 0.13 & 0.14 & 0.08 & 0.17 & 0.23 & 0.16 & 0.19 & 0.04 & 0.03 & 0.02 \\
\hline & 41502 & 1 & 410 & 0.33 & 0.1 & 0.3 & 0.32 & 0.04 & 0.16 & 0.12 & 0.3 & 0.47 & 0.13 & \begin{tabular}{|l|}
0.2 \\
\end{tabular} & 0.37 & 0.14 & 0.21 & 0.06 & 0.09 & 0.11 \\
\hline & & & & & & & & & & & & & & & & & & & & \\
\hline Winyah Bay & 39462 & 1 & 688 & 0.2 & 0.1 & 0.31 & 0.33 & 0.03 & 0.19 & 0.22 & 0.17 & 0.08 & 0.1 & 0.1 & 0.3 & 0.33 & 0.09 & 0.16 & 0.22 & 0.08 \\
\hline $5 / 10: 93$ & 39961 & 1 & 743 & & & & & & & & & & & & & & & & & \\
\hline \multirow[t]{2}{*}{ 2nd netting } & 41503 & 2 & 325 & 0.23 & 0.1 & 0.27 & 0.18 & 0.06 & 0.1 & 0.08 & 0.17 & 0.3 & 0.08 & 0.14 & 0.3 & 0.3 & 0.13 & 0.09 & 0.12 & 0.18 \\
\hline & 41504 & 2 & 371 & & & & & & & & & & & & & & & & & \\
\hline \multirow{3}{*}{$\ldots$} & 41505 & 1 & 396 & 0.18 & 0.08 & 0.11 & 0.2 & 0.12 & 0.41 & 0.31 & 0.1 & 0.04 & 0.04 & 0.05 & 0.15 & 0.05 & 0.1 & 0.09 & 0.14 & 0.05 \\
\hline & 41506 & 1 & 447 & 0.43 & 0.11 & 0.23 & 0.22 & 0.16 & 0.21 & 0.12 & 0.16 & 0.11 & 0.06 & 0.09 & 0.23 & 0.18 & 0.4 & \begin{tabular}{|l|}
0.21 \\
\end{tabular} & 0.19 & 0.2 \\
\hline & 39962 & 2 & 549 & 0.27 & 0.14 & 0.26 & 0.26 & 0.09 & 0.24 & 0.18 & 0.21 & 0.11 & 0.15 & 0.22 & 0.26 & 0.21 & 0.38 & 0.14 & 0.16 & 0.17 \\
\hline \multirow{2}{*}{+5} & 39963 & 3 & 59 & 0.36 & 0.17 & 0.25 & 0.28 & 0.02 & 0.09 & 0.03 & 0.28 & 0.14 & 0.09 & 0.14 & 0.22 & \begin{tabular}{|l|}
0.32 \\
\end{tabular} & 0.13 & 0.11 & 0.08 & 0.05 \\
\hline & 41507 & 2 & 382 & 0.19 & 0.07 & 0.24 & 0.23 & 0.03 & 0.06 & 0 & 0.12 & \begin{tabular}{|l|}
0.09 \\
\end{tabular} & 0.17 & 0.12 & 0.37 & \begin{tabular}{|l|}
0.17 \\
\end{tabular} & 0.04 & 0 & 0.04 & 0.03 \\
\hline \multirow{2}{*}{-1} & $41508^{\circ}$ & 1 & 310 & 0.08 & 0.02 & 0.17 & 0.13 & 0.02 & 0.35 & 0.39 & 0 & 0.17 & 0 & 0 & 0.11 & 0.1 & 0.02 & 0.08 & 0.09 & 0.12 \\
\hline & & & & & & & & & & & & & & & & & & & & \\
\hline \multirow{3}{*}{$\begin{array}{l}\text { Grice Cove } \\
5 / 19 / 93 \\
\end{array}$} & $4^{\circ}$ & 1 & 582 & 2.12 & 31 & 78 & 39 & 0.84 & 7 & 2.93 & 0.62 & 47 & 93 & 0.33 & 61 & .81 & 2.63 & \begin{tabular}{|l|}
2.21 \\
\end{tabular} & 2.22 & 2.28 \\
\hline & $6865^{\circ}$ & 1 & 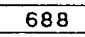 & 2.22 & 1.12 & 0.78 & 0.94 & 0.29 & 0.98 & $\begin{array}{l} \\
\end{array}$ & 0.59 & 1.42 & \begin{tabular}{|l}
2.22 \\
\end{tabular} & \begin{tabular}{|l|}
0.15 \\
\end{tabular} & 1.22 & 2.6 & 3 & \begin{tabular}{|l|}
2.76 \\
\end{tabular} & 1.86 & 2.11 \\
\hline & 03 & 1 & 564 & & & & & & & & & & & & & & & & & \\
\hline \multirow{2}{*}{$\ldots$} & $8537^{\circ}$ & 2 & 577 & 1.11 & 0.81 & 0.95 & 0.74 & 0.41 & 0.78 & 0.75 & 0.39 & 0.35 & .81 & 0.6 & 1.17 & 1.13 & 2.53 & \begin{tabular}{|l|}
1.87 \\
\end{tabular} & 1.53 & 1.65 \\
\hline & & 1 & & $0 . \overline{74}$ & 0.29 & 0.61 & 0.58 & 0.57 & 0.71 & 0.69 & & \begin{tabular}{|l|}
0.2 \\
\end{tabular} & & 0. & 77 & 0.76 & 1.05 & \begin{tabular}{|l|}
1.32 \\
\end{tabular} & 0.82 & 0.89 \\
\hline \multirow{4}{*}{ - } & 35144 & 1 & 39 & 1.27 & 0.1 & 0.59 & 1.65 & 0.52 & 2.31 & 2.38 & 0.51 & 0.47 & \begin{tabular}{|l|} 
\\
\end{tabular} & 0.41 & 1.59 & 1.6 & 2.02 & \begin{tabular}{|l|}
1.72 \\
\end{tabular} & 1.57 & 1.7 \\
\hline & & 1 & 56 & 0.62 & 0.69 & 0.72 & 0.65 & 0.82 & 1.6 & 1.5 & 0.31 & 0.47 & 0.51 & \begin{tabular}{|l|}
0.67 \\
\end{tabular} & 0.91 & 0.68 & 0.91 & \begin{tabular}{|l|}
0.95 \\
\end{tabular} & 0.69 & 0.85 \\
\hline & 34765 & 1 & 42 & 0.77 & 0.4 & 0.78 & 0.38 & 0.27 & 1.03 & 1.01 & 0.25 & 0.38 & 0.19 & 0.34 & 0.69 & \begin{tabular}{|l|}
0.26 \\
\end{tabular} & 0.65 & \begin{tabular}{|l|}
0.95 \\
\end{tabular} & 0.52 & 0.49 \\
\hline & 36199 & 1 & & 0.71 & 0.13 & 0.4 & 0.63 & 0.27 & & 0.56 & 0.18 & & & 0.61 & 0.53 & 0.27 & 0.61 & 0.51 & 0.44 & 0.47 \\
\hline & 8645 & 1 & 62 & 1.25 & 1.34 & 0.98 & 2.98 & 0.24 & 1.56 & 1.29 & 0.25 & 0.34 & 1.72 & 0.28 & 0.98 & 0.18 & 1.65 & 1.85 & 1.55 & 1.59 \\
\hline & & 1 & & 1.34 & 0.36 & 0.63 & 1.86 & 0.6 & 0.42 & 0.48 & 0.19 & \begin{tabular}{|l|}
0.33 \\
\end{tabular} & $\begin{array}{l} \\
\end{array}$ & 0.47 & 0.72 & 0.5 & 1.77 & \begin{tabular}{|l|}
2.65 \\
\end{tabular} & \begin{tabular}{|l|}
0.55 \\
\end{tabular} & 0.98 \\
\hline & 39967 & 2 & 696 & 0.71 & 0.15 & 0.79 & 0.33 & 0.07 & 0.33 & 0.32 & 0.27 & \begin{tabular}{|l|}
0.19 \\
\end{tabular} & 0.33 & 0.15 & 0.44 & 0.26 & 1.22 & \begin{tabular}{|l|}
0.5 \\
\end{tabular} & 0.37 & 0.23 \\
\hline \multirow{5}{*}{$\begin{array}{l}\text { Grice Cove } \\
6 / 17 / 93 \\
\end{array}$} & & & & & & & & & & & & & & & & & & & & \\
\hline & 18 & 1 & & 1.12 & 0.07 & 0.53 & 1.16 & 0.34 & 35 & 1.31 & 0.3 & 58 & .74 & 0.32 & 91 & 0.63 & 0.96 & 1.9 & 1.11 & 0.97 \\
\hline & 41619 & 1 & 41 & 0.49 & 0.18 & 1.69 & 0.66 & 0.22 & 0.82 & 0.79 & 0.62 & \begin{tabular}{|l|}
0.66 \\
\end{tabular} & 0.41 & \begin{tabular}{|l|}
0.25 \\
\end{tabular} & 0.74 & 1.64 & 0.86 & \begin{tabular}{|l|}
0.58 \\
\end{tabular} & 0.83 & 0.7 \\
\hline & 41620 & 1 & & 1.07 & 0.32 & 1.25 & 1.29 & 0.11 & 131 & 1.62 & 0.99 & 1.26 & 2.02 & 0.5 & 1.22 & 0.94 & 1.57 & \begin{tabular}{|l|}
1.65 \\
\end{tabular} & 1.41 & 1.55 \\
\hline & 41621 & 1 & 410 & 0.67 & 0.11 & 0.63 & 0.32 & 0.93 & 0.73 & 0.55 & 0.26 & \begin{tabular}{|l|}
0.47 \\
\end{tabular} & \begin{tabular}{|l|}
0.72 \\
\end{tabular} & \begin{tabular}{|l|}
0.76 \\
\end{tabular} & 0.28 & \begin{tabular}{|l|}
0.45 \\
\end{tabular} & 0.48 & \begin{tabular}{|l|}
0.84 \\
\end{tabular} & 0.53 & 0.57 \\
\hline \multirow{3}{*}{ 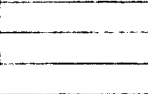 } & & 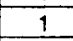 & & 1.35 & 0.42 & 0.58 & 0.62 & 0.2 & 1.36 & 1.23 & 0.25 & 0.29 & & \begin{tabular}{|l|}
0.39 \\
\end{tabular} & 1.12 & 3.6 & $\begin{array}{l}1.72 \\
\end{array}$ & \begin{tabular}{|l|}
1.94 \\
\end{tabular} & 1.06 & 1.12 \\
\hline & 39759 & 1 & 738 & 2.1 & 1.13 & $\begin{array}{l}0.82 \\
\end{array}$ & 0.67 & 0.27 & 0.84 & 0.86 & 0.81 & \begin{tabular}{|l|}
0.7 \\
\end{tabular} & \begin{tabular}{|l|} 
\\
\end{tabular} & 0.56 & 0.92 & \begin{tabular}{|l|}
0.63 \\
\end{tabular} & 2.11 & 2 & 1.71 & 1.8 \\
\hline & 32940 & 1 & 577 & 1.12 & 0.63 & $\begin{array}{l}0.89 \\
\end{array}$ & 0.71 & 0.55 & 1.33 & 1.21 & 0.66 & \begin{tabular}{|l}
0.52 \\
\end{tabular} & 0.79 & 0.81 & 0.81 & 0.7 & 1.68 & \begin{tabular}{|l|}
1.41 \\
\end{tabular} & 0.85 & 0.91 \\
\hline \multirow{6}{*}{ 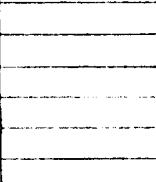 } & 41626 & 2 & 475 & 0.79 & 0.15 & 1.01 & 0.3 & 0.18 & 0.57 & 0.63 & 0.46 & 0.26 & \begin{tabular}{|l|}
0.17 \\
\end{tabular} & 0.26 & 0.15 & 0.18 & 0.56 & \begin{tabular}{|l|}
0.39 \\
\end{tabular} & 0.23 & 0.29 \\
\hline & 33385 & 1 & 608 & 1.51 & 1 & $\begin{array}{l}0.47 \\
\end{array}$ & 0.43 & 0.13 & 1.43 & 1.21 & 0.39 & 0.3 & \begin{tabular}{|l|}
0.27 \\
\end{tabular} & 0.34 & 0.8 & 0.37 & 1.92 & \begin{tabular}{|l|}
1.69 \\
\end{tabular} & 0.77 & 0.69 \\
\hline & $39966^{\circ}$ & 2 & 61 & 1.49 & 1.26 & 0.84 & 2.98 & 0.63 & 1.09 & 1.12 & \begin{tabular}{|l|}
0.21 \\
\end{tabular} & 0.55 & \begin{tabular}{|l|l} 
\\
\end{tabular} & 0.42 & 0.85 & \begin{tabular}{|l|}
0.64 \\
\end{tabular} & 3.83 & \begin{tabular}{|l|}
3.85 \\
\end{tabular} & 1.48 & 2.33 \\
\hline & 39970 & 2 & 747 & 1.26 & 0.32 & 1.04 & 1.38 & 0.37 & 1.97 & 2.08 & 0.71 & 0.5 & \begin{tabular}{|l|}
0.76 \\
\end{tabular} & \begin{tabular}{|l|}
0.49 \\
\end{tabular} & 0.8 & 0.5 & 1.97 & \begin{tabular}{|l|}
2.14 \\
\end{tabular} & 1.12 & 1.25 \\
\hline & Unknown & 1 & & 1.07 & 0.18 & 0.6 & 0.58 & 0.25 & 0.8 & 0.65 & 0.3 & \begin{tabular}{|l|}
0.29 \\
\end{tabular} & 0.42 & \begin{tabular}{|l|}
0.35 \\
\end{tabular} & 0.72 & 0.39 & 0.88 & 1.27 & 0.74 & 0.59 \\
\hline & & & & & & & & & & & & & & & & & & & & \\
\hline
\end{tabular}




\title{
Fit To Eat?
}

The Effects of Microwaving on the Bacterial counts in oysters

\author{
Kimberly A. Frampton \\ mentor: Dr. Susan J. Morrison \\ College of Charleston
}

Summer Undergraduate Research Program Medical University of South Carolina Summer 1993 


\begin{abstract}
The effects of microwaving on the bacterial load in oysters were examined to determine the reliability of this cooking procedure as a means of rendering oysters safe for human consumption. Oysters were microwaved in the shell for $0,3,4,6$, and 8 minutes, diluted, and biended before being plated in a dilution series from $10^{\circ}$ to $10^{-6}$. The general trend was a decrease in the number of viable bacteria, measured as colony forming units per gram of oyster tissue. However, consistent patterns did not occur due to a number of complicating factors.
\end{abstract}




\section{Introduction}

In the Lowcountry of South Carolina, a new culinary trend is appearing. People have begun microwaving oysters as a means of cooking them, or at least heating them and loosening the shells. This practice brings up the question of the reliability of this method in making the oysters safe to eat. The aim of this project is to prove or disprove that microwave cooking effectively reduces the bacterial load of the oyster to a level that is safe for human consumption while maintaining a desired level of edibility. If microwave cooking kills bacteria in oysters, then there will be fewer colony forming units per unit of oyster tissue following microwaving as determined by standard plate count procedures.

studies on how microwaves heat foods have shown that the ability of the microwave to effectively cook the food depends on certain characteristics of the food itself. Moisture, salt content, and the physicochemical characteristics of the food affect the penetration depth of the microwave. Nonuniform heating rates can be caused by "spatial field intensity variations within the oven" (3). A study done on the survival of Salmonella species in various foods heated in the microwave found that sodium chloride was a significant factor in bacterial survival, leading to the conclusion that the presence of sodium chloride in food results in a lack of uniform heating during microwave cooking and an increased chance of survival by bacteria (3) . 
Through general conversation, it was discovered that many people microwave oysters as a means of cooking them. An interview with one person yielded more specific information. Loy Harn, a local businessman, has been microwaving oysters for many years. He piles nearly 2 dozen on a plate with a small amount of water under them to produce steam, then cooks them for 6 minutes. His aim is to crack open the shells just enough to make them easy to shuck and get the meat hot without drying it out. Harn commented that he has never gotten sick from this practice (2). While some people eat oysters raw, it is not a safe practice. Oysters are filter feeders and easily accumulate microorganisms from their environment. These microorganisms can include pathogenic bacteria and viruses. It has been established that shellfish can carry bacteria such as vibrio cholerae, vibrio vulnificus, and salmonella typhi as well as viruses such as hepatitis A, Norwalk virus, and a group of viruses referred to as "small round viruses" $(1,4,7)$. Shellfish often collect these pathogens "through their ability to concentrate microorganisms from their environmental sea water" (4).

Previous studies done by Dr. Susan Morrison of the College of Charleston have shown that batches of oysters with artificially high bacterial loads are affected by microwave cooking. The starting load of between $10^{7}$ and $10^{9}$ showed a 2 log reduction after 5 minutes and a 4 log reduction after 10 minutes. The bacterial count was reduced, but the count overall still remained high. This may have been due to the artificially high 
initial load. Therefore, it is hypothesized that microwaving oysters with naturally occurring bacterial loads would reduce the number of bacteria to negligible levels. 
Materials and Methods

The procedures in this study were done using aseptic techniques. Handling and shucking of the oysters were done using techniques outlined in Laboratory Procedures for the Examination of Seawater and Shellfish, 5 th ed (5). When the oysters were not being used or were between steps, they were kept in a refrigerator at $4^{\circ} \mathrm{C}$. A flowchart of the procedure is depicted in Figure 1 .

The oysters were bought from a reputable commercial seafood store. They were divided into batches of 8 to 11 , depending on size and overall number available. The oysters were then scrubbed under running tap water until all loose dirt and debris was removed.

The batches were cooked for $0,3,4,6$, or 8 minutes at power level 6 in a General Electric Model JE1465G, 700 watt microwave on a mechanical tirntable, immediately shucked, and placed in sterile jars. One at a time, the batches were weighed and diluted 1:1 with sterile phosphate buffer with magnesium chloride (5). The mixture was blended in a blender for 90 seconds, with 2 ten second pauses to aid in consistent mixing and to avoid further heating of the sample.

Immediately following blending, the oyster "soup" was measured out in a dilution series as diagrammed in Figure 2. Each sample was plated in duplicate or triplicate. The plates were inoculated with the appropriate dilution of the specimen. Melted standard plate count agar (Difco Laboratories, Detroit, 
MI) was poured in and the plate gent?y swirled to attain even spreading of the inoculum. Once the agar solidified, an additional overlay of the same agar was added to the top to prevent overgrowth of colonies near the surface of the agar. Upon complete solidification, the plates were transferred to a walk-in incubator at $37^{\circ} \mathrm{C}$ and placed in an inverted position to prevent condensation from dropping on the surface of the agar. After 48 hours, the plates were inspected for bacterial growth. A Quebec colony counter was used to count the number of colonies in each plate. The results from the series of plates with counts within the range of 30 to 300 colonies were then averaged and multiplied by the dilution power to attain the number of colony forming units per gram (cfu/g) of oyster meat. Subcultures were done of some of the colonies present in the plates. Using standard procedures, various colonies were streaked onto solidified plate count agar (Difco Laboratories, Detroit, MI). From the subcultures, Gram stains were done. A few of the cultures were subsequently transferred to trypticase soy agar slants (BBL Microbiology systems, Cockeysville, MD) and placed in a refrigerator at $4^{\circ} \mathrm{C}$ to keep for further study. 
Resuits and Discussion

observations of the oyster meat were noted during the shucking procedure, based on personal judgement. The edibility of the meat was judged by taking into account the temperature, moistness, and texture of the meat after cooking. The results are listed in Table 1.

The uncooked batches were all cold and very moist. The three minute batches were slightly warm to the touch and moist, with few of the shells popped open. The four minute batches were generally hot to the touch, moist, and easy to open but not popped. On average, the six minute batches were hot to the touch, with some shells popped open and the meat rubbery. The ones that remained closed were generally molit but not as soft as the less cooked batches. The eight minute batches were very hot, with most of the shells popped open and the meat very dry and rubbery.

The data from the experiments are shown in Figures $3-10$. Log analysis of the data was also done, but did not significantly change the pattern of the results and is therefore not presented.

Experiment A (Figure 3) showed a marked decrease in the cfu/g in the batch cooked.for 4 minutes, followed by a slight increase at 6 minutes. The $8 \mathrm{minute}$ batch increased to a level nearly equal to the baseline count. The decrease at 4 minutes was expected, but the results for the 6 and 8 minute batches were not. Explanations for this are discussed later.

Experiment B (Figure 4) produced very different data from 
Experiment $A$. The baseline count was much lower, and the $\mathrm{cfu} / \mathrm{g}$ increased at $4 \mathrm{minutes}$ instead of decreasing. The lower baseline count is most likely due to the variability in the bacterial load from oyster to oyster and batch to batch. This would also explain why the 4 minute batch had a higher number of cfu/g. Batches cooked for 6 and 8 minutes showed the expected decrease in the bacterial count.

The oysters used for experiment $C$ (Figure 5) had a very low initial bacterial load, making any changes in that level difficult to see. There were more cfu/g of oyster tissue in the 8 minute batch. This could be due to the high variability among oysters or water weight loss, which are discussed later.

Experiment D (Figure 6) also involved oysters with low initial loads. There was little variability from batch to batch, but a small decrease is seen, with the exception of the 8 minute batch, as seen previously.

The final experiment was a double batch experiment. Two batches of oysters were processed for each time. The data produced curves that illustrate the gradual decrease in bacterial load in connection with longer cooking time (Figures 7 and 8 ). The decline correlates fairly well with the increasing length of microwaving time. This data supports the hypothesis that there will be fewer cfu/g following microwaving.

The results of this study were extremely variable. The baseline counts from the different experiments ranged from $2.6 \times$ $10^{3} \mathrm{cfu} / \mathrm{g}$ to $1.2 \times 10^{6} \mathrm{cfu} / \mathrm{g}$, as seen in Figure 9 , thus making 
comparison of the results of the cooked batches difficult. A comparison of all the data is presented in Figure 10. The line represents the average trend for the experiments. While it does sinow a slight decrease in the number of $\mathrm{cfu} / \mathrm{g}$ of oyster meat in conjunction with longer cooking time, the decrease is not as sharp as expected. In more than one experiment, batches of cooked oysters had higher counts than the uncooked batch. There are several possible explanations for this phenomenon.

The most basic problem is the amount of variability in the bacterial load of each individual oyster. In a study of the bacterial accumulation by the Gulf coast oyster, Kelly et al. noted broad fluctuations in the coliform MPN (Most Probable Number] of oysters that did not appear to be related to any changes in the bacterial content of the surrounding water $(6)$. Sample sizes of at least eight oysters were used to diffuse this effect somewhat. Another difficulty was judging how much the shell affected heating. Often, the size of the shell belied its actual thickness and the size of the oyster within. Batches with more oysters or thicker shells tended to not get as hot as those with less shell. Inconsistent heating by the microwave could also have been caused by the presence of moisture and sodium chloride in the oysters, thus increasing the variability of the survival rates of the bacteria they contained (3).

In all but one of the experiments, the batch cooked for eight minutes had higher counts than the batches cocked for less time. One problem with the longer cooked oysters was their 
rubbery consistency. The toughness of the oyster meat resulted in inconsistent mixing in the blender. The dry oyster meat also caused a discrepancy when comparing the grams of oyster meat to the number of bacteria. In the less cooked batches, water weight in the oyster was taken into account while in the eight minute oysters, the water evaporated, possibly leaving a higher concentration of bacteria per gram of oyster tissue. This resulted in a higher number of $c f u / g$ of oyster tissue.

When Gram stains were done of some of the bacterial colonies subcultured from the original plates, many Gram positive and Gram negative rods were seen. There is a possibility that some of these rods are spore formers and are relatively unaffected by heat. This could help account for not seeing a total elimination of bacteria in the oysters. 
Conclusion

While some of the data does show a decrease in the bacterial counts with cooking (Figures 6-8), other data does not (Figures 3-5). This discrepancy is most likely due to the high variability of bacterial counts among oysters, combined with the relatively low bacterial load, which may serve to exaggerate the actual difference between the batches. Water weight loss in the longer cooked batches is another complicating factor. When the overall trend of the experiments is graphed, an average decline in cfu/g can be seen (Figure 10), but bacteria remain present in all of the batches. The question that persists is: does microwave cooking kill the harmful bacteria found in raw oysters? If the bacteria that remain are not pathogens, the bacterial load that is left after microwaving may be safe for human consumption. Further study should be conducted in this area. Perhaps an experiment can be designed where the oysters are first treated with a pathogen, cooked, and then analyzed for survival of the target pathogen. Another approach would be to quantify the bacteria in another fashion. One strategy would be to analyze the bacterial load per gram of protein to reduce the effects of moisture on the results. While this will not completely eliminate the complicating factor of water weight loss in the longer cooked batches, it should decrease the impact. The results of this study do not decisively show that microwave cooking is a procedure that will reduce the bacterial loads of raw oysters to a level that is safe for human consumption. 


\section{Acknowledgements}

The author would like to thank the Department of Energy for funding this project through a grant to the Medical University of South Carolina's Summer Undergraduate Research Program. The author would also like to thank Dr. Susan J. Morrison of the college of Charleston for her invaluable guidance throughout the project. 
References

1. De Leon, Ricardo and Charles P. Gerba. 1990. Viral Disease Transmission by seafood in Food Contamination from Environmental Sources. Jerome Nriagu and Milagros S. Simmons, eds. New York: John Wiley and Sons, Inc. pp. 639-662.

2. Harn, Loy. Personal Interview. August 2, 1993. Mt. Pleasant, SC.

3. Heddleson, Ronald A., Stephanie Doores, Ramaswamy $C$. Anantheswaran, Gerald D. Kuhn, and Morris G. Mast. 1991. Survival of Salmonella Species Heated by Microwave Energy in a Liquid Menstruum Containing Food Components. J. Food Protection 54 (8): 637-642.

4. Heffernan, W. Paul and Victor J. Cabelli. 1970. Elimination of Bacteria by the Northern Quagaug (Mercenaria mercenaria): Environmental Parameters Significant to the process. J. Fisheries Research Board of Canada 27:1569-1577.

5. Greenberg, Arnold E. and Daniel A. Hunt, eds. 1985. Laboratory Procedures For the Examination of Seawater and Shellfish, 5th ed. Washington, D. C.: American Public Health Association. $144 \mathrm{pp}$.

6. Kelly, C. B., W. Arcisz, M. W. Presnell, and E. K. Harris. 1960. Bacterial Accumulation by the Oyster, Crassostrea virginica, on the Gulf Coast. U.S. Dept. of Health Education and Welfare. Public Health Service. $45 \mathrm{pp}$.

7. Metcalf, T. G., L. W. Slanetz, and C. H. Bartley. 1973. Enteric Pathogens in Estuary waters and Shellfish in Microbial Safety of Fishery products, $C$. O. Chichester and H. D. Graham, eds. New York: Academic Press. pp. 215-234. 


\section{Table 1}

Edibility Observations

\begin{tabular}{|c|c|c|c|}
\hline Minutes & General & Meat & Shell \\
\hline Cooked & Temperature & Characteristics & Condition \\
\hline 0 & $\operatorname{cold}$ & very moist, soft & closed \\
\hline 3 & warm & moist, soft & closed \\
\hline 4 & not & moist, soft & most closed \\
\hline 6 & not & $\begin{array}{l}\text { moist, slightly } \\
\text { tough }\end{array}$ & $\begin{array}{l}\text { some closed, } \\
\text { some open }\end{array}$ \\
\hline 8 & hot & dry, rubbery & $\begin{array}{l}\text { almost all } \\
\text { open }\end{array}$ \\
\hline
\end{tabular}




\title{
Fiqure 1
}

\section{Gulf Coast Oysters obtained \\ from local seafood store}

$\downarrow$

\begin{abstract}
Oysters scrubbed with sterile brush under running tap water to remove dirt and debris
\end{abstract}

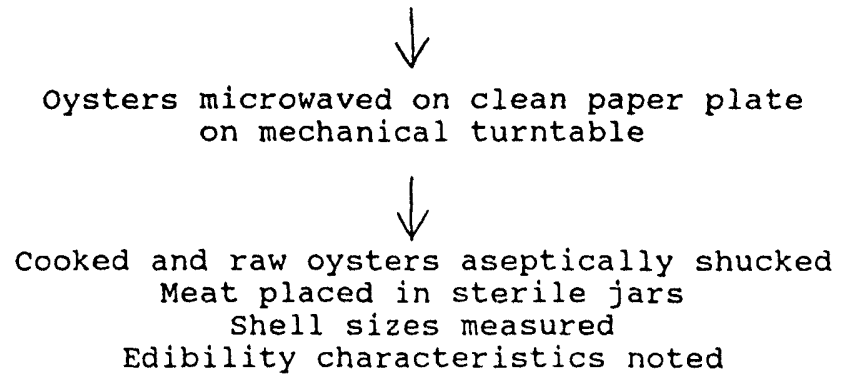

Oyster meat weighed and diluted 1:1 with phosphate buffer Mixture blended for 90 seconds<smiles>C=IC</smiles>

Serial dilution prepared samples plated out in duplicate or triplicate<smiles>C=IC</smiles>

Pour plates prepared with

melted standard plate count agar overlays poured with same type agar

Plates inverted and incubated at $37^{\circ} \mathrm{C}$ for 48 hours<smiles>C[Al]</smiles>

Plates containing 30-300 colonies counted

Average of counts of duplicate or triplicate plates calculated to give colony forming units (CFU) per gram of oyster meat 


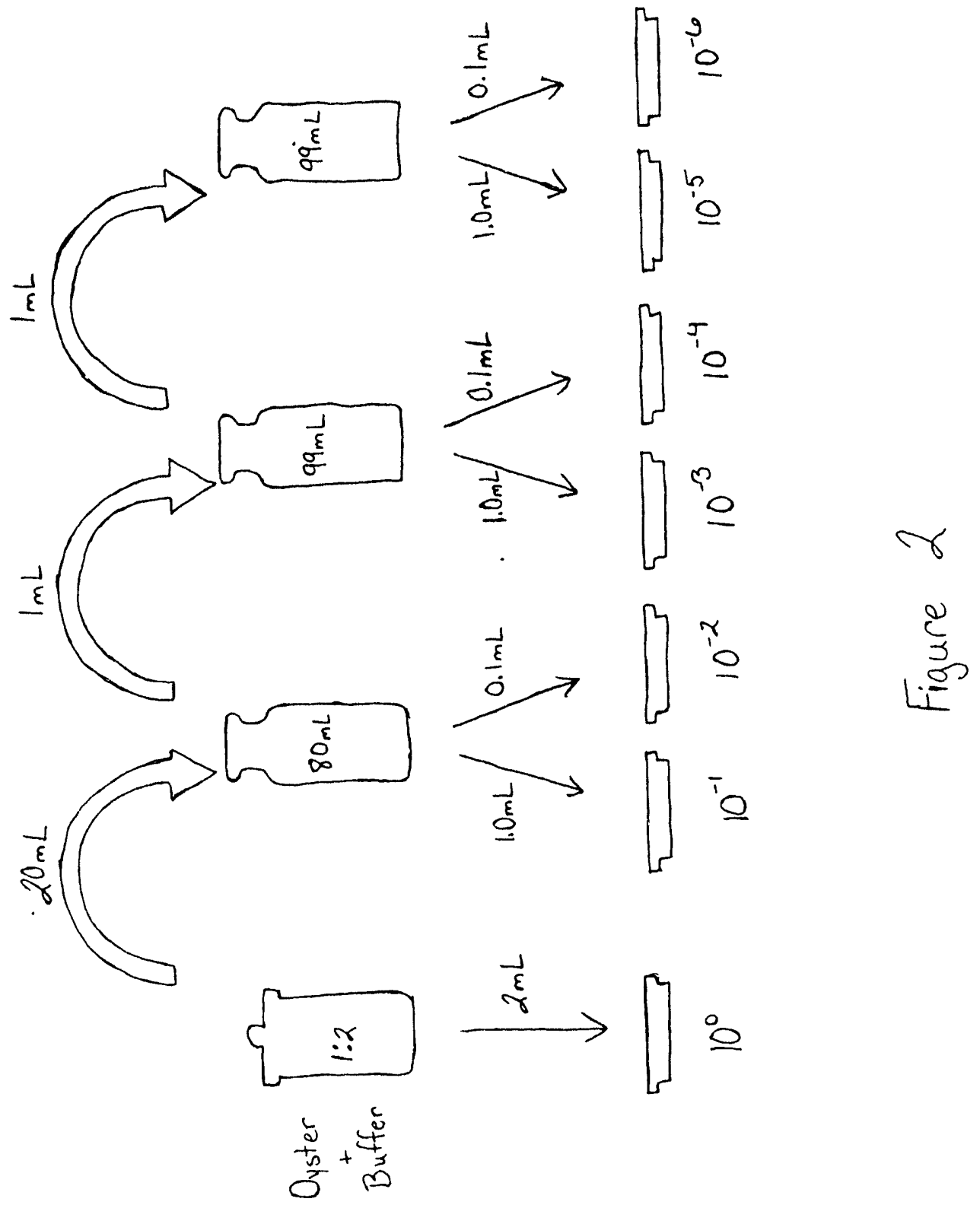




\section{Figure 3: Oyster Experiment A}

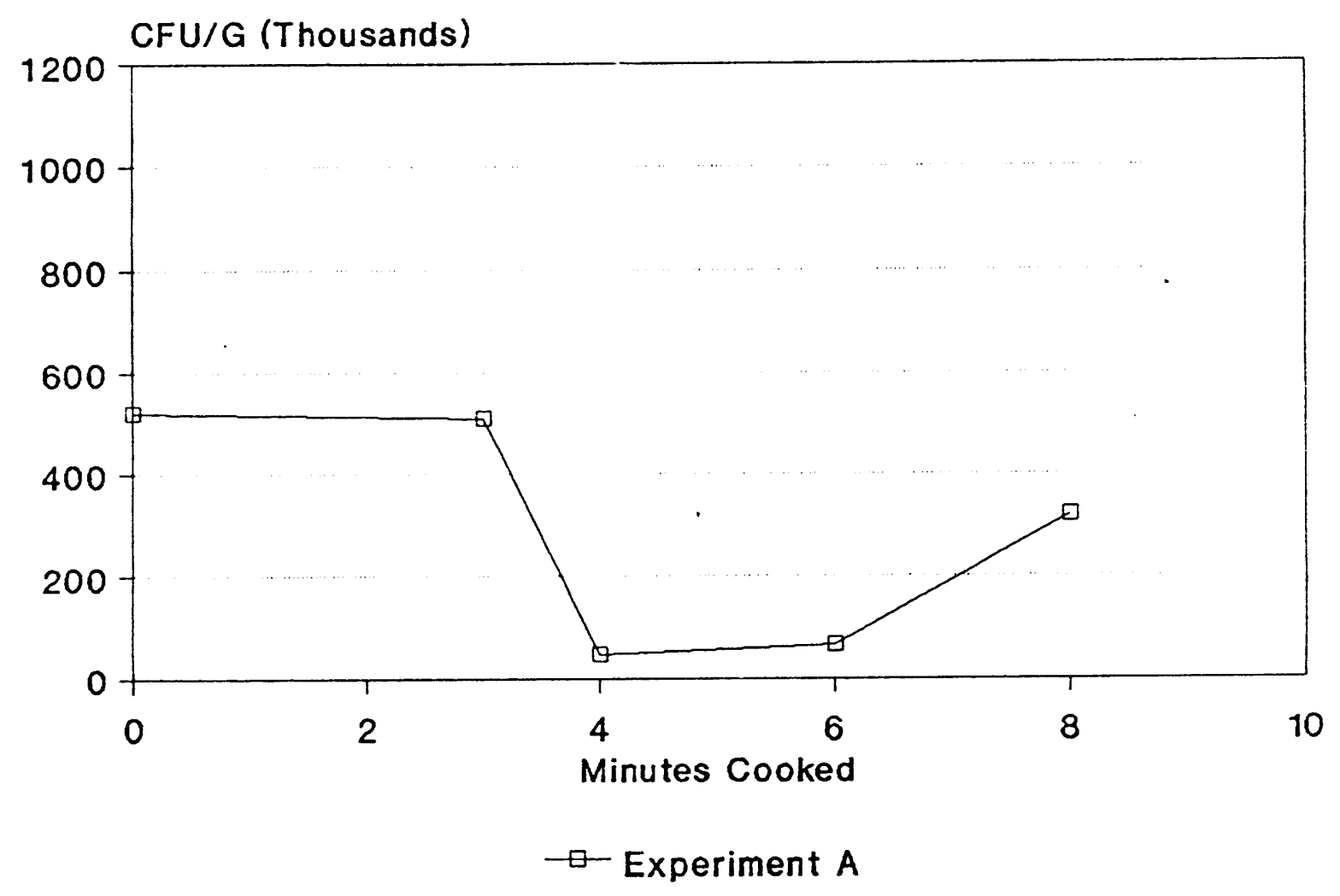




\section{Figure 4: Oyster Experiment B}

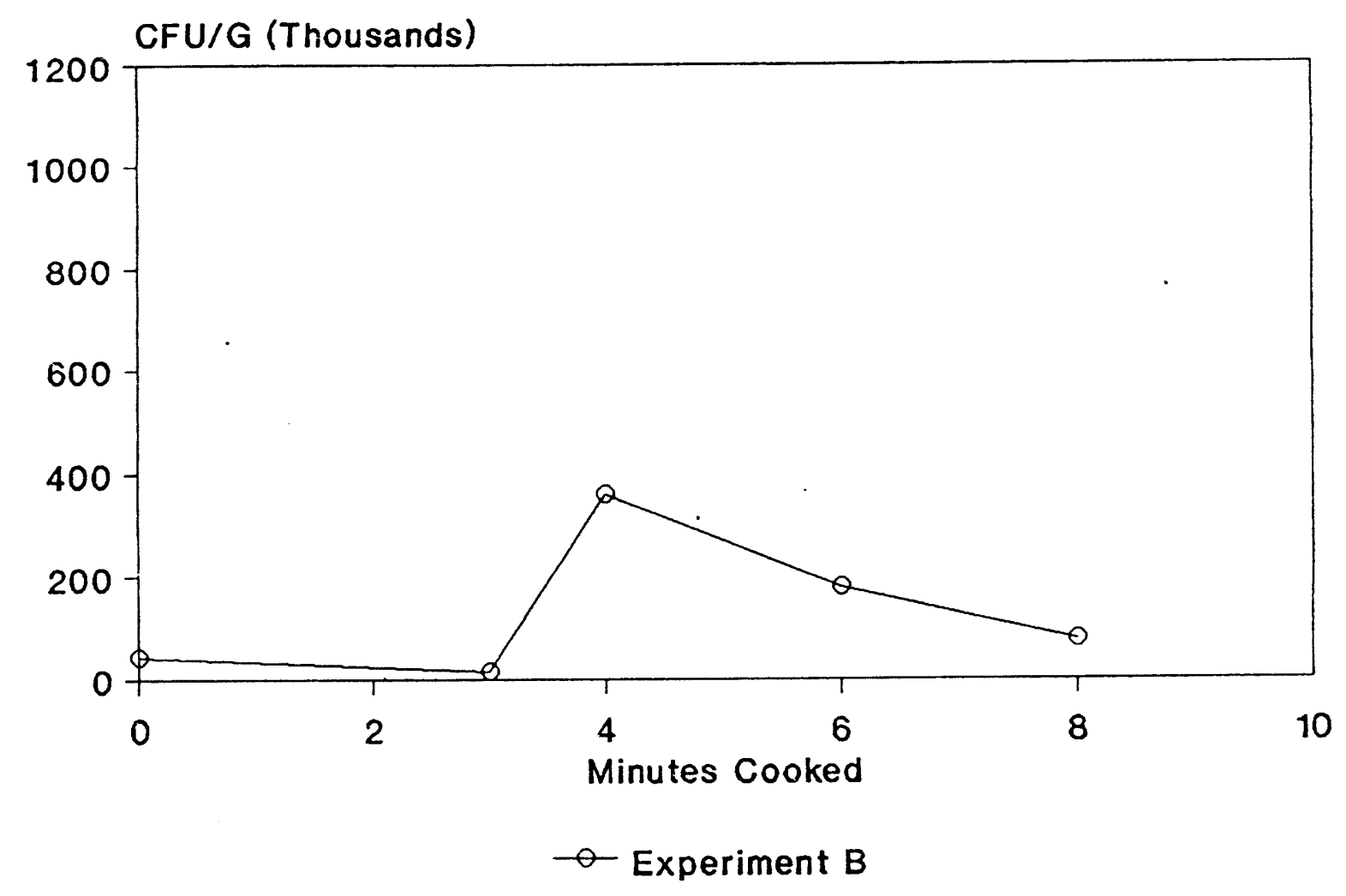


Figure 5: Oyster Experiment $\mathrm{C}$

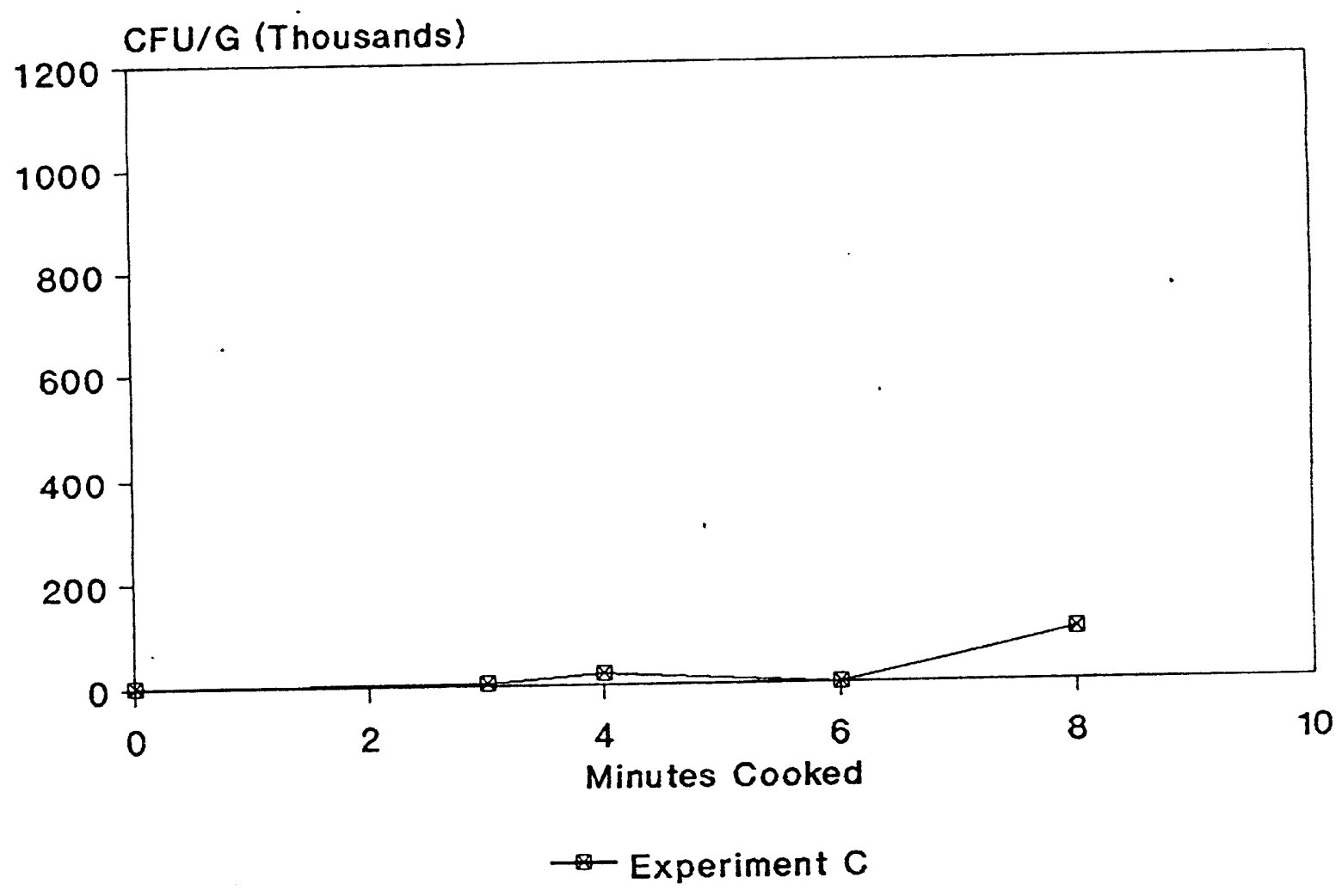


Figure 6: Oyster Experiment D

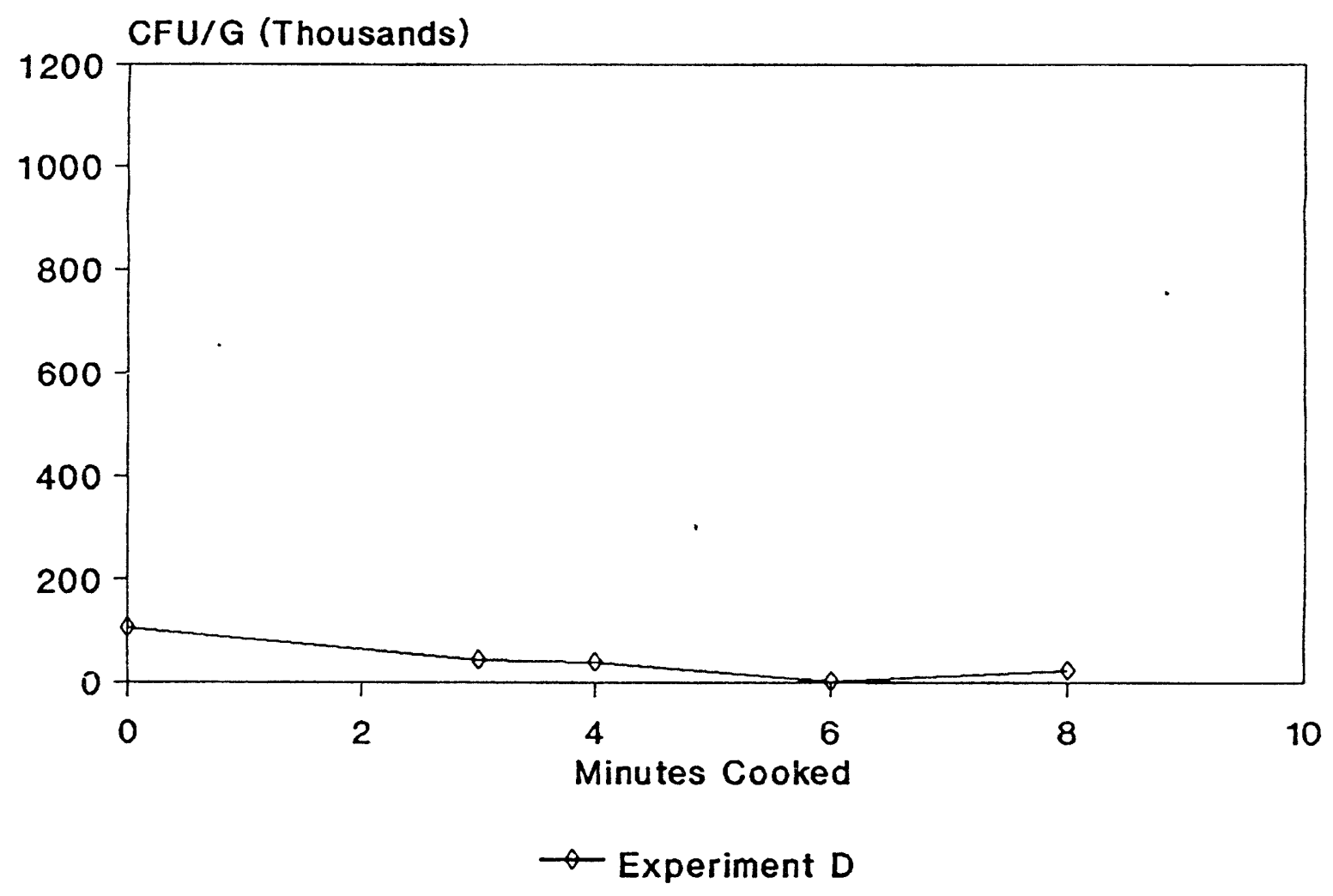


Figure 7: Oyster Experiment E-1

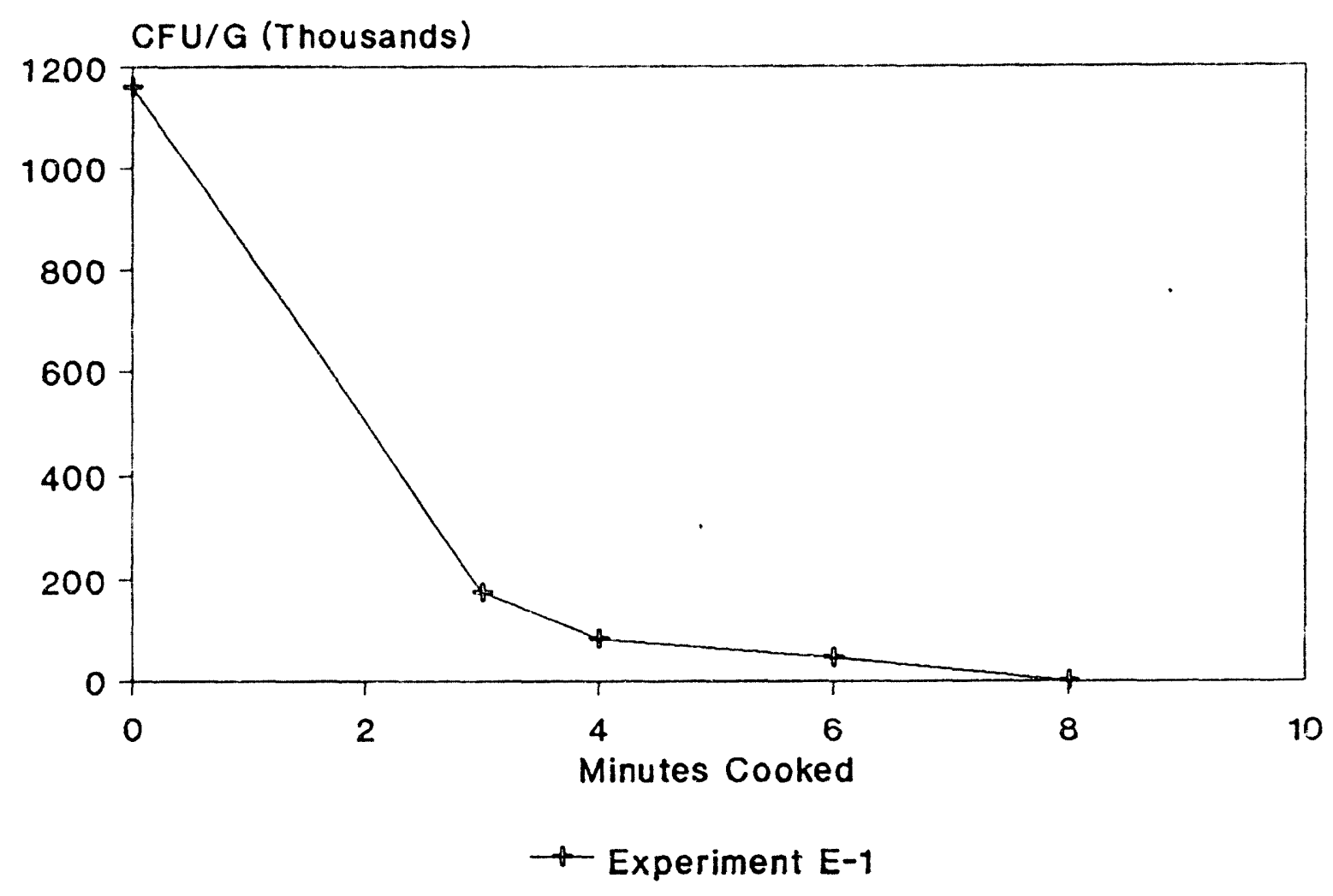


Figure 8: Oyster Experiment E-2

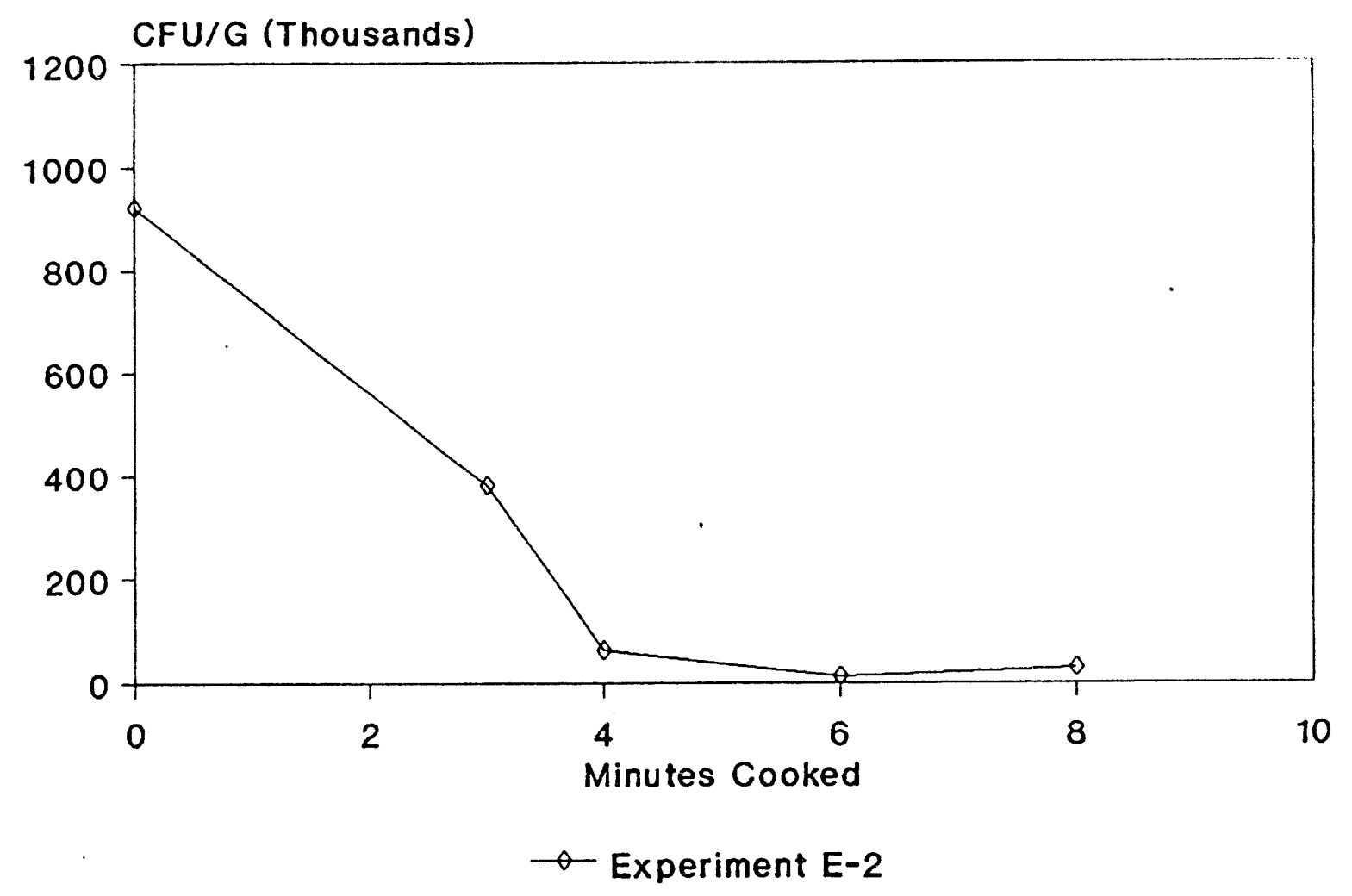




\section{Figure 9: Baseline Counts}

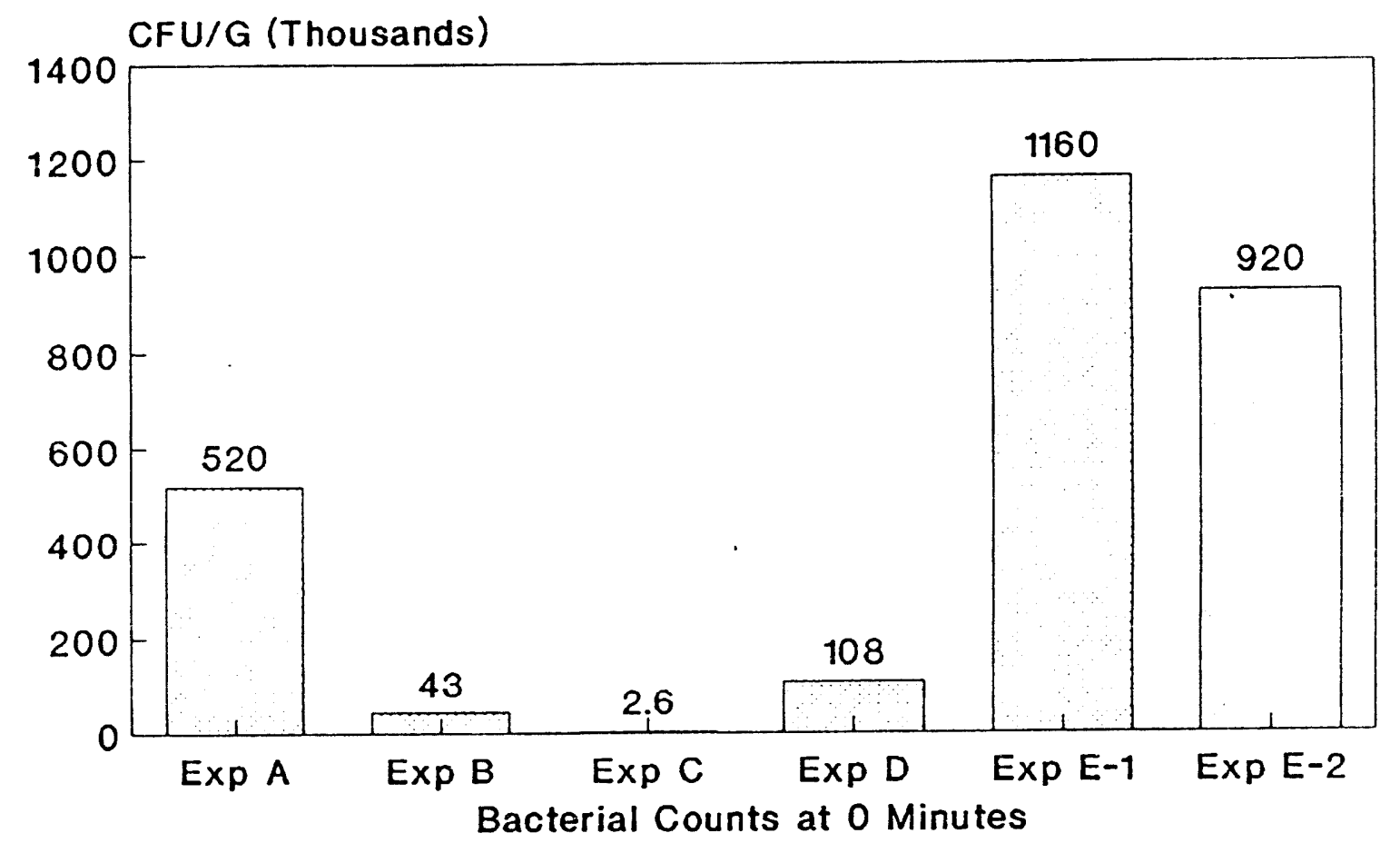

CFU/G 
Figure 10: Average Bacterial Count

A Comparison of Selected Experiments

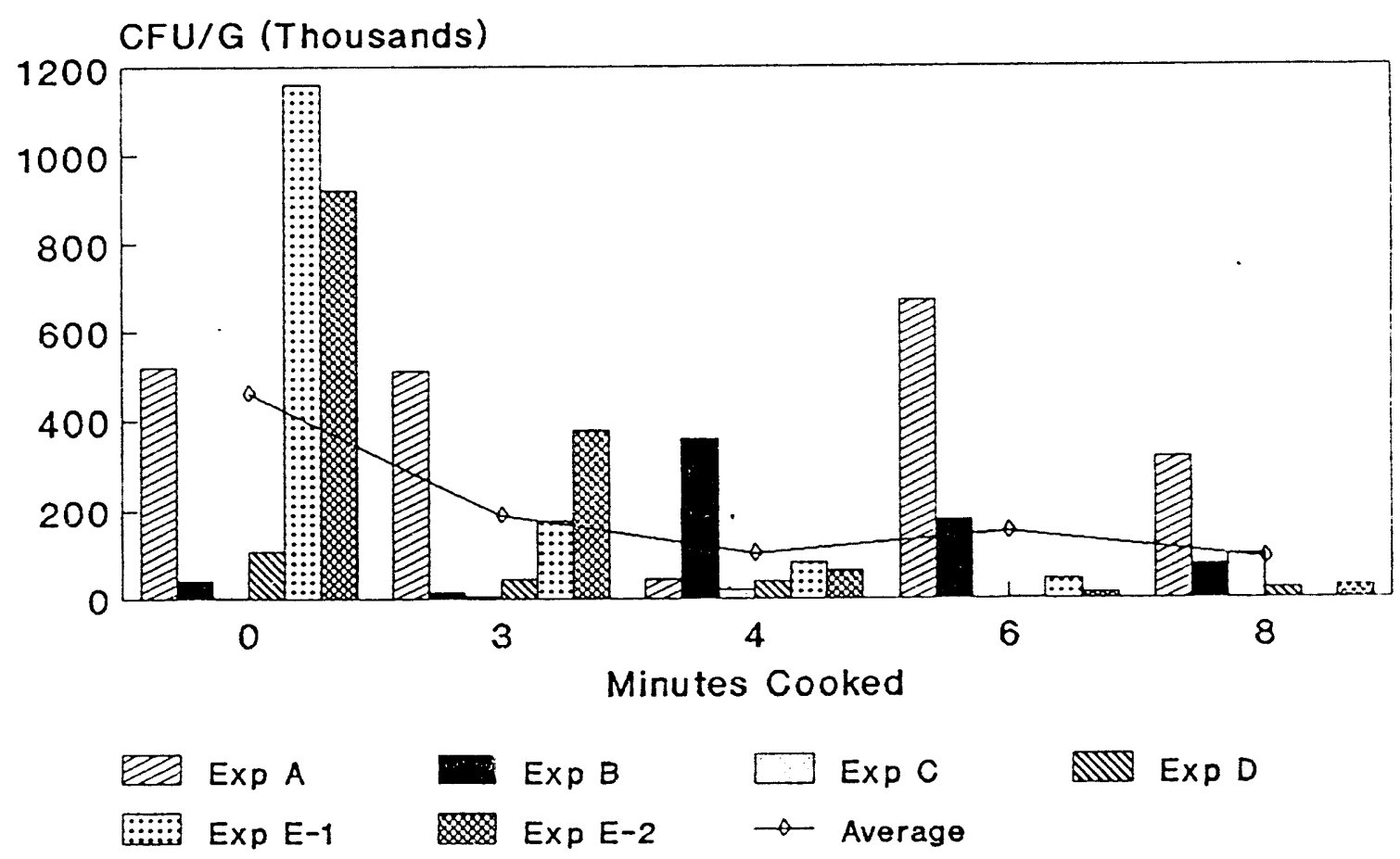

Kimberly A. Frampton

Fit To Eat? 


\title{
Isolation and Purification of Marine Biotoxins Produced by a Caribbean Strain of Gambierdiscus toxicus.
}

\author{
Jill Huntington1, Peter Moeller Ph.D2 \\ 1SURP, Med. Univ. of South Carolina \\ University of Buffalo \\ 2National Marine Fisheries Service \\ Charleston, South Carolina
}

\begin{abstract}
A large scale, preparative isolation and purification protocol has been developed for maitotoxin (MTX) and ciguatoxic(CTX) congeners that were extracted from a Caribbean strain of Gambierdiscus toxicus. These two toxins have both been implicated in Ciguatera poisoning. The subsequent purification of a moderately polar family of maitotoxin, designated $M T X-B$, is described.
\end{abstract}

Introduction: Maitotoxin is a very potent marine biotoxin and is one toxin responsible for ciguatera seafood poisoning that results from eating contaminated reef fish. MTX was first isolated from the viscera of surgeon fishes, Ctenochaetus striatus 1 and is believed to be produced, initially, by the marine dinoflagellate, Gambierdiscus toxicus 2 . We have been working with a Caribbean strain of $G$. toxicus, isolated from the Martinique Islands, and propogated by mass culture. These cultures produce CTX-congeners, as well as highly polar and moderately polar families of MTX.

Maitotoxins, in general, are a valuable pharmacological tool because of their biological activity to activate voltage dependent calcium channels 3.4 . However, the important chemical features, such as molecular weight and chemical structure are only known for a highly polar MTX from a Pacific strain of G. toxicus. The molecular weight of this Pacific MTX is $3424 \mathrm{Da}$ (as a disodium salt) 5 , and its chemical structure (Fig.1) has only been recently elucidated, making it the largest known natural product that has been fully characterized6. This information if not yet available for the moderately polar MTX-B, or for any other Caribbean MTX.

Currently, there is a shortage of analytical samples of Caribbean strain MTX, thereby making further pharmacological evaluation and structural elucidation difficult. What we attempted to do was take MTX-B and develop a protocol to isolate the toxin and then take a simplified and 
more direct approach to a preparative scale purification scheme that would circumvent the problems other research groups have encountered. Our purpose was to purify MTX-B to the point of obtaining an analytical sample, while in the process, to retain the maximum amount of toxic material free from degradation and/or oxidation.

Experimental Design: Before beginning the actual isolation procedure (Fig.2), we suspended a known, frozen wet-weight of cultured $G$. toxicus in $100 \% \mathrm{MeOH}$. The dinoflagellates were sonicated to ensure the maximum release of toxins with the use of a high intensity ultrasonic processor (GCA/Precision Scientific) for 10-12min per 5-7g.

The MTX-B sample that was used to determine the remainder of this protocol, was isolated using a $\mathrm{C} . ! 8$ reverse phase chromotography column. The column was packed in $100 \% \mathrm{H}_{2} \mathrm{O}$ and the solvents began at $40 \%$ $\mathrm{MeOH} / \mathrm{H}_{2} \mathrm{O}$ and increased stepwise to $100 \% \mathrm{MeOH}$. At this point, the majority of the toxins had eluded off the column, and we were able to separate them into three families; CTX-congeners, MTX-B, and the highly polar MTX, based on their polarities and where they eluded off the column. The column was then washed with portions of ethyl acetate (EtAc) and chloroform $\left(\mathrm{CCl}_{3}\right)$ to remove any residual toxic material.

We have since begun using a more novel approach to toxin isolation with the Soxhlet extraction. This, however, is not the isolation method used for the MTX-B that was used in determining the purification protocol.

We began the Soxhlet extraction by applying the crude, sonicated sarnple onto a cellulose thimble and freeze-drying it, before using the standard Soxhlet apparatus and allowing $500 \mathrm{~mL}$ of each solvent to reflux and condense over the thimble. The solvent scheme included nine solvents starting with a non-polar solvent, with each of the following solvents increasing in polarity. It began with hexane, followed by benzene, petroleum ether, ethyl acetate, acetone, acetonitrile, 2-propanol, methanol, and ending with water. One fraction per solvent was collected and submitted for cytotoxicity determination.

Toxicity of the collected fractions was determined by the CellTiter 96 TM Non-Radioactive Cell Proliferation/Cytotoxicity Assay (Fig.3). Once cytotoxicity was determined, we were able to classify the toxins into families of CTX-congeners or MTX. This knowledge was obtained by using sodium channel activation and calcium influx 7,8 bioassays that were developed and used in-house. The maitotoxins were identified by a positive calcium influx assay, and CTX-congeners, known sodium channel activators, showed a positive result for that bioassay. 
Our preparative purification protocol for MTX-B involved use of size-exclusion chromatography and HPLC (Fig.4). Purification began with size-exclusion chromatography using LH2O Sephadex packing (Pharmacia) and a column $200 \mathrm{~cm}$ in length and $1 \mathrm{~cm}$ in width. Run \#1 used 45:45:10 $\mathrm{MeOH}: E t A c: \mathrm{H}_{2} \mathrm{O}$. Toxic fractions were again identified by cytotoxicity bioassay. For run \#2, we loaded toxic fractions from run \#1 onto column using the same packing with $100 \% \mathrm{MeOH}$. Toxic fractions were again identified by cytotoxicity bioassay.

Our next step was HPLC, using ISCO ChemResearch, model 2350. We chose a semi-preparative $(250 \mathrm{~mm} \times 10 \mathrm{~mm}$ ) silica column (Alltech, Econosil Silica 10u) with a linear gradient, dual pump, and single detector. Wavelength was set at $260 \mathrm{~nm}$, sensitivity at 1.0 , and rise time at .80 .

Solvent B was $100 \%$ HPLC-grade ethyl acetate; solvent A was $100 \%$ HPLCgrade methanol. Injections were all $2.0 \mathrm{~mL}$.

Eluent scheme:

DUAL PUMP, LINEAR GRADIENT
NUMBER OF SEGMENTS: 4
$\begin{array}{cccc}\text { SEGMENT } & \text { TIME } & \text { FLOW RATE } & \% \text { SOLVENT } \\ \# & \text { (MIN) } & \text { (ML/MIN) } & \text { [B] } \\ 0 & & & 100 \\ 1 & 15 & 5 & 100 \\ 2 & 52 & 5 & 10 \\ 3 & 75 & 5 & 10 \\ 4 & 85 & 5 & 100\end{array}$

We are currently in the process of developing the final puritive step to obtain an analytically pure toxin sample.

Results and Discussion: After the sonication of $G$. toxicus, approximately $85-90 \%$ of the cells were shattered and we felt a maximum amount of toxin had been released into solution. The results of the C.18 allowed us to form three toxic groups of CTX-congeners, MTX-B, and highly polar MTX. We found that the highly polar MTX would elude off the column first in $40 \% \mathrm{MeOH} / \mathrm{H}_{2} \mathrm{O}$, followed by $\mathrm{MTX}-\mathrm{B}$, in $70-90 \% \mathrm{MeOH} / \mathrm{H}_{2} \mathrm{O}$. CTXcongeners would elude off last in $100 \% \mathrm{MeOH}$. We were able to begin washing the column after this point, because we knew that the majority of the toxins had come off the column. During the wash, we did receive a few residual toxic fractions, but their quantities were small, and they were less potent. 
The Soxhlet extraction procedure, however, has proven to be a more productive method of toxin isolation as was determined by the bioassay results that indicated very clear separations (Fig.5). In general, the toxin fractions off the Soxhlet extraction were purer than those received off the C.18, in that there was a more defined separation of toxins, and each fraction contained fewer pigments.

The Soxhlet extraction gave us two cytotoxic fractions with the non-polar solvents, hexane and benzene, that were also sodium channel active, indicating the presence of CTX-congeners. We also found two cytotoxic and calcium influx positive fractions with both the moderately polar solvents (ethyl acetate, acetone) and highly polar solvents (isopropyl alcohol, methanol, (water)). The fact that these fractions were calcium bioassay positive suggested the presence of maitotoxins. We focused the rest of our studies on the moderately polar toxic fractions.

Run \#1 with the size-exclusion chromatography did little else but remove some pigments from the toxic fraction. Run \#2, however, immediately separated into three distinct bands of color, and we collected one fraction that was both cytotoxic and calcium channel active.

We took the toxic fraction and applied it to the HPLC, using the eluent scheme described above. Fig. 6 is a representative chromatogram for all HPLC injections with this particular sample of MTX-B. ifter again using the cytotoxicity bioassay, we determined that we had obtained two toxic fractions (highlighted areas along bottom axis of Fig.6), whose retention times remained consistent throughout all injections. We have arbitrarily labeled these toxic fractions $B_{1}$ and $B_{2}$, with their retention times 16-22 $\mathrm{min}$ and 36-75 min, respectively. We then took $B_{1}$ and $B_{2}$, and reinjected them, each individually, back onto the HPLC, following the same eluent scheme, with the intention of repurifying them, and again received two toxic fractions ( $F i g .7$ ) with the same retention times of $B_{1}$ and $B_{2}$. To ensure that $B_{1}$ was not simply a carryover from a previous injection, we injected only solvent onto the column and ran a blank run, and after that, flushed the column with $300 \mathrm{~mL} 100 \% \mathrm{MeOH}$ before repurifying each $\mathrm{B}_{1}$ and $B_{2}$. We verified these results by injecting the $B_{2}$ fraction obtained during the repurification of the original $B_{1}$. Again we obtained $B_{1}$ and $B_{2}$. What these results indicate is that an equilibrium process exists between $B_{1}$ and $B_{2}$ that is based on a conformational or configurational change of the MTX-B molecule. We are particularly interested in these results because such an equilibrium process has already been described for ciguatoxing. The research into this matter is currently ongoing, but if we 
continue to receive $B_{1}$ and $B_{2}$ during our verification process, then we will be able to eliminate any doubt that the MTX-B we are working with is anything other than a single entity, indicating that the analytical sample is only one or two steps away.

Summary: In the pursuit of obtaining analytically pure samples of Caribbean strain MTX and CTX-congeners we have developed preparative isolation and purification techniques that have brought us close to our goal. Also, while in the process, we have indicated an apparent equilibrium process between isomers of $M T X-B$, that may be a clue to the relational biosynthetic origins of both $\mathrm{CTX}$ and MTX-B.

Acknowledgments: We would like to thank the following people for the efforts they have directed toward our research: B. Lanoue, S. Knoepp, T. Darby, D. Sandel. 


\section{REFERENCES}

YYasumoto, T.; Bagnis, R.; Vernoux, J.P. (1976). Toxicity of the surgeonfishes-11. Properties of the principle water soluble toxin. Bull. Jpn. Soc. Sci. Fish. 42, pp. 359-365.

2Yasumoto, T.; Nakajima, I.; Bagnis, R.; Adachi, R. (1977b). Finding of a dinoflagellat as a likely culprit of ciguatera. Bull. Jpn. Soc. Sci. Fish. 43, pp. 1021-1026.

3Xi, D.; Van Dolah, F.M.; Ramsdell, J.S. 1992 Maitotoxin activates type Lvoltage dependent calcium channels and induces a calciun dependent membrane depolarization in $\mathrm{GH}_{4} \mathrm{C}_{1}$ pituitary cells. J. Biol. Chem. 267:25025-25031.

4Takahashi, M.; Ohizumi, Y.; Yasumoto, T. J. Biol. Chem. 1982, 257, pp. 7287-7289.

5Yokoyama, A.; Murata, M.; Oshima, Y.; Iwashita, T.; Yasumoto, T. J. Biochem. 1988, 104, pp. 184-187.

6Murata, M.; Naoki, H.; Iwashita, T.; Matsunaga, S.; Sasaki, M.; Yokoyama, A.; Yasumoto, T. J. Am. Chem. Soc., Vol. 115, No. 5, 1993, pp. 2060-2062.

7Van Dolah, F.M.; Ramsdell, J.S. 1993 Maitotoxin induced calcium influx inhibits activation of CDC2 kinase and progression through G2 of the cell cycle in $\mathrm{GH}_{4} \mathrm{C}_{1}$ cell. J. Biol. Chem. (in press).

8Van Dolah, F.M.; Finley, E.L.; Haynes, B.L.; Doucette, G.J.; Moeller, P.D.; Ramsdell, J.S. Development of rapid and sensitive high throughput assays for marine phycotoxins (submitted to Natural Toxins).

9Holmes, M. Personal Communication (in press).

10Murata, M.; Naoki, H.; Iwashita, T.; Yokoyama, A.; Sasaki, M.; Yasumoto, T. J. Am. Chem. Soc., Vol. 114, No. 16, 1992, pp. 6594-6596. 


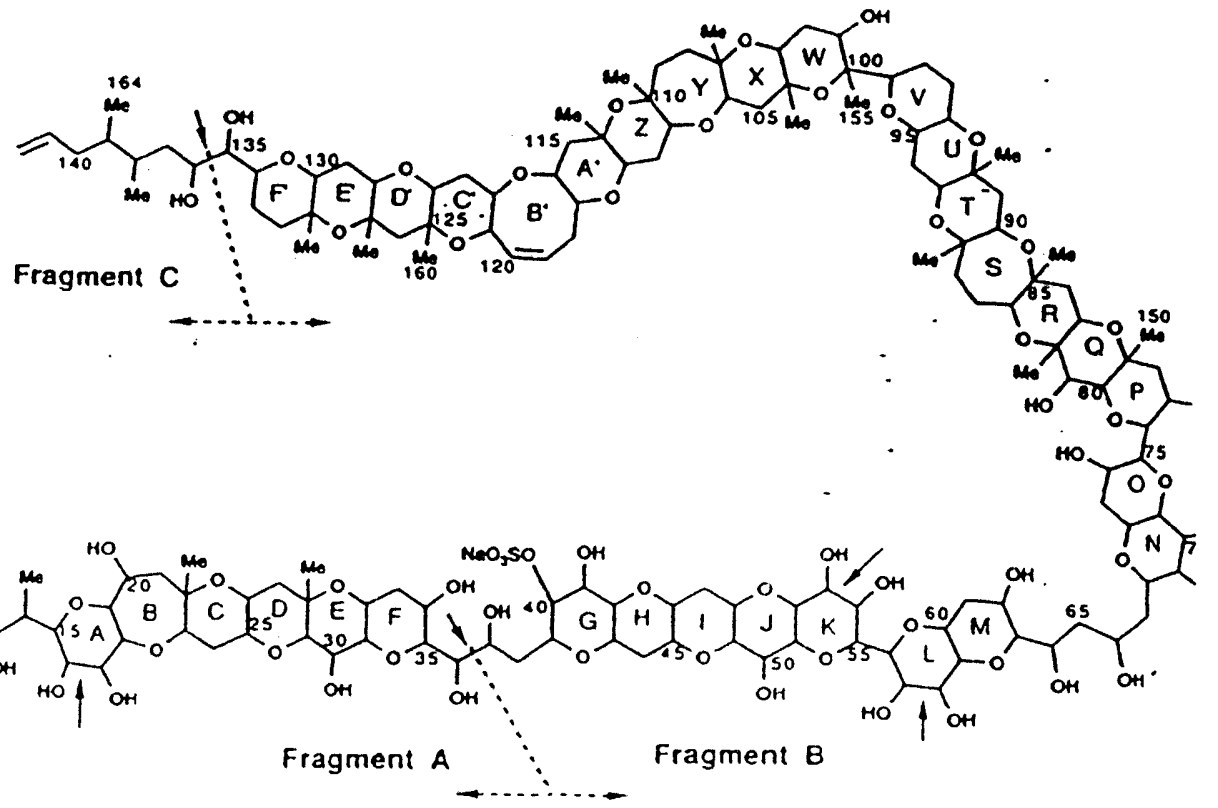

Tows denote cleavage sites by periodate.

FIGURE.1 Structure of a Pacific strain of MTX. 


\section{ISOLATION}

\section{Gambierdiscus toxicus}

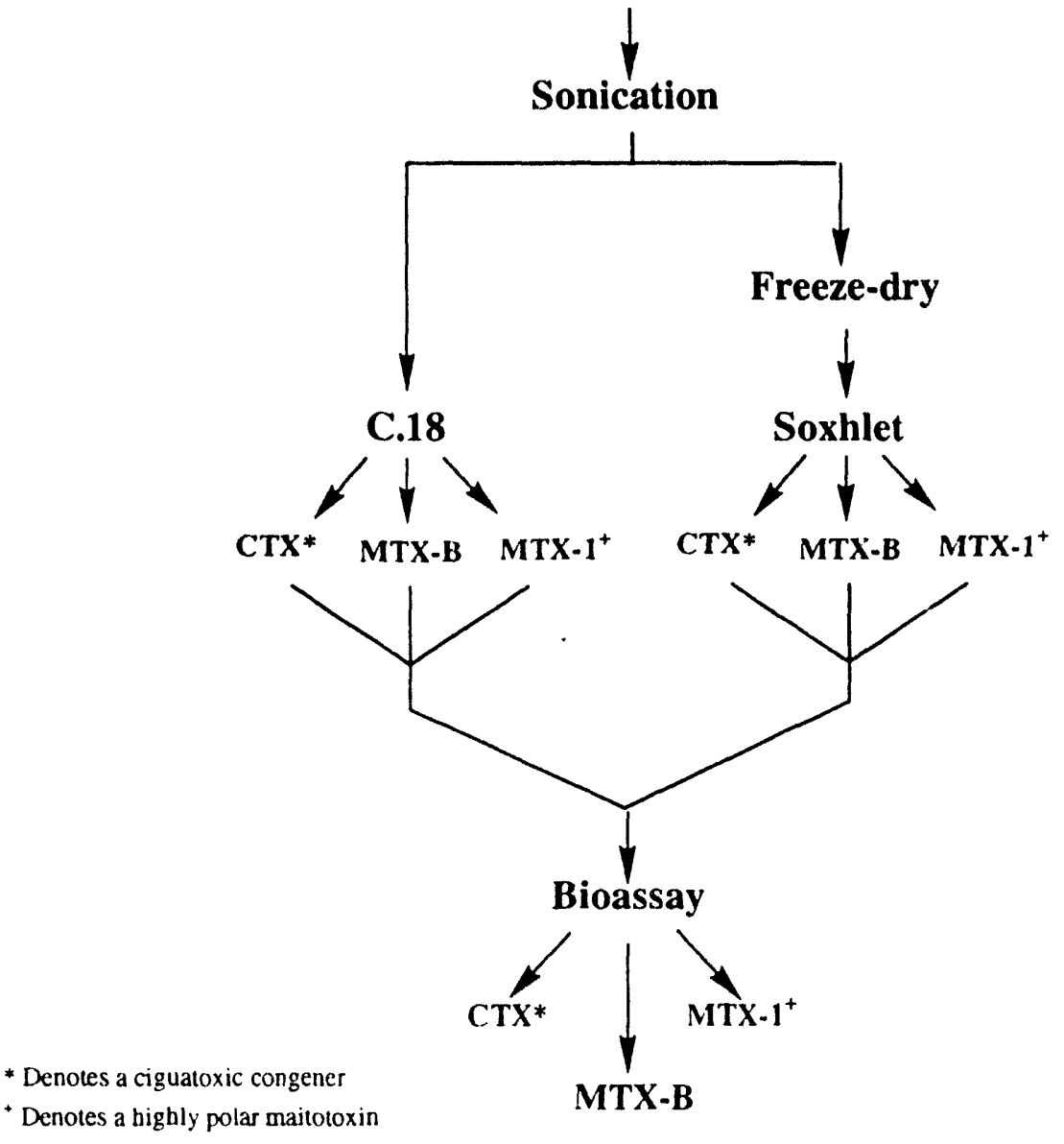

FIGURE.2. The isolation procedure including an alternative method. 


\section{CellTiter $96^{\mathrm{TM}}$ Non-Radioactive Cell \\ Proliferation/Cytotoxicity Assay}

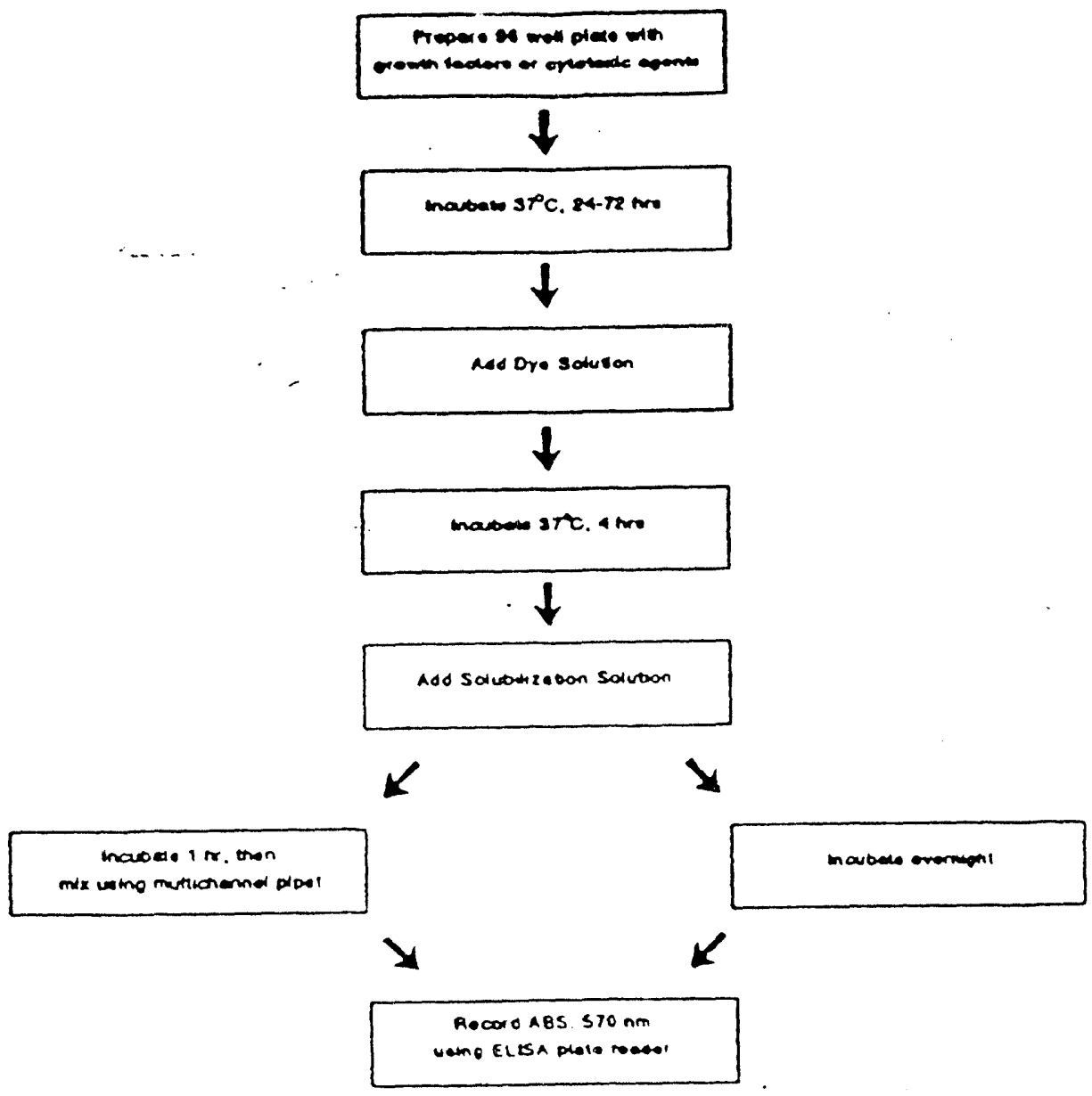

FIGURE.3 Standard protocol for cytotoxicity bioassay (Promega). 


\section{PURIFICATION}

\section{MTX-B}

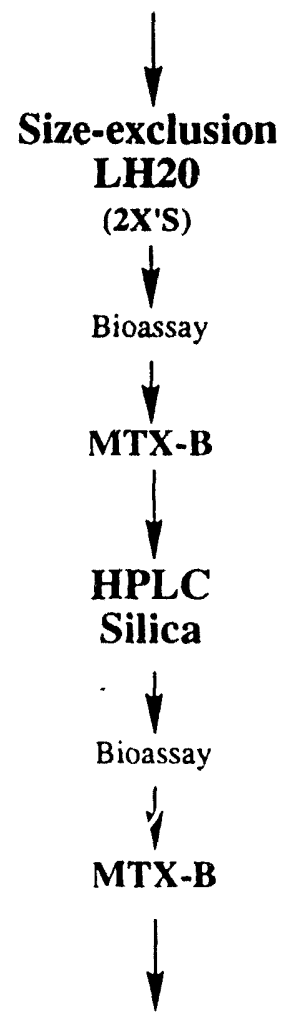

In development

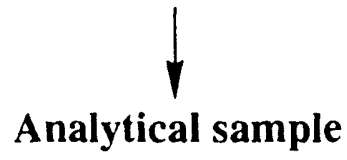

FIGURE.4 Protocol for purification of MTX-B. 


\section{SOXHLET EXTRACTION \\ BIOASSAY RESULTS}

SOLVENT

Hexane

Benzene

Pet. Ether

Ethyl Acetate

Acetone

Acetonitrile

Isopropyl Alcohol

Methanol

Water

-Indicates partial activity
CYTOTOX

$\underline{\mathrm{Ca}}^{++}$

$\mathrm{Na}^{+}$

$+$

$+$

$+$

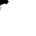

$+$

$+$

$+$

$+$

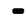

$(+)^{\star}$

$(+)^{*}$

FIGURE.5. Results are for $10 \mathrm{~g}$ frozen, wet-weight, of $\underline{G}$. toxicus. 


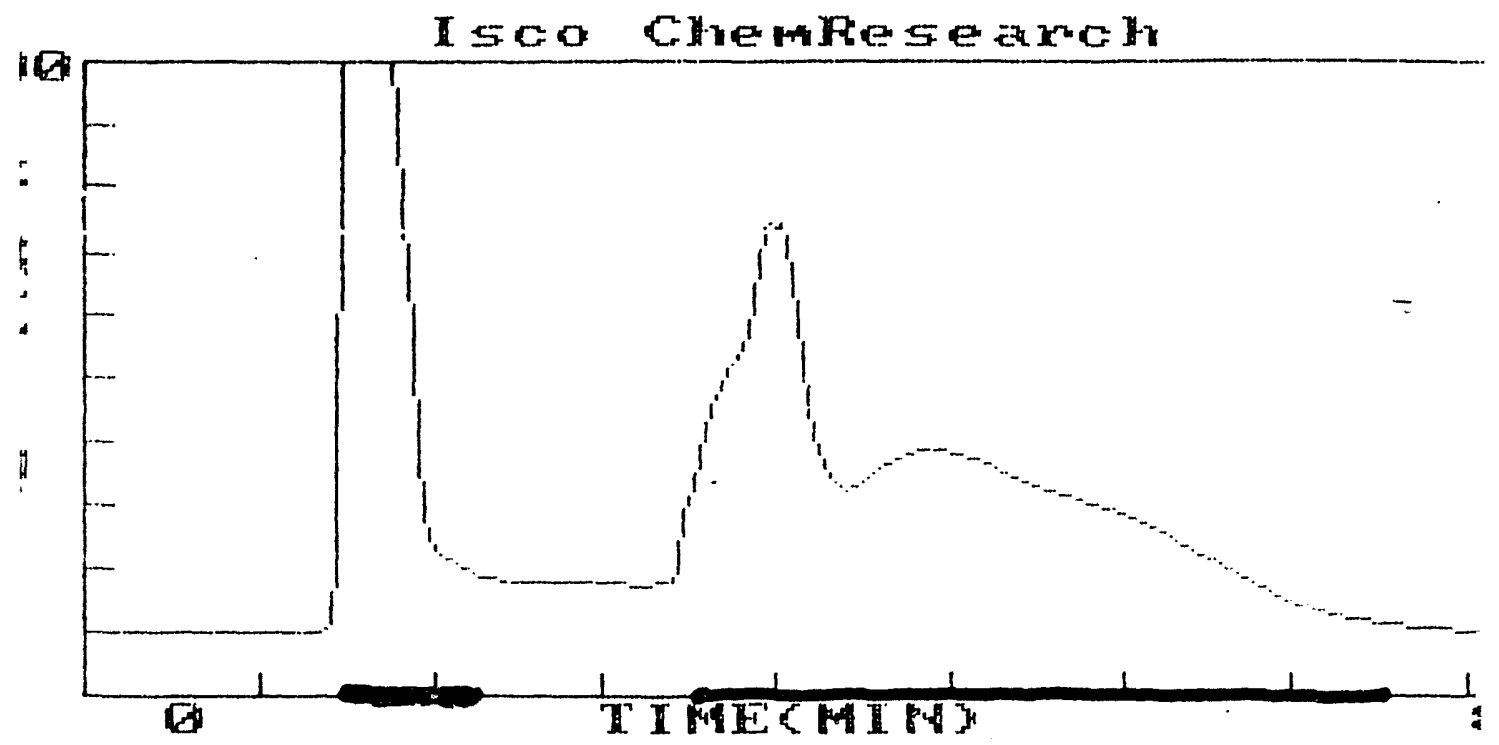

FIGURE.6 Chromatogram for HPLC. Darkened areas along bottom axis signify times that toxic fractions were collected. 


\section{HPLC}

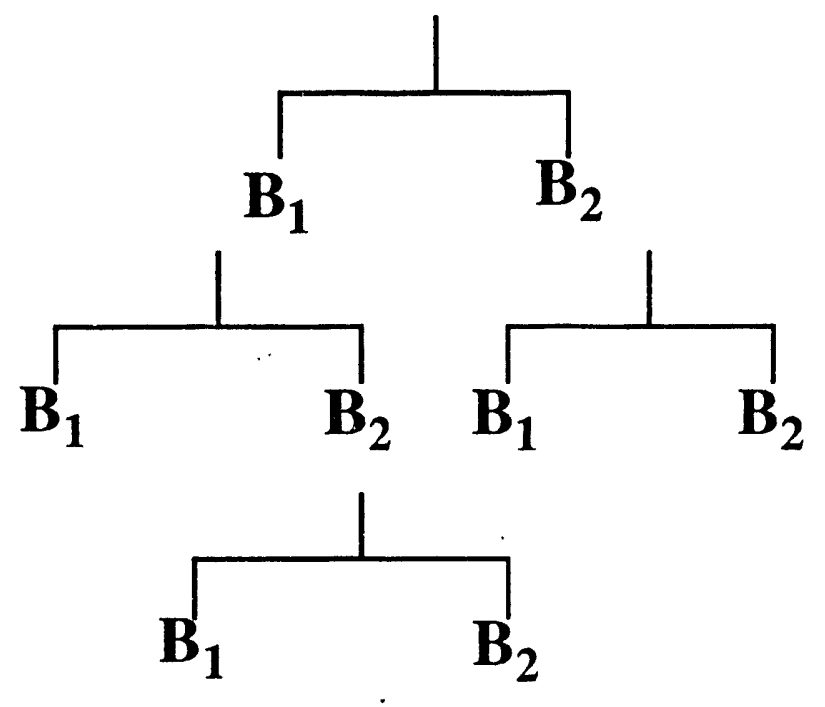

$\underline{\text { LEGEND }}$
$\mathrm{B}_{1}=\mathrm{MTX}-\mathrm{B}_{1}$
$\mathrm{~B}_{2}=\mathrm{MTX} \cdot \mathrm{B}_{2}$

FIGURE.7 Repurification and verification scheme for two toxic fractions that are believed to be in equilibrium with each other. 


\title{
Medical University of South Carolina

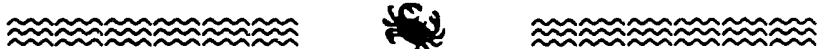 \\ Marine Biomedical \& Environmental Sciences
}

Sister Chromatid Exchange as an Indicator of Environmental Stress

\author{
by Lisa M. Johnson \\ Advisor: Dr. Donald R. DiBona
}




\section{Summary}

Environmental characterization requires the application of analytical procedures from a wide variety of disciplines. In the aquatic environment, resident fish reflect the surrounding stresses through a number of biological responses (biomarkers). Parallel investigations have been undertaken to: 1) examine the genetic basis of susceptibility to dioxin, and 2) to develop $a$ laboratory assay of genotoxic stress. In each case experimental material has been collected, procedures developed, and assessment of results is underway. Consequently, this manuscript represents a progress report.

\section{Introduction}

Biomarkers are biochemical, physiological and histiological changes in organisms used to estimate exposure to chemicals or resultant effects. Here I explore the use of biomarkers from two perspectives: use of a sentinel speries, Rivulus marmoratus, and testing a known assay, sister-chromatid exchange.

Rivulus marmoratus is the only internally self-fertilizing hermaphroditic vertebrate known. Clonal propagation of these fish eventually has resulted in homozygosity at every allele in their DNA. The benefit of this situation lies in the reliability of controls. Rivulus are also euryhaline, which makes them a good model because they can be used to test any environment from freshwater to two-three times marine water concentrations. Another advantage is that, with fish, we can completely control the environment of the experimental animal eliminating outside sources of variation between treatments. The only real disadvantage of using this organism is that propagation is slow, thus it takes a long time to get large enough numbers for experiments. Multiple strains of Rivulus were available at the marine biomedicine lab eliminating this problem. Spontaneous variation within the species accounts for the many different clonal strains of Rivulus. Different strains may vary with susceptibility to different stresses and offer a means to genetically characterize the basis of susceptibility.

In December 1992 the first experiment to begin and identify the genes that confer susceptibility to dioxin was made. Dioxin is a chemical produced in paper mills that is often a source of environmental contamination. The results of that preliminary experiment, in which several strains were screened, indicated that Rivulus is very sensitive to dioxin. The goal for the experiments that followed has been to verify suggested differences in susceptibility between strains and to use two strains that differ in susceptibility to try and identify the gene responsible for this difference. Gene sequencing of susceptible and nonsusceptible fish should locate the parts of the genome that are different between the two strains. Another goal of these experiments is to construct a dose-response curve for Rivulus exposed to different concentrations of dioxin. 
In my experiment, I exposed three strains of Rivulus marmoratus to five different concentrations of dioxin. Through this experiment I hoped to detect some difference in susceptiblility between the three strains and to begin construction of a dose-response curve for Rivulus marmoratus.

Sister-chromatid exchange can be used as an environmental biomarker because such exchanges are an indication of DNA damage (genotoxic stress). Using a special staining procedure it is possible to visualize recornbination between sister chromatids and to calculate the frequency of such exchanges.

The Savannah River has been a site of public concern with respect to pollution generated by a defense plant (Savannah River Site) that is located on the river a few miles south of North Augusta. The production of nuclear materials has led to the release of both nuclear and other contaminants into the river. The extent of this contamination and its ultimate effect on man has been the concern of the studies done in this area. This concern was the reason for choosing the Savannah River as the location to be tested by SCE analysis.

Choosing an organism to use for my SCE experiment was a challenge. First of all, the organism had to be aquatic because of the environment I was testing and because of the ability to completely control an aquatic environment. However, not just any fish can be used for SCE analysis because most fish have many $(2 n \geq 48)$ very small $(<3 \mu \mathrm{m})$ chromosomes that make visualisation of SCE nearly impossible under light microscopy. The mudminnow, Umbra sp., has been- a common organism used for sister chromatid exchange tests ${ }^{1-4}$ because of its low number $(2 n=22)$ of large $(3-8 \mu \mathrm{m})$ chromosomes. Umbra appeared to be ideal for my use because it is supposedly native to the Savannah River as well as to other local waters. Also, being a freshwater fish it is suitable to test areas from around the SRS. The availability of Umbra was not what I expected however, so I explored a couple of other options. One of these options was a small tropical fish, the chocolate gourami, Sphaerichthys osphromenoides. They can be conveniently purchased from pet stores, but the difficulty encountered with them is their extreme sensitivity to any changes in their environment. They were very difficult to keep alive in the laboratory even before any experimentation was tried with them. The only apparent alternative after that was the oyster toadfish, Opsanus tau. The oyster toadfish is found in estuarine to marine water and is locally available in Charleston harbor. They have been used for SCE tests ${ }^{5}$, have a small number $(2 n=)$ of large chromosomes and are very hardy and easy to keep in a laboratory situation. All of these characteristics made the oyster toadfish my best choice. The only problem with use of this fish is its limited salinity range. It is not found in freshwater and therefore could not be a "resident" test for the whole area of interest. 


\section{Methods and Materials}

\section{Dioxin}

Three strains of Rivulus marmoratus were exposed to different concentrations of dioxin in $50 \mathrm{ml}$ of $50 \%$ seawater. Three fish from each of the strains were exposed to each concentration (10ppt, 1ppt, .1ppt, .01ppt and controls with no dioxin). The fish were exposed over a 48 hour time period and water treatments were changed twice a day to ensure a semi-constant dioxin concentration. Fish were not fed during the exposure. After 48 hours the fish were rinsed three times with $50 \%$ seawater and one fish from each strain for each concentration was placed in a clean bowl, put back on a regular feeding schedule, and kept for observation. The other 2 fish per strain per concentration were rinsed three times with $50 \%$ seawater and immediately preserved in $10 \%$ formalin. Later the preserved fish were shipped to Dr. John Stegeman at Woods Hole Oceanographic Institution for analysis. In his laboratory, the generation of cytochrome P450 enzymes is directly assessed as an index of dioxin-derived tumorigenesis ${ }^{6}$.

$\underline{S C E}$

Collection of organisms

Much time and effort was spent in search of Umbra pygmaea, the eastern mudminnow, which seemed ideal for the type of experimentation I planned on doing. Unfortunately, a very substantial collecting effort only established that the fish is far from abundant. Umbra pygmaea are documented as being found in freshwater, slow moving, lowland creeks and streams along the Atlantic coast from Long Island, New York to Florida. Many techniques were used in my search for Umbra, including cast nets, minnow traps and dip nets. Although using a seine net appeared to be a popular technique used by others in the past ${ }^{1}$, I was unable to seine in any of the areas I looked due to the geography of the creek bottoms and surrounding shore. I searched for Umbra in many sights along the Cooper and Savannah Rivers with no luck. A local expert in the field pointed me toward some sites throughout the state where Umbra were previously spotted. I tried a number of these sites plus anything along the way that looked promising. At two particular sites in Darlington county I was not only troubled with the absence of Umbra, but with the absence of water as well, as a local drought seemed to have dried up the small creek in which Umbra were previously found. I did finally locate Umbra pygmaea in a small pool of water isolated from the Mechaw creek in the Frances Marion National Forest. Dip netting was my successful procedure for catching the unsuspecting fish, however, only three fish were found at this site, two of which died before I got them back to the laboratory. With my options exhausted I decided to settle for using the oyster toadfish for my experiments. The oyster toadfish used for my experiment were collected from the Charleston harbor using a dredge. They were then brought back to the laboratory and kept in well aerated aquaria (salinity = $\sim 23$ ppt) until use. 


\section{Injections and treatments}

Two separate aquaria were prepared for Savannah River simulations. The two Savannah River simulations differed only in that one was prepared using sediment taken from a location above the SRS and the other sediment was taken from a location below the SRS. The Savannah River simulations consisted of sediment approximately one inch thick in a small aquarium with approximately $2.5 \mathrm{~L}$ of $23 \mathrm{ppt}$ saltwater. The sediment and water were well mixed and allowed to settle for about three hours. Both aquaria were well aerated. Fish were first weighed and then injected with $500 \mu \mathrm{g}$ of 5bromodeoxyuridine (BrdU) per gram body weight and placed into one of the aquaria prepared. Control fish were place back into the original aquarium after injection. Three fish were injected per treatment. After 5 days fish were injected with $10 \mu \mathrm{g}$ colchicine/g body weight to arrest dividing cells in metaphase. After 4-7 hours fish were sacrificed and various tissues were removed for possible analysis. Tissues were place in $5 \mathrm{ml} .4 \% \mathrm{KCl}$ solution for 30 minutes. They were then fixed in 3 changes of 3:1 methanol:acetic acid and refridgerated for later use.

\section{Slide preparation}

Tissues were prepared and stained using a modification of the procedure used by van der Gaag et. al. 19857. The procedure involved the following:

1. Remove tissue from fixative and touch to filter paper to remove excess fixative.

2. Place in well of a depression slide and add 2-3 drops 50\% acetic acid

3. Mince gently for one minute and return unsuspended tissue to fixative

4. With draw one capillary tube full of suspension and expel onto clean slide heated to $40-50^{\circ} \mathrm{C}$ and quickly withdraw suspension back into the capillary tube (repeat to produce 2-3 rings/slide)

5. Treat for 15 minutes with 33258 Hoechst $(200 \mu \mathrm{g} / \mathrm{ml}$ PBS solution)

6. Rinse with distilled water and wet mount in Mcllvaine's buffer.

7. Expose to intense fluorescent light for ten minutes

8. Rinse with distilled water to remove coverslips

9. Treat with $5 \mathrm{~N} \mathrm{HCl}$ for 15 minutes

10. Rinse with distilled water

11. Stain slides in a $3 \%$ giemsa stain made up in $1 / 15 \mathrm{M}$ phosphate buffer for 7-8 minutes

12. Rinse in distilled water, air dry, and mount in permount

Slides were then viewed using light microscopy.

\section{Dioxin}

\section{Results}

Rivulus that were maintained and kept for observation were watched for survival rates. Only one fish died during the treatment. That fish was from the $1 \mathrm{ppt}$ treatment and from strain DS-352. The dates of fish mortality thus far can be seen in table 1 . 
Table 1. Mortality rate of three strains of Rivulus marmoratus after 48 hour exposure to various concentrations of dioxin.

\begin{tabular}{|c|c|c|c|}
\hline Fish \# & Strain & Treatment & Date Died \\
\hline 3 & NA 318 & 10 PPT & June 25, 1993 \\
\hline 6 & 024 & 10 PPT & July 12, 1993 \\
\hline 9 & DS-352 & 10 PPT & June 26, 1993 \\
\hline 12 & NA 318 & 1 PPT & \\
\hline 15 & 025 & 1 PPT & \\
\hline 17 & DS-352 & 1 PPT & June 11, 1993 \\
\hline 21 & NA 318 & .1 PPT & \\
\hline 24 & 021 & .1 PPT & \\
\hline 27 & DS-352 & .1 PPT & \\
\hline 30 & NA 318 & .01 PPT & \\
\hline 33 & 024 & .01 PPT & \\
\hline 36 & DS-352 & .01 PPT & \\
\hline 39 & NA 318 & CONTROL & \\
\hline 42 & 028 & CONTROL & \\
\hline 45 & DS-352 & CONTROL & \\
\hline
\end{tabular}

Rivulus that were preserved and sent to Dr. Stegeman at WHOI have not yet been fully analyzed. Therefore no results from those fish can be included here, but should be received in the near future.

\section{$\underline{S C E}$}

Umbra pygmaea were looked for at many sights from the Cooper and Savannah Rivers as well as from small creeks around South Carolina (see maps 1-4 for location of sights explored). The only place where Umbra pygmaea were found can be seen on map 3. Under this bridge was a small isolated pool of water with a muddy bottom. Three Umbra were found living in the mud at the bottom of this pool. Two of these three Umbra died on the way back to the laboratory because of high water temperature in the bucket they were being kept in. The other Umbra was put into a freshwater aquarium, fed flaked food and appears to be healthy to date. No water was found at two of the sights on map 4. Umbra were previously found in good numbers at these two locations (Scott Lamprecht personal communications) however, a local drought seemed to have dried up these small creeks.

\section{Discussion}

\section{Dioxin}

Results obtained by observation of Rivulus maintained after dioxin exposure indicate a possible difference in susceptibility between different strains. Both the strains DS-352 and NA 318 appear more susceptible than the strain 020-029. Not enough data was collected by this preliminary experiment to be conclusive. A second experiment is underway to further investigate this hypothesis. This experiment will test two of these strains in bulk. Five fish from the strains DS-352 and 020-029 will be exposed to dioxin at a 
concentration of $10 \mathrm{ppt}$ for a period of 48 hours. Fish will be maintained in the same manner as in this experiment and observed for rate of mortality. This should better enable us to determine any difference in susceptibility between these two strains.

$\underline{S C E}$

No data were collected for the SCE test done using the oyster toadfish. I am presently having some difficulty with the slide preparation and viewing of the chromosomes. Plenty of tissue has been preserved for analysis and this work will be continued in the laboratory.

There are a couple of unanswered questions that need to be adressed regarding the SCE test. First, what is the proper method for testing for environmental contaminants? Is my method of putting contaminated sediments in uncontaminated water appropriate, or is their another method commonly used? I was unable to locate anything in the literature to help me answer this question. Eventual SCE results will address the issue of appropriate protocols for stress assessment.

Another question that has been asked with regard to the SCE test is whether or not fish will eventually become adapted to a contaminated environment and no longer show an increase in SCE frequency, or if fish can be sampled directly from the environment and analyzed for SCE frequency in a meaningful way. Adaptations within populations from various locations will exploit fingerprinting techniques.

Although there are a number of questions left unanswered, further data analysis of material collected during both the dioxin exposure and SCE experiment will continue. Through long distance communication I hope to be a part of this data analysis and continue to seek out the answers to these questions. 


\section{Literature Cited}

1. Kligerman, A.D., W.E. Bishop, and L.C. Valentine. 1981. Use of the Mudminnow, Umbra sp., in an In Vivo Sister Chromatid Exchange Test. In: Use of Small Fish in Carcinogenicity Testing. Monograph 65, National Cancer Institute.

2. Kligerman, A.D. 1979. Induction of Sister Chromatid Exchanges in the Central Mudminnow Following In Vivo Exposure to Mutagenic Agents. Mutation Research, 64:205-217.

3. Kligerman, A.D., S.E. Bloom. 1977. Rapid Chromosome Preparations from Solid Tissues of Fishes. J. Fish. Res. Board Can., 34:266-269.

4. Kligerman, A.D., S.E. Bloom. 1976. Sister Chromatid Differentiation and Exchanges in Adult Mudminnows (Umbra limi) after in vivo Exposure to 5Bromodeoxyuridine. Chromosoma (Berl.) 56:101-109.

5. Maddok, M.B., H. Northrup, T.J. Ellingham. 1986. Induction of SisterChromatid Exchanges and Chromosomal Aberrations in Hematopoietic Tissue of a Marine Fish Following In Vivo Exposure to Genotoxic Carcinogens. Mutation Research, 172:165-175.

6. Stegeman, J.J. 1993. The cytochromes P450 in fish. In: Biochemistry and Molecular Biology of Fish, P. Hochachka and T. Mommsen (eds.).

7. Van der Gaag, M.A. and J.F.J. van de Kerkhoff. 1985. Mutagenicity Testing of Water with Fish: A Step Forward to a Reliable Assay. The Science of the Total Environment, 47:293-298. 


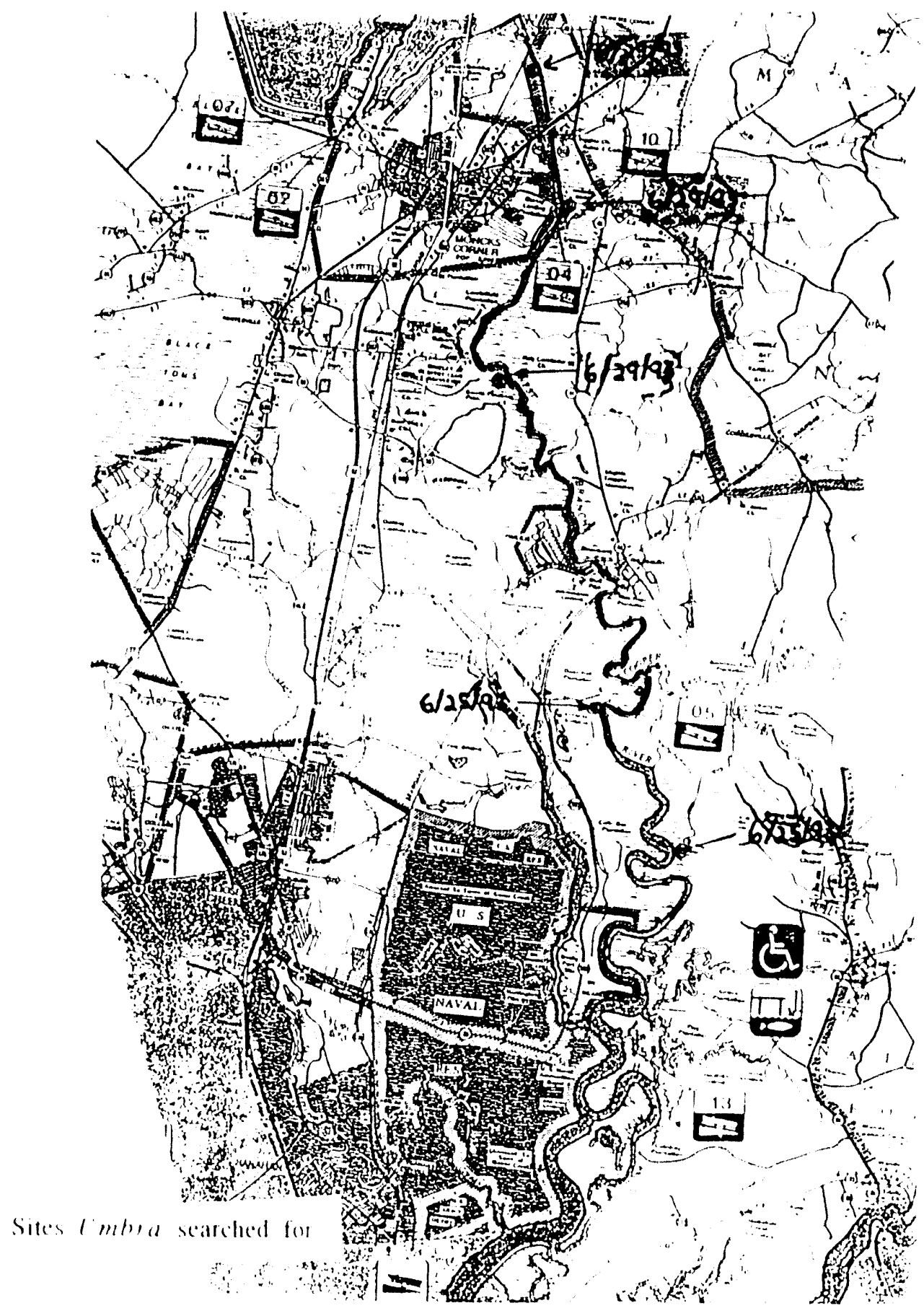

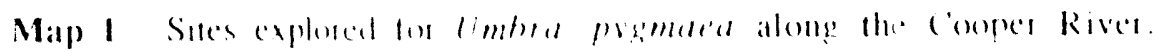




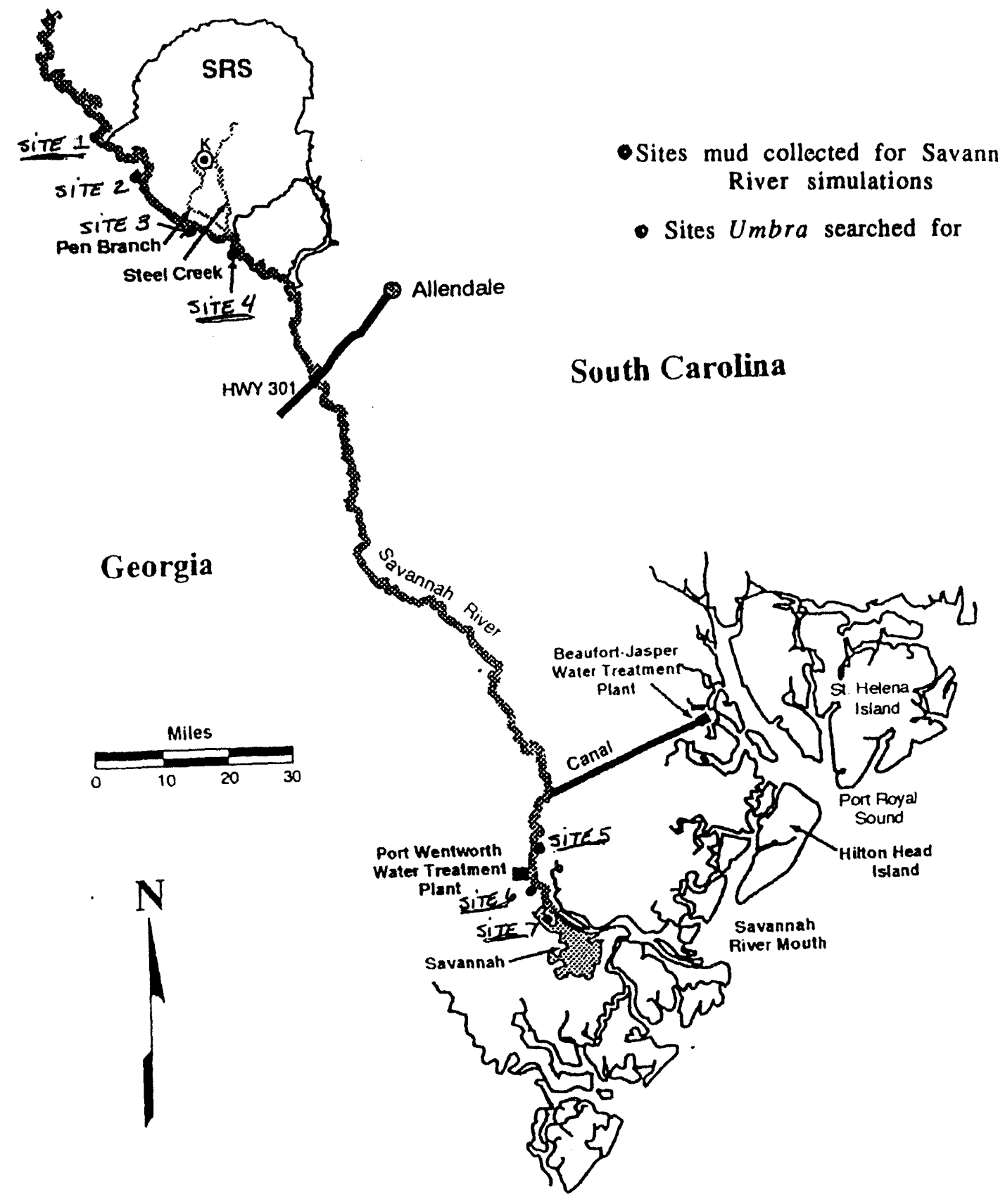

Map 2 Sites explored for Umbra pygmaea along the Savannah River. 


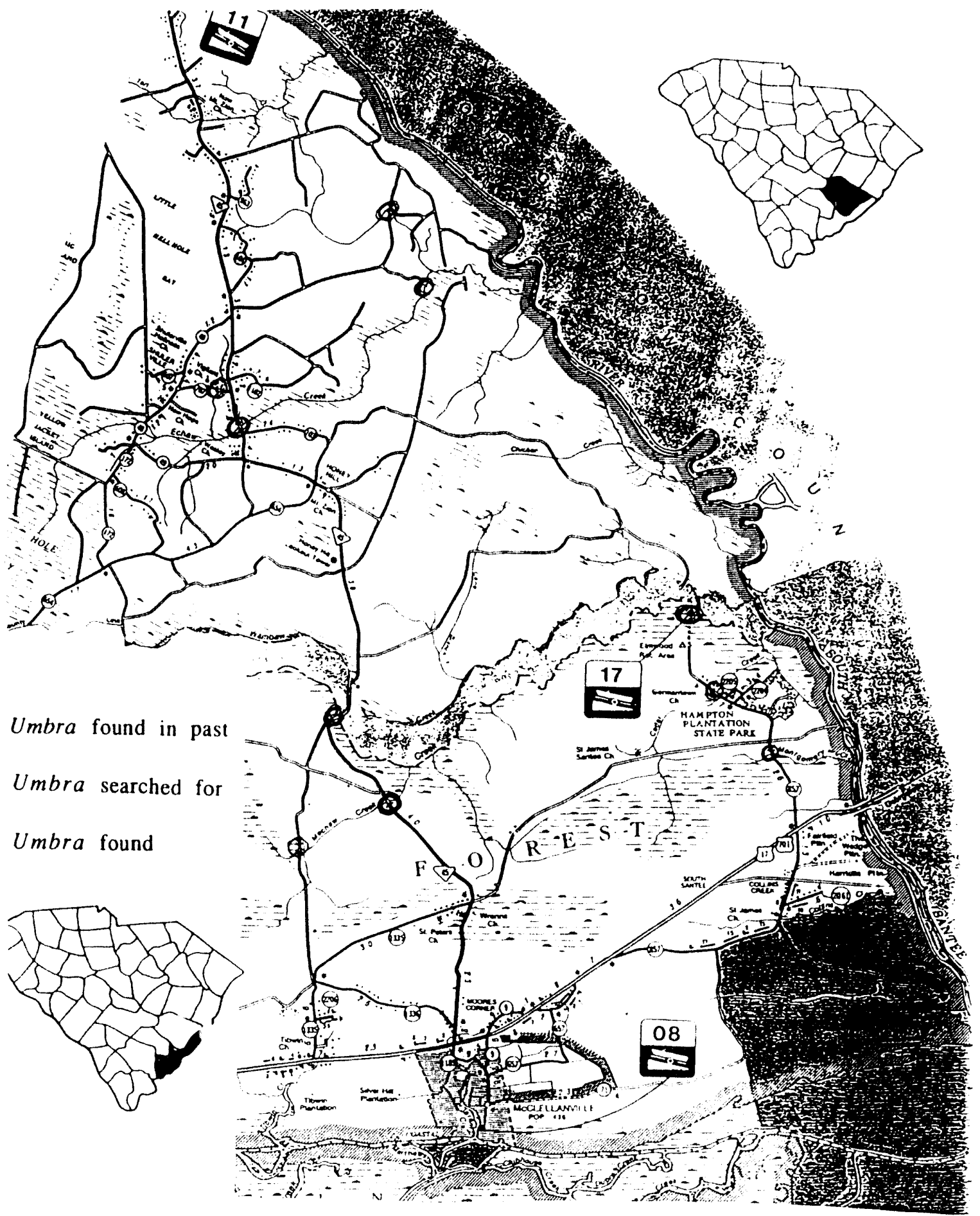

Map 3 Sites explored for Limbra pygmaea in Charleston and Berklev. counties. 
- Sites Umbra found in past

- Sites Umbra searched for

- Lookout tower
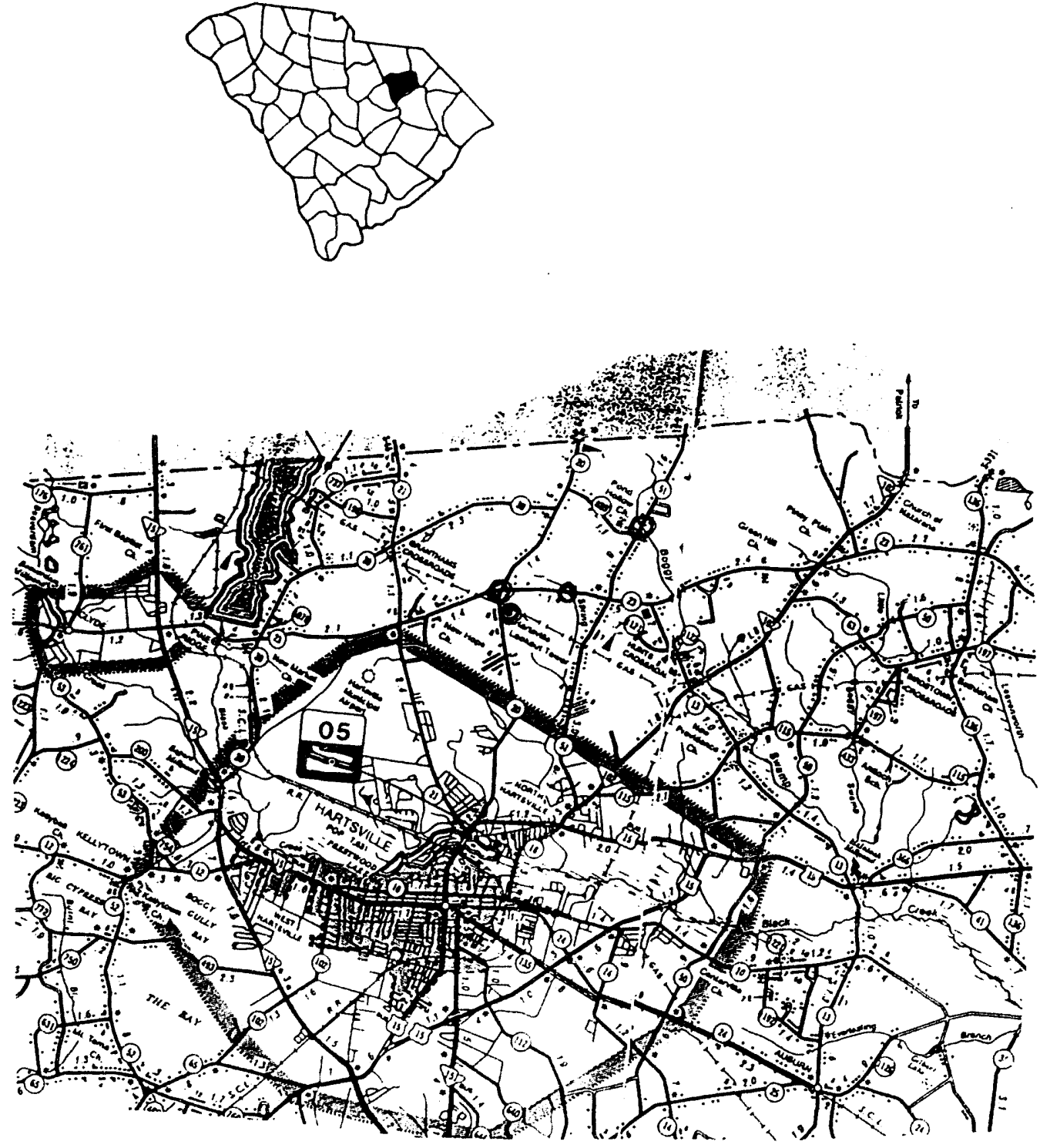

Map 4 Sites explored for Umbra nvemaea in Darlinoton rnuntv 


\title{
Use of Diatom Distributions to Monitor Environmental Health
}

\author{
by Rachel H. Levine* \\ Advisor: Dr. Donald R. DiBona**
}

* Summer Undergraduate Research Intern

Wesleyan University

Middletown, CT

Sponsor: U.S. Department of Energy

Medical University of South Carolina

Marine Biomedical and Environmental Sciences

**Medical University of South Carolina

Director, Marine Biomedical and Environmental Sciences

Fort Johnson Marine Laboratory

221 Fort Johnson Road

James Island, SC 29412 


\section{Use of Diatom Distributions to Monitor Environmental Health}

Summary: A variety of approaches has been used in the past to assess the environmental impact of anthropogenic contaminants. One reliable index for aquatic environments is the analysis of diatom species distribution; the focus in this case being on the Savannah River. The completed objectives of this study were: $A$ ) the development and use of procedures for measuring diatom distribution in the water column and $B$ ) the development and evaluation of sediment sampling methods for retrospective analysis.

\section{Introduction}

In the early 1950's, the Savannah River Site (SRS) was established on the bank of the Savannah River, near Aiken South Carolina, to begin production of nuclear materials. Over the years, various radiaoactive substances such as plutonium, tritium, cesium and strontium have been released into the ponds and creeks within the SRS plant (SRS 1991). Because of the continuous exchange of water between the Savannah River and its tributaries, much of the toxic waste has become dispersed throughout the approximately 160 miles of river between SRS and the river's mouth.

For the 40 years that SRS has been in operation, there exist only irregular records of both the amounts and types of waste materials released into the environment and their effects on the ecological systems of the Savannah River. In order to initiate a comprehensive history of the river's exposure to heavy metals and radionuclides, an analysis of diatoms was begun. It is possible that this approach will help in retrospective assessment of environmental contamination.

Diatoms are single-celled plants that are found both as phytoplankton and periphyton. Usually brown in color, and exhibiting a large range of shapes and sizes, diatoms exist in almost every aquatic habitat world-wide. Diatoms are unique in that they secrete silicon oxide, forming symmetrical shells, or frustules, which earn them the name "glass-houses." Along with the silicon 
oxide, however, diatoms also incorporate into their frustules any elements accumulated from their aquatic surroundings. Materials enter the cell by diffusion (Rand and Petrocelli 1985), where they are packaged by various organelles and then secreted (Robinson and Sullivan 1987). The relative amounts of different elements in the frustule should therefore reflect the ratios of various materials in the water at the time of frustule formation.

When the diatom dies, the frustules sink and become part of the sediment. The cell decomposes, but there is little or no depuration from the frustule. All elements in the molecular structure of the shell remain intact and, by analyzing diatoms in the river sediment, it is possible to determine the ratio of toxic materials that were present in the water column over a long period of time. In this study, the initial aspects of that approach have been explored. Existing water column samples were analyzed, focusing on species composition to discover any present differences between the Cooper and the Savannah Rivers. Diatom distribution patterns in the water column will be used to initiate a database comparing past and present species composition as well as the amounts of different heavy metals and radionuclides that are suspected components of SRS effluent.

\section{Materials and Methods}

\section{Field Procedures:}

To collect field samples, both water column and sediment, from the Savannah River, two separate trips were made. The first, on July 1, 1993, began approximately at mile marker 10 , north of the river's mouth, and continued upriver to mile 33, over which distance three sample sites were chosen (see figure 1). The second, on July 21, 1993, covered approximately 30 miles of river and 4 different sample sites, beginning 7 miles above SRS and ending close to the southern border of SRS territory (see figure 2). Three samples were also collected on each of two different days, June 25 and June 29 , 1993, from the Cooper River as a control (see figures 3 and 4).

Sediment sample sites along both rivers were chosen where there was neither a strong current nor visible eddies and there appeared to be a lot of deposition, such as the inner curve of a bend in the river bed. A Wildco lexan hand corer (Wildlife Supply Co., Saginaw, MI), 2 inches in diameter, was used to take one core sample per site, core length ranging from 10 to 16 
inches. Each core was then divided into three sections and placed into ziploc baggies.

Water column samples from both the Savannah and Cooper Rivers were taken in the same area as the sediment cores but in water at least 2 meters deep to avoid collecting bottom material. A submersible pump (Atwood 800 gpm, Attwood Corp.) attached to tygon tubing was lowered halfway into the water column and run for approximately 5 minutes per site (pump time was either increased or decreased depending on the amount of material collected). The water was run through a stack of 5 8-inch diameter sieves, with mesh sizes of $800,270,120,70$, and 37 microns (stacked downward from 800 to 37 microns) (Carolina Biological Supply Co.). The material from the 37, 70, and 120 micron sieves was then washed with river water from the mesh into separate collection bottles. Water column samples from the Cooper River, however, were combined by sicve size, i.e. all material collected in the 37 and 70 micron sieves from each site on the same day were washed into the same jar. A Hydrolab was used to measure the salinity/conductivity, $\mathrm{pH}$, dissolved oxygen (DO), temperature, and depth of each water column site. Water column samples were maintained at $4 \mathrm{C}$ during transportation to the lab.

Both water column and sediment samples were stored in a refrigerator when brought back to the lab withoü any preservation techniques, although $10 \%$ formalin was added to some of the water column samples a few days after collection in an attempt to preserve some of the organic material.

\section{Laboratory Procedures: Water Column samples}

In order to reduce the volume and concentrate the water column samples from both the Savannah River and the Cooper River, each sample was put into a $15 \mathrm{ml}$ centrifuge tube and spun down at approximately $1000 \mathrm{rpm}$ for 5 minutes. The supernatant was decanted, a few drops of distilled water was added, and the pellet was dispersed. Wet mounts were prepared from a few different samples and examined under a light microscope (Zeiss ICM-405 Inverted microscope equipped with video capabilities) both at $400 \mathrm{x}$ and at 1000x. Diatoms were visible at both magnifications and video thermal prints were made of some species to aid in classification (see figure 5).

Because of the ease with which diatoms were founc under the scope, permanent slides were made. Three slides from each of the three sieve sizes collected (37, 70 and 120 microns) from all 7 sites sampled on the Savannah 
River, and 4 slides from each sample size (37/70 and 120/270 microns) from each of the two Cooper River trips were prepared. A few drops of concentrated sample were placed on a glass slide and heated over an electric hot plate to dry. First Permount and then a coverslip were added to the dry samples before leaving them in a hood overnight for the Permount to harden. Completed slides were examined under the microscope at 400x, and the first twenty diatoms seen on each slide were classified by genus and tallied (see table 1A). Percentages were then calculated of each genus at each sample site (see table 2B).

\section{Laboratory procedures: Sediment samples}

Because of the density of the sediment cores and the large amount of material from each site, aliquots of each section of each core were filtered similar to the water column samples. Approximately $75 \mathrm{ml}$ of sediment from each sample was placed on the 800 micron sieve and washed through the 4 smaller sieves. Any material remaining on the 37, 70, and 120 micron sieves was then washed into separate sample bottles. After 3-5 spins at approximately $1000 \mathrm{rpm}$ (beginning with $15 \mathrm{ml}$ each time and then decanting the supernatant) for 5 minutes per spin, the samples were completely concentrated. A few drops of distilled water were added and the pellets were dispersed, then allowed to settle naturally.

The top layer of material from a few of the samples was pipetted onto glass slides and dried on a hot plate. Three slides were made from each of three samples (see table 2). When dry, the slides were examined under a dissecting scope at 50x. Diatoms appeared milky white among the other material on the slides. They were lifted off the slide with an eyebrow hair and a drop of distilled water and placed on a grid, each grid box representing a different shape if diatom.

\section{Electron Microprobe Analysis}

Special arrangements were made with Dr. Ann LeFurgey, Director of the Microscope Facility in the Department of Cell Biology at Duke University to use the lab's facilities and scanning electron microscope (SEM) to examine diatoms with electron probe analysis. That analysis would show the relative amounts of all the major elemental components in the diatom frustules. 
To prepare the samples for examination in the SEM (JSM-6400), small aliquots of each sample were placed in petri dishes and left overnight under a hood to dry. Under a $10 x$ dissecting scope, diatoms were identified, lifted by a fine brush with a drop of distilled water and placed on carbon stubs (made of spectroscopically pure carbon to avoid a false signal in the microscope) coated with colloidal graphite carbon paste. Approximately 4-10 diatoms were placed on a stub, then the stubs received a top layer of carbon. Completed carbon stubs were placed one by one in the SEM and examined. Three different types of images were used in the analyses: a Secondary Electron Image (SEI), a Backscattered Electron Image (BEI), and an Energy Dispersive X-ray (EDX). Black and white pictures were also taken of each diatom examined with Polaroid $4 \times 5$ Type 55 film (see figure 6).

\section{Results}

Diatom distributions from water column samples from the Savannah River as well as the Cooper River were calculated (see table 3 ). The most common diatom genus in the Savannah River is Melosira, comprising an average of $33 \%$ of the population. One interesting fact is that Melosira, while still the most abundant genus at each site, shows a definitive decrease in numbers, going from $50 \%$ of the diatom population at site 1 (farthest from the river's mouth) to only $22 \%$ at site 7 (at mile marker 10). Pleurosigma (also called Gyrosigma) (Heurck 1896) and Coscinodiscus are the next most common diatoms in the Savannah River, averaging $16 \%$ and $13 \%$ respectively. Except for Synedra (9\%) and Navicula (8\%), the majority of the other diatoms counted were classified in genera that each accounted for $4 \%$ or less of the total population.

The diatom distribution in the Cooper River was found to vary substantially from that of the Savannah. Although the most common diatom there is also Melosira at $32 \%$, next on the list is Cyclotella, composing $21 \%$ of the diatom population, and Navicula at $15 \%$. There is also a smaller variety of genera in the Cooper where only 13 genera were identified, compared to 19 in the Savannah River.

In the sediment samples taken from Savannah River sites 1 and 2, a large number of diatoms were found, including a high number of centric diatoms. This corresponds with the large percentage of centric diatoms (Coscinodiscus) found in the water column samples. In the slides from Savannah River site 
4, however, insufficient numbers of diatoms were identified to analyze the population. Extracting diatoms from sediment is an exacting process, and considerable work will be required to develop reproducible procedures. Therefore, many more cores will have to be used for developing technical procedures before diatom populations of the past can be calculated on a routine basis.

SEI and BEI taken on the SEM were used for the photographs of the water column diatoms, clearly showing each frustule in detail (see figure 6). EDX data, printed in graph form, showed the relative amounts of each element present in a small section of each frustule. The most common elements were silicon, chlorine, potassium, calcium and barium (see figure 7). The chlorine peak is suspect, however, because there is a chlorine contamination factor from the SEM itself. An EDX was also done on the material inside one of the frustules, and much higher peaks of both aluminum and iron were recorded (see figure 8).

\section{Discussion}

The most common diatoms from mile markers $165-135$ and 33-10 of the Savannah River are Melosira, Pleurosigma and Coscinodiscus (see table 3). When compared with previous calculations of diatom distributions, some interesting questions are raised.

For the most part, diatom species composition of the Savannah River has changed little over the past 40 years. In a study done by Louis G. Williams from 1960-1962 (Williams 1964), the most common diatoms at Port Wentworth, GA (near Savannah) were Melosira and Coscinodiscus. The Alvin W. Votgle Nuclear Power Plant's report on the algal populations at Port Wentworth from 1951-1968 also listed Melosira and Coscinodiscus as the most prevalent genera (Georgia Power Co. 1972). The results of this study agree with those results in that Melosira and Coscinodiscus comprise a large percentage of the total diatom population in the area; the presence of significant numbers of Pleurosigma is the striking difference to be accounted for.

Further upriver, near North Augusta, SC, Williams (1964) stated that Melosira was the most common diatom genus. The Votgle iviclear Plant report (1972) concurrred, and also added Navicula to the list. This study has calculated that Melosira and Navicula are still a major portion of the area's 
total diatom population. It deviates, however, in that Pleurosigma was also determined to be one of the most common genera, yet it is not prominent in the Savannah River in either of the 2 other studies mentioned above. Not enough information has been uncovered about diatoms as indicator species to be able to determine exactly what the increased appearance of Pleurosigma signifies, but future sediment analyses in areas where Pleurosigma exists in high percentages will hopefully be able to provide a history of the genus' population. That history may follow the rise and fall of the river's toxicity level, or it may show a general adaptation of different diatoms to changing environmental parameters.

On another level, the diatom populations of the Savannah River were compared to those of the Cooper River, and while there were some similarities, other variations were immediately visible (see table 3). For example, Melosira is the most common genus in each of the rivers but, where Pleurosigma and Coscinodiscus are also prominent in the Savannah River, they are not found in great numbers in the Cooper. On the other hand, Fragilaria and Cyclotella, two of the most common diatoms in the Cooper River, are very rare in the Savannah. While it is possible that these differences are due to the increased amount of toxic waste dumped into the Savannah (i.e from SRS) than the Cooper, there are numerous, nonanthropogenic differences between the two watersheds that must be considered.

More research must be completed before firm conclusions of environmental significance can be drawn from this data, although river quality assessment through diatom analysis appears to be a reliable procedure. Results agreed with assessments made previously, and sample sizes proved to be sufficient for statistical analysis. As more information continues to be collected, the database for Savannah River environmental health will be progressively enlarged. 


\section{References}

Georgia Power Company, Alvin W. Votgle Nuclear Plant Applicant's Environmental Report, August 1, 1972, Vol. 1, pp. 2.7-101-2.7-104

LeFurgey, A., and St. Jean, Jr., J., "Foraminifera in Brackish-Water Ponds Designed for Waste Control and Aquaculture Studies in North Carolina," lournal of Foraminifera Research, 1976, Vol. 6, No. 4, pp. 274-294

Rand, G., PhD., and Petrocelli, S., PhD., Fundamentals of Aquatic Toxicology, Hemisphere Publishing Co., New York, 1985, pp. 495-525

Robinson, D. H., and Sullivan, C. W., "How do diatoms make silicon biominerals?" TIBS, 1987, Vol. 12, No. 4, pp. 151-154

Savannah River Site, SRS Environmental Report for 1991, WSRC-TR-92-186, 1991

Williams, L. G., "Possible Relationships Between Plankton-Diatom Species Numbers and Water-Quality Estimätes," Ecology 1964, 45:809-823 


\section{South Carolina}

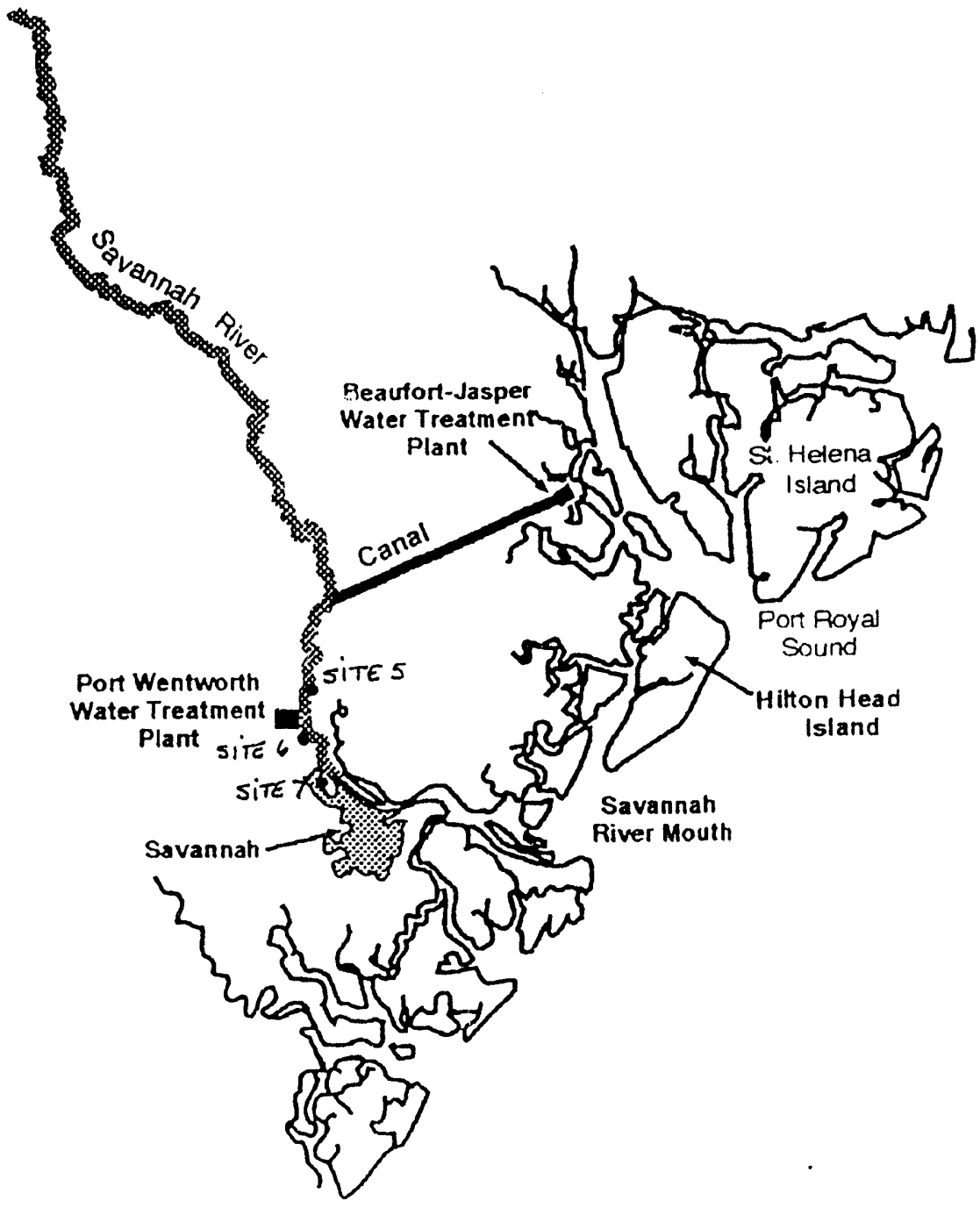

Figure 1. Sites 5-7 sampled on the Savannah River at mile markers 33, 20, and 10 on $7 / 1 / 93$ are marked with a. 


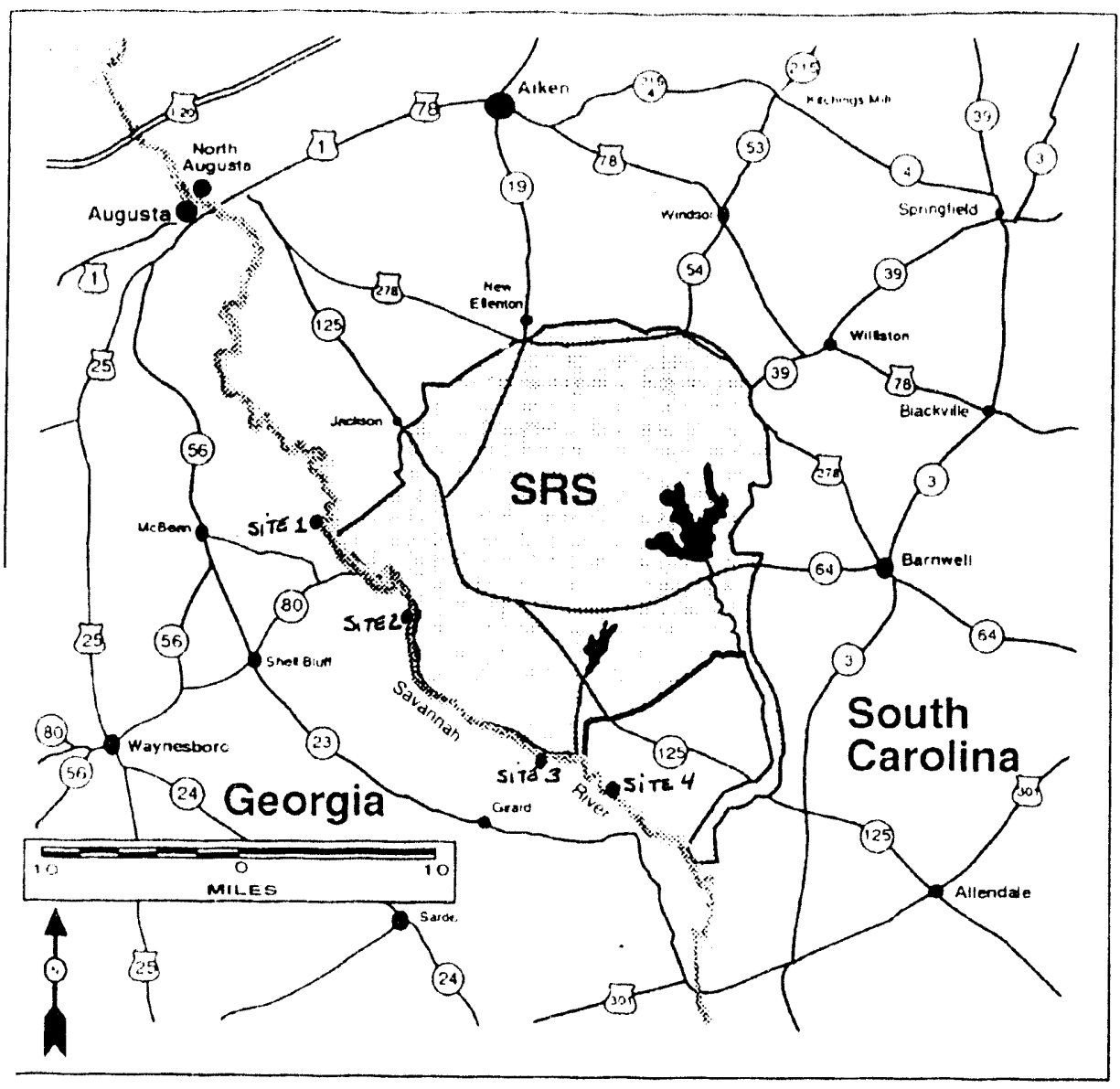

Figure 2. Sites 1.4 sampled on the Savannah River at mile markers $165,155$. 145. and 135 on $7 / 21 / 93$ are marked with a $\bullet$ 


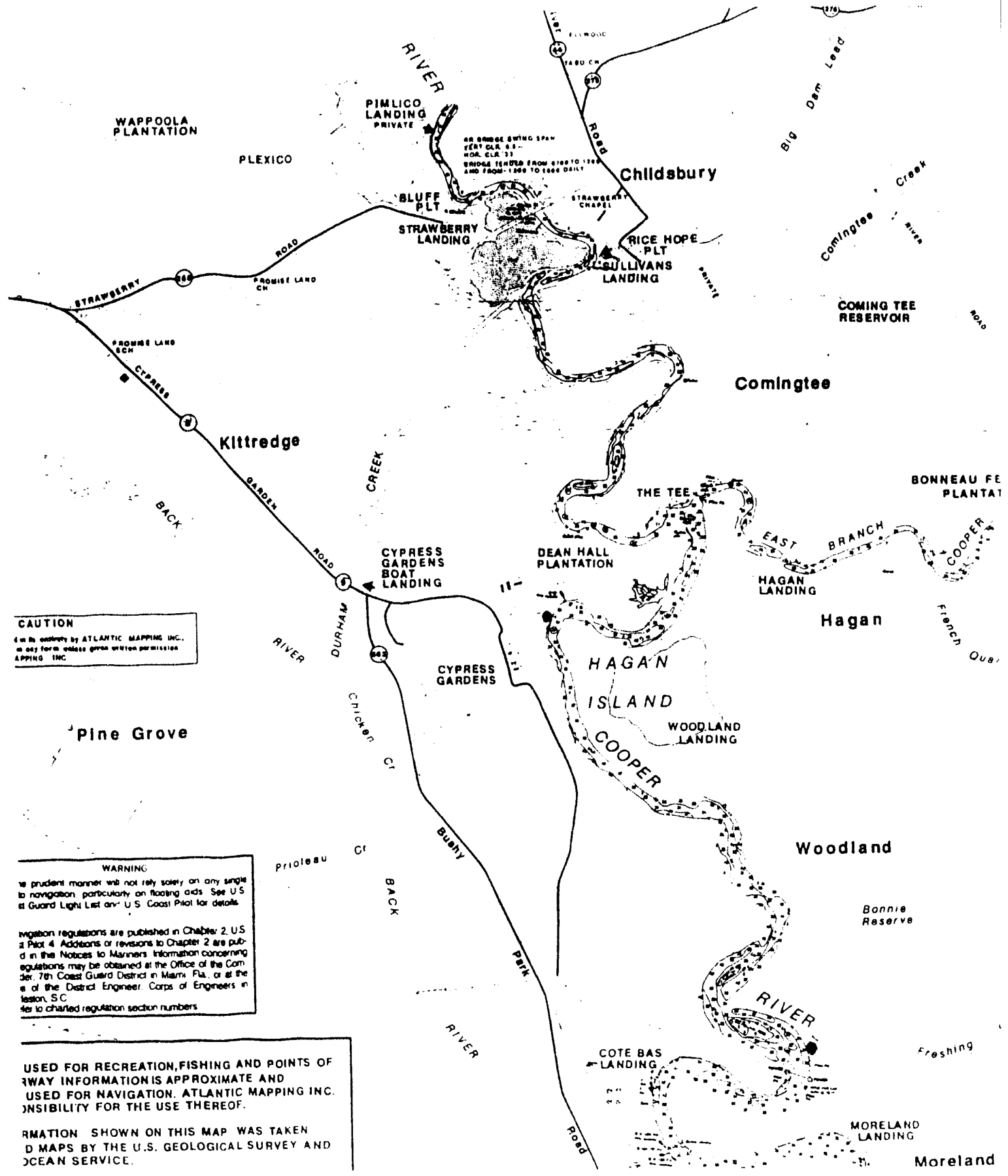

Figure 3. Sites sampled on the Cooper River on $6 / 25 / 93$ are marked with a 


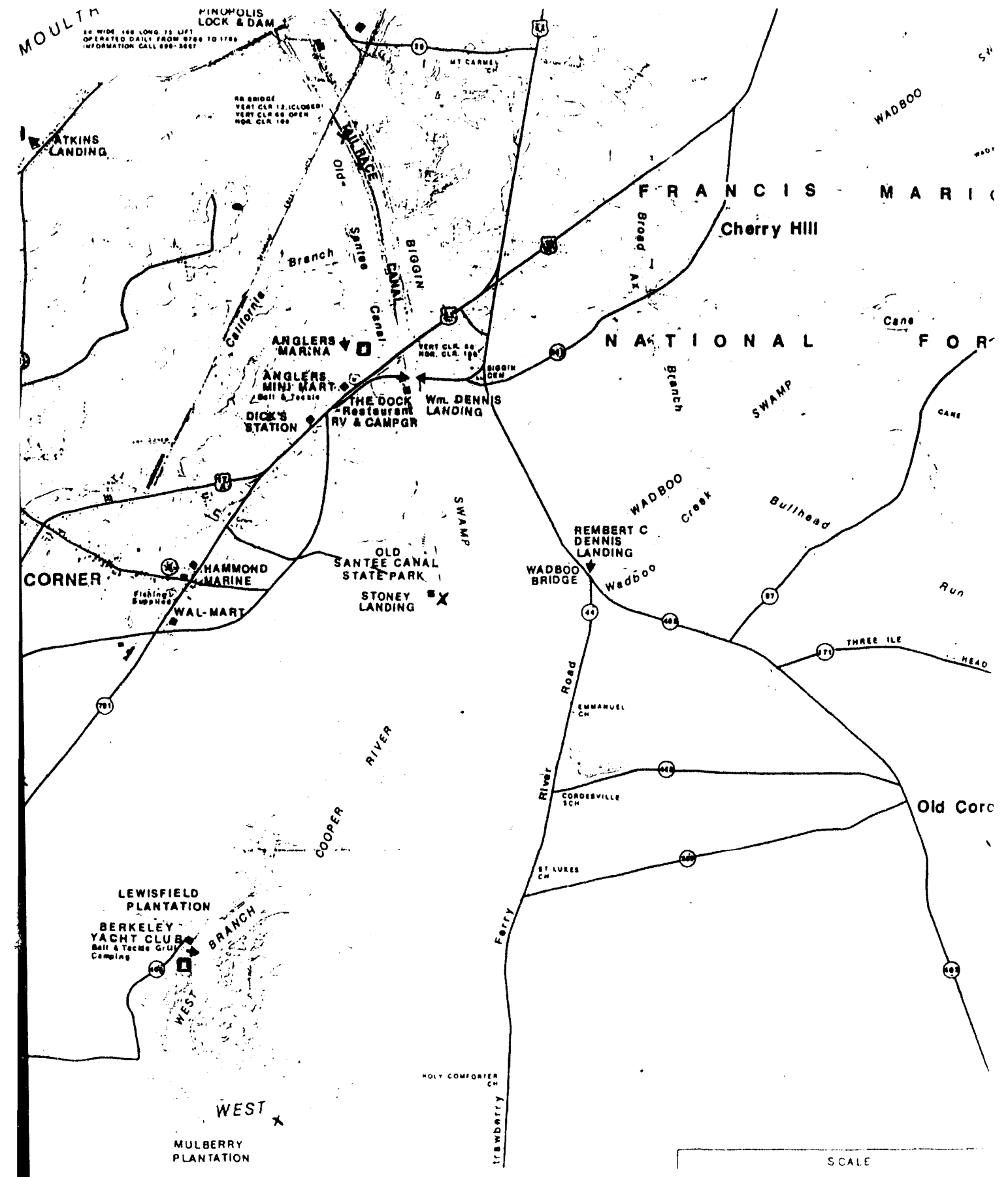

Figure 4. Sites sampled on the Cooper River on $6 / 29,93$ are marked with an $\mathrm{X}$. 

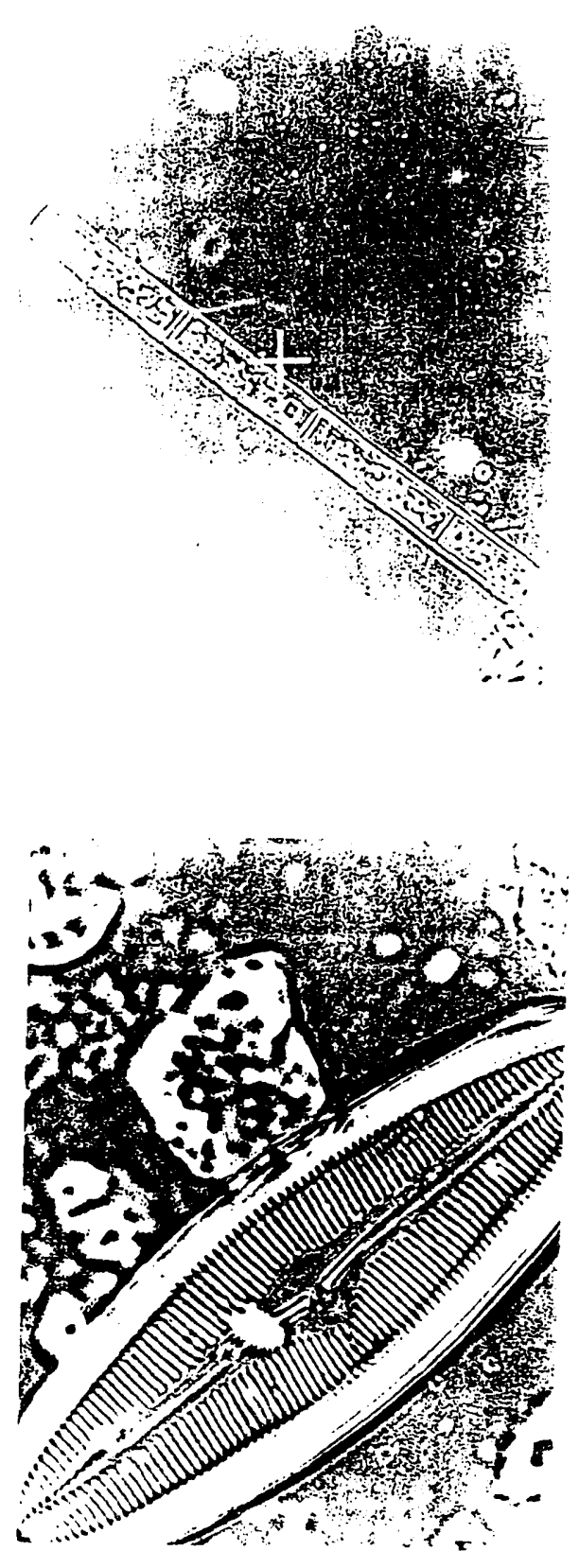
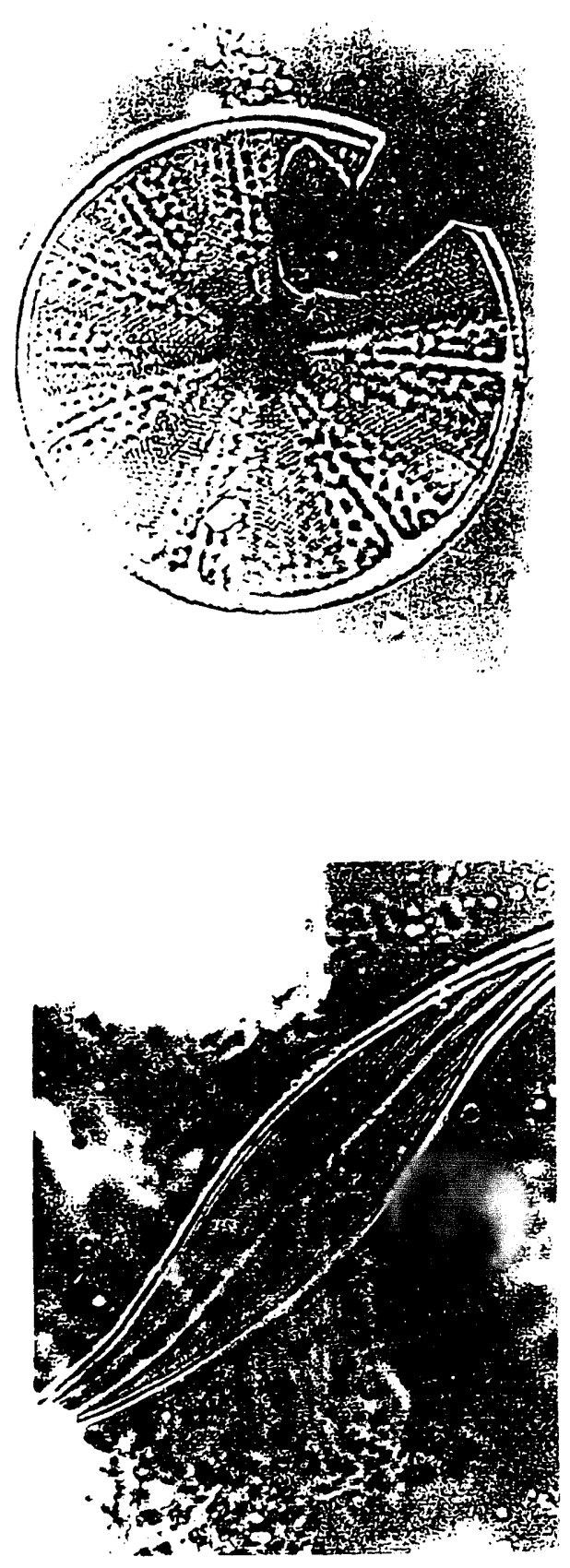

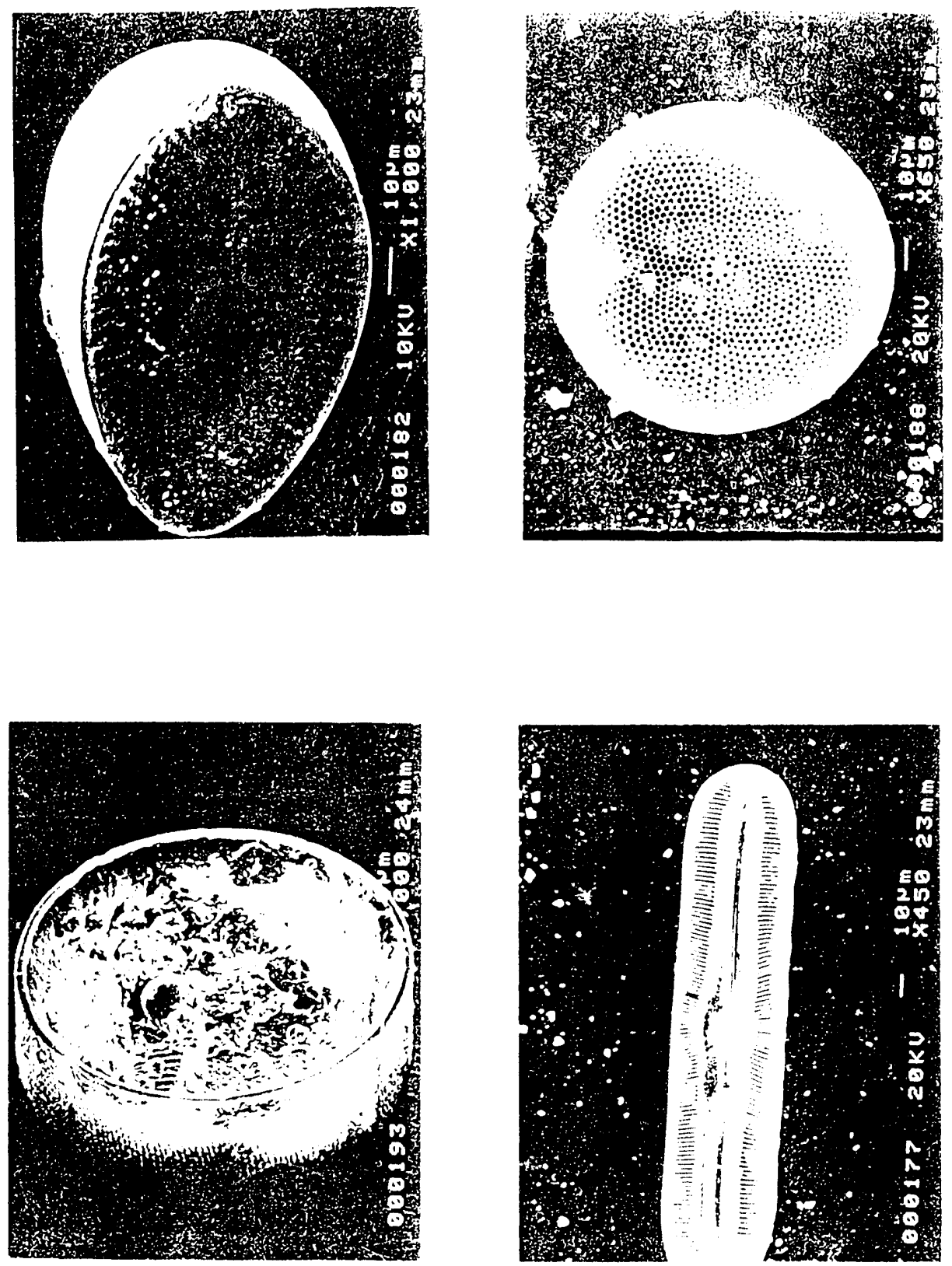


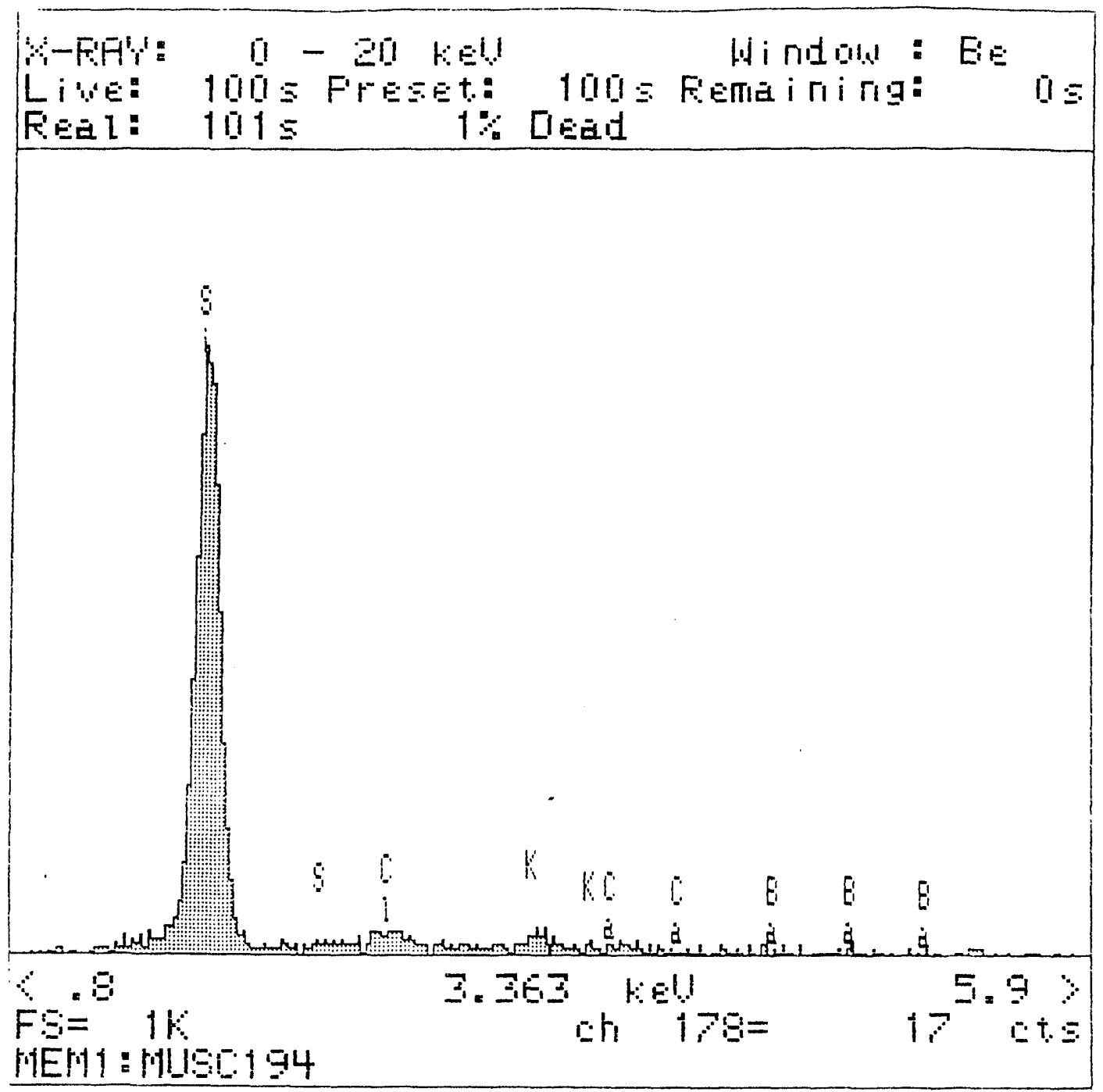

Figure 7. EDX data in graph form showing elemental composition of a diatom frustule. The most common elements are silicon, chlorine, potassium, calcium and barium. 


\section{Y.FiY:}

$$
0-20 \quad \forall E !
$$

Hi ridulu: EE

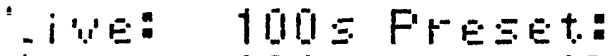

Yeal: 1015

$1 \%$ [leat

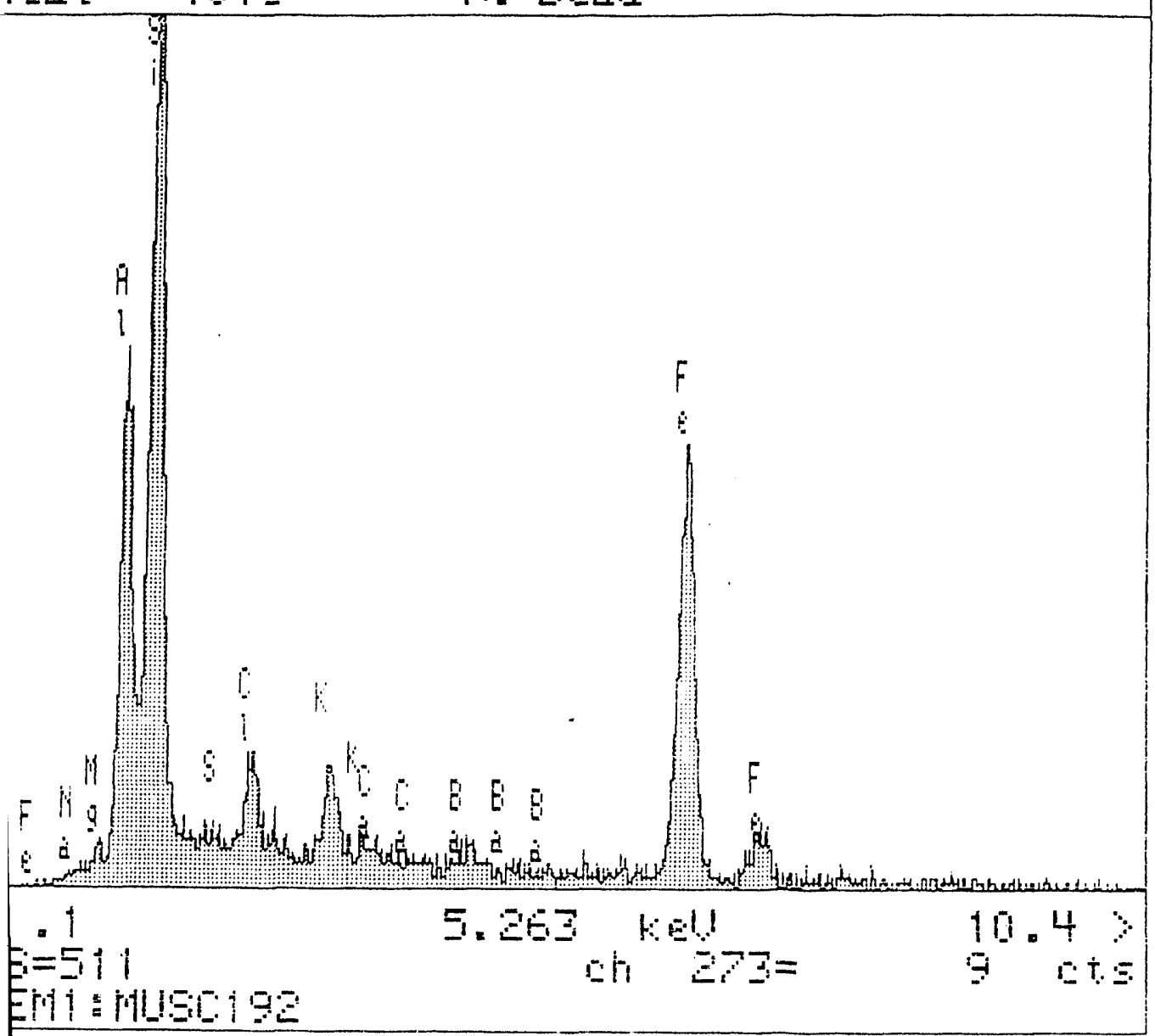

Figure 8. EDX data in graph form showing elemental composition of the material inside part of a diatom frustule. The most common elements are silicon, aluminum, and iron. 


\begin{tabular}{|l||c|c|c|c|c|c|c|c|c|c|}
\hline & $7 / 21 / 93$ & $7 / 21 / 93$ & $7 / 21 / 93$ & $7 / 21 / 93$ & $7 / 21 / 93$ & $7 / 2193$ & $7 / 21 / 93$ & $7 / 21 / 93$ & $7 / 21 / 93$ & $7 / 2193$ \\
\hline & SR1A 37 & SR1B 37 & SRIC 37 & S1A 70 & SR1B 70 & SR1C 70 & SR1A 120 & SR1B 120 & SR1C 120 & SR1 TOT \\
\hline MELOSIRA & 14 & 9 & 10 & 3 & 9 & 10 & 14 & 10 & 11 & 90 \\
\hline PLEUROSIGMA & 0 & 1 & 1 & 1 & 2 & 1 & 1 & 5 & 4 & 16 \\
\hline SURIRELLA & 3 & 4 & 2 & 0 & 0 & 0 & 1 & 0 & 0 & 10 \\
\hline COSCINODISCUS & 3 & 3 & 5 & 1 & 0 & 1 & 0 & 1 & 0 & 14 \\
\hline SYNEDRA & 0 & 0 & 0 & 1 & 1 & 1 & 0 & 2 & 1 & 6 \\
\hline FRAGILARIA & 0 & 2 & 0 & 4 & 0 & 4 & 0 & 1 & 0 & 11 \\
\hline CYCLOTELLA & 0 & 1 & 0 & 0 & 1 & 0 & 0 & 0 & 1 & 3 \\
\hline TERPSINOE & 0 & 0 & 2 & 1 & 1 & 0 & 4 & 1 & 0 & 9 \\
\hline NAVICULA & 0 & 0 & 0 & 6 & 4 & 0 & 0 & 0 & 0 & 10 \\
\hline CLAVULARIA & 0 & 0 & 0 & 2 & 1 & 2 & 0 & 0 & 0 & 5 \\
\hline NITSCHIA & 0 & 0 & 0 & 1 & 1 & 1 & 0 & 0 & 0 & 3 \\
\hline STARONEIS & 0 & 0 & 0 & 0 & 0 & 0 & 0 & 0 & 1 & 1 \\
\hline ASTERIONELLA & 0 & 0 & 0 & 0 & 0 & 0 & 0 & 0 & 2 & 2 \\
\hline & & & & & & & & & & \\
\hline
\end{tabular}

4. Tallies of diatoms in water column samples from Savannah River sample site 1 were classified by genus.

\begin{tabular}{|l||c|c|c|c|}
\hline & $7 / 21 / 93$ & $7 / 21 / 93$ & $7 / 21 / 93$ & $7 / 21 \% 9$ \\
\hline \hline SR1 37 & SR1 70 & SR1120 & SR1\% \\
\hline MELOSIRA & $55 \%$ & $37 \%$ & $58 \%$ & $50 \%$ \\
\hline PLEUROSIGMA & $3 \%$ & $6 \%$ & $16 \%$ & $9 \%$ \\
\hline SURIRELLA & $15 \%$ & $0 \%$ & $2 \%$ & $6 \%$ \\
\hline COSCINODISCUS & $18 \%$ & $3 \%$ & $2 \%$ & $8 \%$ \\
\hline SYNEDRA & $0 \%$ & $5 \%$ & $5 \%$ & $3 \%$ \\
\hline FRAGILARIA & $3 \%$ & $13 \%$ & $2 \%$ & $6 \%$ \\
\hline CYCLOTELLA & $2 \%$ & $2 \%$ & $2 \%$ & $2 \%$ \\
\hline TERPSINOE & $3 \%$ & $3 \%$ & $8 \%$ & $5 \%$ \\
\hline NAVICULA & $0 \%$ & $16 \%$ & $0 \%$ & $6 \%$ \\
\hline CLAVULARIA & $0 \%$ & $8 \%$ & $0 \%$ & $3 \%$ \\
\hline NITSCHIA & $0 \%$ & $5 \%$ & $0 \%$ & $2 \%$ \\
\hline STARONEIS & $0 \%$ & $0 \%$ & $2 \%$ & $1 \%$ \\
\hline ASTERIONELLA & $0 \%$ & $0 \%$ & $3 \%$ & $1 \%$ \\
\hline & & & & \\
\hline & & & & \\
\hline
\end{tabular}

B. The percentage of each diatom genus in Savannah River sample site 1 was calculated from the data in table $1 \mathrm{~B}$. 
Savannah River Sediment Samples

\begin{tabular}{|c|l|c|c|c|}
\hline SAMPLE \# & RNER & SITE & CORELENGTH & SIEVE SIZE \\
\hline \hline 1 & Savannah & 1 & $0-6^{\prime \prime}$ & 120 \\
\hline 2 & Savannah & 2 & $0-8^{\prime \prime}$ & 120 \\
\hline 3 & Savanriah & 4 & $0-6^{\prime \prime}$ & 120 \\
\hline & & & & \\
\hline
\end{tabular}

Table 2 
Savannah River and Cooper River Diatom \% Comparison

\begin{tabular}{|c|c|c|c|c|c|c|c|c|}
\hline & $\mathrm{SR} 1 \%$ & $S R 2 \%$ & SR3\% & $\mathrm{SR} 4 \%$ & SR5 $\%$ & SR6\% & SR7 $\%$ & AVG. \\
\hline MELOSIRA & $50 \%$ & $38 \%$ & $42 \%$ & $26 \%$ & $28 \%$ & $25 \%$ & $22 \%$ & $33 \%$ \\
\hline PLEUROSIGMA & $9 \%$ & $18 \%$ & $17 \%$ & $16 \%$ & $18 \%$ & $24 \%$ & $8 \%$ & $16 \%$ \\
\hline SURIRELIA & $6 \%$ & $3 \%$ & $2 \%$ & $6 \%$ & $4 \%$ & 39 & 79 & $4 \%$ \\
\hline COSCINODISCUS & $8 \%$ & $15 \%$ & $11 \%$ & $12 \%$ & $9 \%$ & 99 & $29 \%$ & $13 \%$ \\
\hline SYNEDRA & $3 \%$ & 99 & $12 \%$ & $9 \%$ & $14 \%$ & $11 \%$ & $8 \%$ & $9 \%$ \\
\hline FRAGILARIA & $6 \%$ & $4 \%$ & $1 \%$ & $3 \%$ & $0 \%$ & $0 \%$ & $1 \%$ & $2 \%$ \\
\hline CYCLOTEUA & $2 \%$ & $0 \%$ & $29 \%$ & $2 \%$ & $3 \%$ & $3 \%$ & $4 \%$ & $2 \%$ \\
\hline TERPSINOE & $5 \%$ & $2 \%$ & $1 \%$ & $2 \%$ & $1 \%$ & $4 \%$ & $0 \%$ & $2 \%$ \\
\hline NAVICULA & $6 \%$ & $8 \%$ & $8 \%$ & $11 \%$ & $9 \%$ & $8 \%$ & $6 \%$ & $8 \%$ \\
\hline CLAVULARIA & $3 \%$ & $1 \%$ & $4 \%$ & $6 \%$ & $7 \%$ & $7 \%$ & $3 \%$ & $4 \%$ \\
\hline NIIZSCHIA & $2 \%$ & $1 \%$ & $1 \%$ & $0 \%$ & $3 \%$ & $2 \%$ & $3 \%$ & $2 \%$ \\
\hline STARONES & $1 \%$ & $0 \%$ & $1 \%$ & $2 \%$ & $1 \%$ & $0 \%$ & $3 \%$ & $1 \%$ \\
\hline ASTERIONELUA & $1 \%$ & $3 \%$ & $0 \%$ & $3 \%$ & $1 \%$ & $0 \%$ & $1 \%$ & $1 \%$ \\
\hline CYMBELA & $0 \%$ & $0 \%$ & $1 \%$ & $2 \%$ & $0 \%$ & $0 \%$ & $0 \%$ & $0 \%$ \\
\hline EPITHEMIA & $0 \%$ & $0 \%$ & $0 \%$ & $1 \%$ & $0 \%$ & $0 \%$ & $0 \%$ & $0 \%$ \\
\hline BIDDULPHIA & $0 \%$ & $0 \%$ & $0 \%$ & $0 \%$ & $1 \%$ & 29 & 39 & $1 \%$ \\
\hline CHAETOCEROS & $0 \%$ & $0 \%$ & 09 & $0 \%$ & $0 \%$ & $1 \%$ & $0 \%$ & $0 \%$ \\
\hline ACHNANTHES & $0 \%$ & $0 \%$ & $0 \%$ & $0 \%$ & $0 \%$ & $0 \%$ & $1 \%$ & $0 \%$ \\
\hline \multirow[t]{3}{*}{ RAPHONES } & $0 \%$ & $0 \%$ & $0 \%$ & $0 \%$ & $0 \%$ & $0 \%$ & $1 \%$ & $0 \%$ \\
\hline & & & & & & & & \\
\hline & CR 6/25\% & CR $6 / 299_{0}$ & & & & & & AYG. \\
\hline MELLOSIRA & $28 \%$ & $35 \%$ & & & & & & $32 \%$ \\
\hline PLEUROSIGMA & 29 & $0 \%$ & & & & & & 19 \\
\hline SURIRELLA & $1 \%$ & $0 \%$ & & & & & & $1 \%$ \\
\hline COSCINOOISCUS & $3 \%$ & $1 \%$ & & & & & & $2 \%$ \\
\hline SYNEDRA & $3 \%$ & $39 \%$ & & & & & & $3 \%$ \\
\hline FRAGILARIA & $9 \%$ & $18 \%$ & & & & & & $14 \%$ \\
\hline \multirow[t]{2}{*}{ CYCLOTELLA } & $22 \%$ & $20 \%$ & & & & & & $21 \%$ \\
\hline & & & & & & & & $0 \%$ \\
\hline NAVICULA & $15 \%$ & $15 \%$ & & & & & & $15 \%$ \\
\hline CLAVULARIA & $2 \%$ & 09 & & & & & & $1 \%$ \\
\hline \multirow[t]{3}{*}{ NITZSCHIA } & $10 \%$ & $5 \%$ & & & & & & $8 \%$ \\
\hline & & & & & & & & $0 \%$ \\
\hline & & & & & & & & $0 \%$ \\
\hline \multirow[t]{3}{*}{ CYMBELLA } & $2 \%$ & 09 & & & & & & 19 \\
\hline & & & & & $\because$ & & & $0 q_{c}$ \\
\hline & & & & & & & & $0 \%$ \\
\hline \multirow[t]{3}{*}{ CHAETOCEROS } & $0 \%$ & $1 \%$ & & & & & & $19 c$ \\
\hline & & & & & & & & $0 \%$ \\
\hline & 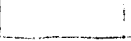 & & & & & & & $0 q_{c}$ \\
\hline ODD & $3 \%$ & $0 \%$ & & & & & & $2 \varphi_{c}$ \\
\hline
\end{tabular}




\title{
BACTERIAL PRODUCTION OF PSP TOXINS
}

\author{
by \\ Kathy Maze
}

\begin{abstract}
Biology Department
Georgetown College

Georgetown, KY 40324
\end{abstract}

\begin{abstract}
Supervisor: Dr. Greg Doucette
Marine Biotoxin Program

National Marine Fisheries Service

Charleston, SC 29412
\end{abstract}

and

Marine Biomedical and Environmental Sciences

Program, MUSC

Charleston, SC 29412

(Acknowledgements: M. Logan, D. Best, E. Finley, B. Lanoue) 


\begin{abstract}
Paralytic Shellfish Poisoning (PSP) is a marine biotoxin syndrome caused by neurotoxins which are produced by unicellular algae known as dinoflagellates. These toxins act by blocking the voltage-sensitive sodium channels of the nervous system. This experiment tesied whether the bacterium Pseudomonas stutzeri, isolated from the toxic dinoflagellate $A$ lexandrium lusitanicum, was capable of autonomously producing PSP toxins. A defined minimal growth medium was developed for this bacterium using succinate as the carbon/energy source so that bacteria could be subjected to various types of nutritional stress. Several concentrations of growth limiting nutrient were tested in order to optimize the biomass yield of cultures grown under nitrogen or phosphorus stress. Using this information, large scale bacterial cultures were then grown under nutrient-replete, nitrogen-deplete, and phosphorus-deplete conditions. Finally, extracts from these cultures were tested for toxin using high performance liquid chromatography (HPLC) and a saxitoxin receptor binding assay. Extracts were analyzed for the presence of GTX1,2,3,4, and 5 using the HPLC. Samples tested positive for the presence of GTX1,2,4,and 5. The bacterium Pseudomonas stutzeri appears to be able to autonomously produce at least some of the PSP toxin derivatives, based on HPLC analysis. The GTX composition of $P$. stutzeri grown under different nutrient conditions with succinate as a carbon/energy source appears to be relatively constant. The experimental design used during this project proved to be a satisfactory approach to the study of PSP toxin production by bacteria associated with toxic dinoflagellates.
\end{abstract}

\title{
INTRODUCTION
}

The neurotoxins which cause Paralytic Shellfish Poisoning (PSP) are produced by a group of unicellular algae called dinoflagellates (for review, see Hall et al. 1990). When certain species of marine dinoflagellates bloom, filter-feeding bivalves become toxic by ingesting the algae as a source of food. Bivalves are not greatly harmed by the accumulation of PSP toxins. However, human poisoning results when bivalves containing sufficiently high levels of these toxins are consumed. The PSP toxins, comprised of saxitoxin and its derivatives, act by blocking voltage sensitive sodium channels of the nervous system.

One group of researchers has demonstrated that bacteria isolated from toxic strains of the dinoflagellate $A$ lexandrium tamarense, can autonomously synthesize PSP toxins (Kodama 1990). However, their measurements of bacterial toxin production were at levels far below those documented for dinoflagellates. Other workers, unable to detect toxins in bacterial extracts, have suggested that the interference of intracellular bacteria in the metabolism of dinoflagellates mediates the algal toxicity (Silva 1990). Given this range of opinions, the question of bacterial involvement in PSP toxicity remains a very contentious issue.

The hypothesis tested was that the bacterium Pseudomonas stutzeri, isolated from the toxic dinoflagellate Alexandrium lusitanicum, can autonomously produce PSP toxins. The approach taken involved growing bacterial cultures in artificial medium under conditions of nutritional stress. Since it is known that PSP toxin production by dinoflagellates is enhanced 
under such conditions (Anderson et al. 1990), we anticipated that the bacteria would exhibit a similar response. As a result, our ability to detect these toxins would be optimized. In addition, the growth rate of nutrient-limited bacteria would be comparable to that of the associated dinoflagellate, and would thus be more representative of natural conditions than growth rates in a rich nutrient broth.

Manipulation of bacterial nutrient physiology requires the use of a defined growth medium so that the concentrations of the growth-limiting nutrients can be precisely determined. Therefore, a defined minimal growth medium was first developed for the cultivation of $P$. stutzeri. This growth medium provided a means by which the bacteria could be subjected to various types of nutritional stress. Second, several concentrations of growthlimiting nutrients were tested in order to optimize the biomass yield of cultures grcwn under conditions of nitrogen or phosphorus stress. Third, large scale bacterial cultures were grown under nutrient-replete, nitrogen-deplete, and phosphorus-deplete conditions, providing large quantities of material for toxin extraction. Finally, extracts from the bacterial cultures were tested for the presence of toxin using the high performance liquid chromatography (HPLC) and a saxitoxin receptor-binding assay.

\section{MATERIALS AND METHODS}

Experimental organism: The bacterial strain used in this study, Pseudomonas stutzen (strain SF2P) was isolated from the PSP-producing dinoflagellate Alexandrium lusitanicum (strain 18-1; culture collection of S. Franca, Inst. Nacional de Saude, Lisboa, Portugal), and was a gift of S. Franca. The bacterial isolation techniques used were designed to eliminate all bacteria external to the dinoflagellate cells. Therefore, this strain of $P$. stutzeri is presumed to have originated from within the dinoflagellate cells.

Experimental growth and maintenance: Bacterial cultures were maintained at $20^{\circ} \mathrm{C}$ on agar slants based on a complete seawater medium (SWC; Haygood and Nealson 1985). All experiments used an artificial seawater-based medium (ASW; Haygood and Nealson 1985). Both SWC and ASW media were modified from the original formulation and their composition is given in Tables 1 and 2, respectively.

In order to identify a suitable carbon/energy $(\mathrm{C} / \mathrm{E})$ substrate for the growth of $P$. stutzen, $3 \mathrm{~mL}$ cultures of ASW medium containing one of 17 substrates were inoculated with cells growing exponentially on SWC. Equimolar concentrations of carbon $(20 \mathrm{mM})$ were achieved by adjusting the amount of $\mathrm{C} / \mathrm{E}$ source added. Figure 1 shows the substrates tested. Two controls, one receiving no C/E source addition and one of SWC were included. Maximum growth rates were calculated based on changes in optical density (OD) measured at $660 \mathrm{~nm}$ over the exponential phase of growth, and using the following equation :

Growth Rate (doublings/day $)=((\log (\mathrm{N} 1 / \mathrm{N} 0)) \times 3.322) /(\mathrm{Tl}-\mathrm{T} 0)$, where $\mathrm{Nl}=\mathrm{OD}_{660}$ at time $\mathrm{l}$ (i.e. T1) 


$$
\begin{aligned}
& \mathrm{N} 0=\mathrm{OD}_{660} \text { at time } 0 \text { (i.e. } \mathrm{T} 0 \text { ) } \\
& \mathrm{T} 1=\text { time } 1 \text { (in days) } \\
& \mathrm{T} 0=\text { time } 0 \text { (in days). }
\end{aligned}
$$

A Bausch \& Lomb Spectronic 21 spectrophotometer was used to measure OD. Based on the results of this experiment and the desire to produce data comparable to those obtained previously for bacterial strains isolated from other toxic dinoflagellates, succinate was chosen as the $\mathrm{C} / \mathrm{E}$ source for the remaining experiments.

Bacterial cultures $(3 \mathrm{~mL})$ used in nutrient depletion experiments were grown in $13 \times 100$ mm Fisherbrand Borosilicate Disposable Culture Tubes in triplicate under conditions of either nitrogen or phosphorus depletion. The following nitrogen concentrations were tested: 0,200 , $400,600,800,1200$, and $1600 \mathrm{uM}$. The phosphorus concentrations tested were: $0,1,2,4,8$, 16 , and $32 \mathrm{uM}$. ASW containing full nitrogen and phosphorus enrichments (=Replete) and SWC cultures were used as controls. Tests were done with and without $50 \mathrm{mM}$ Hepes buffer (pH 7.4) additions. Culture tubes were maintained in Dubnoff Metabolic Shaking Incubator at $20^{\circ} \mathrm{C}$. Bacterial growth was measured at 12 hour intervals by taking OD readings as described above.

Large scale bacterial cultures $(300 \mathrm{~mL})$ were grown in $500 \mathrm{~mL}$ Bellco flasks under nutrient-replete, nitrogen-deplete, and phosphorus-deplete conditions. Cultures were maintained in New Brunswick Scientific Innova 4330 Refrigerated Incubator Shaker at $20^{\circ} \mathrm{C}$ and $175 \mathrm{rpm}$. Growth was monitored daily as previously described. Nutrient-replete cultures were harvested during the log phase of growth. Phosphorus- and nitrogen-deplete cultures were harvested at or near the stationary phase of growth.

At the time of harvesting, triplicate $0.5 \mathrm{~mL}$ samples were collected for total cell protein analysis. Protein samples were spun in an IEC Centra MP4R centrifuge at 12,000 rpm for 12 $\min$ at $4^{\circ} \mathrm{C}$. After centrifugation, protein samples were covered with parafilm, holes were punched for gas exchange, and samples were stored at $-20^{\circ} \mathrm{C}$ until lyophilized. The remaining bacterial culture was harvested by centrifuging $250 \mathrm{~mL}$ for $15 \mathrm{~min}$. at $10^{\circ} \mathrm{C}$ at a force of $12,000 \times \mathrm{g}$. Bacterial pellets were resi'spended in $0.5 \mathrm{~mL}$ of $0.05 \mathrm{~N}$ glacial acetic acid. Samples were transferred to $2 \mathrm{~mL}$ screw-capped tubes and stored at $-20^{\circ} \mathrm{C}$ until extraction.

Toxin extractions were done by splitting each sample into four tubes, each containing $600 \mathrm{uL}$ of $0.05 \mathrm{~N}$ acetic acid. Zirconium beads $(0.1 \mathrm{~mm}$ diam.) were added to each tube. Cells were disrupted by shaking the tubes in a Biospec Products Mini-Bead Beater five times for 45 seconds each. Holes were punctured in the bottom of each tube with a hot needle, and tubes were inserted into $1.5 \mathrm{~mL}$ microcentrifuge tubes. Samples were spun for 20 minutes at 2500 rpm in an IEC Centra-7 centrifuge in order to separate the cell homogenate from the beads. Bead-beater tubes were removed from the microcentrifuge tubes. The microcentrifuge tubes were then spun again for $15 \mathrm{~min}$. at $8^{\circ} \mathrm{C}$ and $12,000 \mathrm{rpm}$ in an IEC Centra MP4R centrifuge to remove cell debris. The supernatants were pooled and placed in a $0.5 \mathrm{~mL}$ microcentrifuge tube and stored at $4{ }^{\circ} \mathrm{C}$ until analyzed. Extracts prepared in this way were first passed over a Sep-pak $\mathrm{C}_{18}$ cartridge (Millipore Corp.) to clean the sample, and then analyzed for PSP toxins according to the method of Oshima et al. (1988). Standards for the analysis and 
quantification: of these toxins were kindly provided by Y. Oshima (Tohoku University, Japan) Toxin extracts were also tested using a saxitoxin receptor binding assay being developed at the National Marine Fisheries Service laboratory by the Marine Biotoxins Group. Briefly, any toxin present in a sample competes against a known concentration of radiolabeled saxitoxin for toxin receptor binding sites present in a rat brain synaptosome preparation. Low radioactivity in the final synaptosome preparation (i.e. after incubation and washing) therefore reflects the presence of high (unlabeled) toxin concentrations in the sample, and vice versa.

\section{RESULTS}

Carbon/energy substrates. Growth of Pseudomonas stutzeri on various carbon/energy substrates is shown in Figure 1. The highest maximum growth rate was observed with the SWC medium. As a group, the organic acids succinate, malate, fumarate, $\alpha$-ketoglutarate $(\alpha K G)$, and citrate represented the substrates most favorable for growth in ASW-based media. Other compounds tested supported far lower growth rates or no growth.

Nutrient depletion. The growth of $P$. stutzeri with nitrogen as the limiting nutrient, in the absence of buffer, is shown in Figure 2. As nitrogen concentration increased, a higher biomass yield was observed. The final yield for the $1600 \mu \mathrm{M} \mathrm{N}$ culture was over five times that of the $200 \mu \mathrm{M} \mathrm{N}$ culture. By comparison, the biomass yield increased only about 1.5 times as $\mathrm{t}$. . phosphorus concentration increased from 1 to $16 \mu \mathrm{M}$ (Figure 3 ). In both of these cultures, a precipitate developed that made it difficult to measure the OD. The $\mathrm{pH}$ of the cultures was measured at the end of the experiment and found to be approximately 9 . Since the $\mathrm{pH}$ of seawater is closer to 8 , it was decided that the medium should be buffered in order to minimize the increase in $\mathrm{pH}$. A test was done to determine if buffer $(50 \mathrm{mM}$ Hepes, $\mathrm{pH}$ 7.4) could be added to the cultures without adversely affected growth (Figure 4). In SWC and in ASW without buffer, the growth rates were similar. However, the growth rate in ASW with buffer slowed somewhat compared to the other two media after the exponential phase of growth. Bacteria in all three media demonstrated the same yield.

Following the test of buffer effects on growth (Figure 4), curves for nitrogen- and phosphorus-deplete cultures with $50 \mathrm{mM}$ Hepes buffer $(\mathrm{pH} \mathrm{7.4)}$ additions were performed. As previously, the biomass yields increased directly with nitrogen and phosphorus concentration (Figures 5 and 6). More importantly, the yields of both the nitrogen- and phosphorus-deplete cultures with buffer were greater than those without the buffer addition, with this difference being most pronounced under phosphorus depletion. The P-deplete cultures with buffer also showed a far greater difference in biomass yield as a function of increasing phosphorus concentration when compared to those cultures without buffer.

Toxin production. From the data shourn in Figures 5 and 6, nitrogen and phosphorus concentrations were chosen for growing large scale nitrogen- and phosphorus-deplete cultures. Figure 7 shows the growth of the large scale toxin production experiment. The final data points for each curve represent the time at which the respective cultures were harvested. The highest growth rate was observed in the nutrient-replete culture. The 16uM P culture produced a higher yield than either of the $4 \mathrm{uM} P$ cultures. The yield of the 4 uM P culture 
with the arginine addition was the same as that without arginine. The $400 \mathrm{uMN}$ culture produced a slightly lower yield than the phosphorus-deplete cultures. A representative chromatogram of the HPLC aralysis of toxin extract from the nutrient-replete culture and a trace of the corresponding analytical standard are presented in Figure 8. Time permitted only the analysis of toxins GTX1,2,3,4, and 5 , and these data are summarized in Table 3. In all cultures, irrespective of nutritional status, GTX5 was the predominant toxin, accounting for approximately $95 \%$ of the GTX toxins present. The relative abundance of GTX 4 varied between treatments, and was high:est in the nitrogen-deplete culture (near 6\%). Toxins GTX1 and GTX2, when present, represented less than $1 \%$ of the total GTX toxins. Results of the saxitoxin receptor binding assay (data not shown) were negative for all samples tested.

\section{DISCUSSION}

The most important observation to result from the present study is that Pseudomonas stutzeri appears to be capable of autonomous production of at least some of the PSP toxin derivatives, as determined by HPLC analysis. This work represents only the second HPLCbased confirmation of toxin synthesis by a bacterium associated with a PSP-producing dinoflagellate. Although the actual amounts of toxin produced by bacteria under different nutrient conditions was not determined, toxins in the extracts were easily detectable and frequently present in substantial quantities. Also, there did appear to be little variation in the GTX toxin composition between experimental treatments.

Since the actual production of PSP toxins by bacteria remains a contentious issue, the HPLC analysis of bacterial extracts warrants specific consideration. A set of chromatograms for the nutrient-replete culture is given in Figure 8 . Also shown are traces of the toxin standards used to quantify the experimental run. The HPLC method employed requires three separate analyses to detect the twelve PSP toxin derivatives contained in the standard mixtures. While only one of these analyses was performed (that for GTX toxins), the cumulative results for all samples (Table 3 ) appear to show the presence of four of the five GTX toxin derivatives. The retention times of the sample peaks correspond either identically to, or are separated at most by $0.5 \mathrm{~min}$ from, the associated standard peak. However, it must be pointed out that these data do not represent unequivocal proof of PSP toxigenesis by this bacterium, and can only be considered as preliminary until other analytical methods, such as mass spectroscopy, can be used to confirm these findings.

The results obtained during this work demonstrate the usefulness of the experimental approach employed. The rivelopment of a defined minimal growth medium not only permitted growth of the "eria under conditions more similar to those found in natural seawater, but also allow. : $:$ ranipulation of bacterial nutritional status. In addition, the organic ailds tested as pc: itial carbon/energy sources represented the substrates most favorable for growth in ASW-based media. These organic acids are intermediates of the Krebs cycle, and from which arginine, a biosynthetic precursor of the PSP toxins, is derived. For this reason it is desirable for future work to examine the remaining organic acids as growth substrates for their effects on toxin production. 
All samples tested negative for toxin by the saxitoxin receptor binding assay. This competitive binding assay relies on the toxins being active and able to bind to rat brain synaptosomes at the sodium channel. The negative results may be due to the toxin being present, but in an inactive form. Another possibility is matrix effects of the bacteria on the toxin or the receptor. The samples tested may not have been concentrated enough for the toxin to be detected. Further concentrating the samples may result in a positive test for toxin The possibilities of matrix effects will be looked at further in future research.

Although the buffer addition may have caused a slight decline in growth rate following the exponential phase of growht. for the slight slowing after the exponential phase of growth of the ASW with buffer culture, all cultures demonstrated the same yield. Therefore, buffer was added to all cultures. The buffer alleviated the precipitate problem by preventing a rise in $\mathrm{pH}$, allowing the cultures to grow for a longer time period and achieve a greater yield for use in toxin tests

There are several areas that renain to be investigated by future research. The extracts need to be tested for the remaining saxitoxin $g$ derivatives using the HPLC, and toxin content of the extracts needs to be normalized to total cellular protein of the culture samples in order to compare the toxin content of the different samples. Also, the entire experiment can be repeated using the remaining organic acids of the Krebs cycle as $\mathrm{C} / \mathrm{E}$ sources to determine whether they have an effect on toxin production.

In summary, the bacterium Pseudomonas stutzeri appears to be capable of autonomous production of at least some of the PSP toxin derivatives, based on HPLC analysis. This is important because this work represents only the second HPLC-based confirmation of toxin synthesis by a bacterium associated with a toxic dinoflagellate. The GTX composition of $P$. stutzeri grown under different nutrient conditions with succinate as a $\mathrm{C} / \mathrm{E}$ source appears to be relatively constant. Finally, the experimental design used during this project proved to be a satisfactory approach to the study of PSP toxin production by bacteria associated with toxic dinoflagellates 


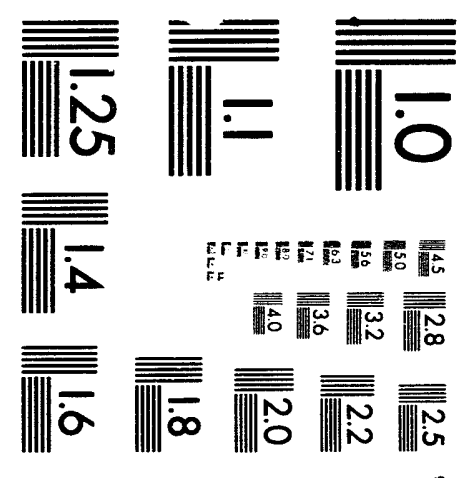



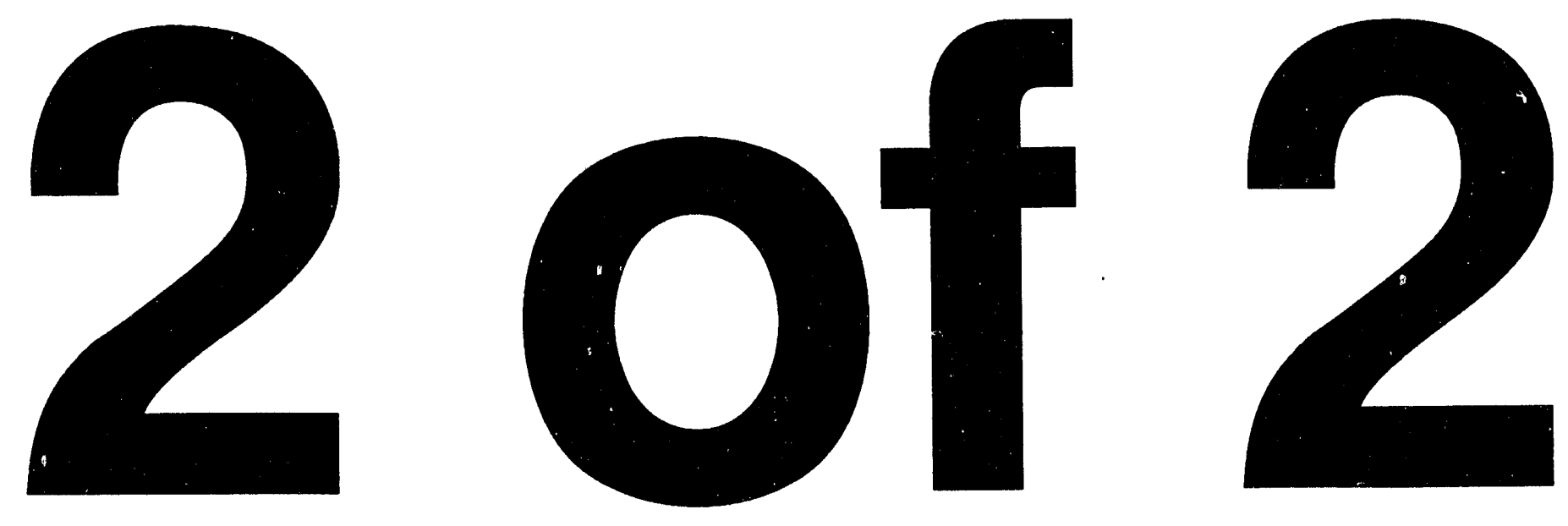


\section{LTTERATURE CITED}

Anderson, D.M., Kulis, D.M., Sullivan, J.J., Hall, S. and Lee, C. 1990. Dynamics and physiology of saxitoxin production by the dinoflagellates Alexandrium spp. Mar. Biol. 104:511-24.

Hall, S., Strichartz, G., Mozydlowski, E., Ravindran, A. and Reichardt, P.B. 1990. The Saxitoxins. In: Hall, S. and Strichartz, G. (eds.) Marine Toxins: Origin, Structure, and Molecular Pharmacology. ACS Symposium Ser. No. 418. pp. 29-65.

Haygood, M.G. and Nealson, K.H. 1985. Mechanisms of iron regulation of luminescence in Vibrio fischeri. J. Bacteriol. 162:209-16

Kodama, M. 1990. Possible links between bacteria and toxin production in algal blooms. In: Toxic marine Phytoplankton, Granelli et al. (eds.). pp. 52-61.

Oshima, Y., Sugino, K. and Yasumoto, T. 1988. Latest advances in HPLC analysis of paralytic shellfish toxins. In: Mycotoxins and phycotoxins '88, Natori, S. et al. (eds.). pp. 31926.

Silva, E.S. 1990. Intracellular bacteria: the origin of dinoflagellate toxicity. JEPTO 10:124-8. 
Table 1. Composition of SWC medium.

\begin{tabular}{||l|l||}
\hline \multicolumn{1}{|c|}{ Reagent } & \multicolumn{1}{c|}{ weight or volume/L } \\
\hline Tryptone & $5 \mathrm{~g}$ \\
\hline Yeast Extract & $3 \mathrm{~g}$ \\
\hline Glycerol (50\%) & $6 \mathrm{~mL}$ \\
\hline $\begin{array}{l}\text { Natural Seawater (30ppt-- } \\
\text { Vero Beach, FL) }\end{array}$ & $1 \mathrm{~L}$ \\
\hline $\begin{array}{l}\text { Agar (1\%); used only for } \\
\text { slants }\end{array}$ & $10 \mathrm{~g}$ \\
\hline
\end{tabular}

Table 2. Composition of ASW medium.

\begin{tabular}{||l|c|}
\hline \multicolumn{1}{|c|}{ Reagent } & Concentration \\
\hline Sodium chloride & $265 \mathrm{mM}$ \\
\hline Potassium chloride & $10.06 \mathrm{mM}$ \\
\hline $\begin{array}{l}\text { Magnesium sulfate } \\
\text { heptahydrate }\end{array}$ & $50.13 \mathrm{mM}$ \\
\hline $\begin{array}{l}\text { Calcium chloride } \\
\text { dihydrate }\end{array}$ & $19.7 \mathrm{mM}$ \\
\hline Ammonium chloride & $18.7 \mathrm{mM}$ \\
\hline Sodium phosphate dibasic & $0.46 \mathrm{mM}$ \\
\hline Ferric sequestrene & $54.58 \mathrm{uM}$ \\
\hline Sodium bicarbonate & $2 \mathrm{mM}$ \\
\hline
\end{tabular}


Table 3. Concentrations ( $\mu \mathrm{M}$ ) of PSP toxins GTX1, GTX2, GTX4, and GTX5 in extracts of Pseudomonas stutzeri (strain SF2P) cultures grown under different nutritional regimes. The relative abundance of each toxin (i.e. percent composition) is also given for purposes of comparing the response to different experimental treatments. See text for further explanation.

\begin{tabular}{|l|l|l|l|l|}
\hline Sample & GTX1 & GTX2 & GTX4 & GTX5 \\
\hline Replete & $\begin{array}{l}0.019 \\
(0.2 \%)\end{array}$ & 0 & $\begin{array}{l}0.311 \\
(2.9 \%)\end{array}$ & $\begin{array}{l}10.356 \\
(96.9 \%)\end{array}$ \\
\hline $\begin{array}{l}\text { Nitrogen } \\
\text { Deplete }\end{array}$ & 0 & 0 & $\begin{array}{l}0.024 \\
(6.1 \%)\end{array}$ & $\begin{array}{l}0.369 \\
(93.9 \%)\end{array}$ \\
\hline $\begin{array}{l}\text { Phosphorus } \\
\text { Deplete (4uM) }\end{array}$ & 0 & 0 & $\begin{array}{l}0.044 \\
(4.2 \%)\end{array}$ & $\begin{array}{l}1.003 \\
(95.8 \%)\end{array}$ \\
\hline $\begin{array}{l}\text { Phosphorus } \\
\text { Deplete } \\
\text { (4uM)+ } \\
\text { Arginine }\end{array}$ & 0 & $\begin{array}{l}0.043 \\
(2.4 \%)\end{array}$ & $\begin{array}{l}1.748 \\
(97.4 \%)\end{array}$ \\
\hline $\begin{array}{l}\text { Phosphorus } \\
\text { Deplete (16uM) }\end{array}$ & 0 & $\begin{array}{l}0.004 \\
(0.2 \%)\end{array}$ & $\begin{array}{l}0.055 \\
(2.9 \%)\end{array}$ & $\begin{array}{l}1.800 \\
(96.9 \%)\end{array}$ \\
\hline
\end{tabular}




\section{GROWTH OF PSEUDOMONAS STUTZERI ON CARBON/ENERGY SUBSTRATES}

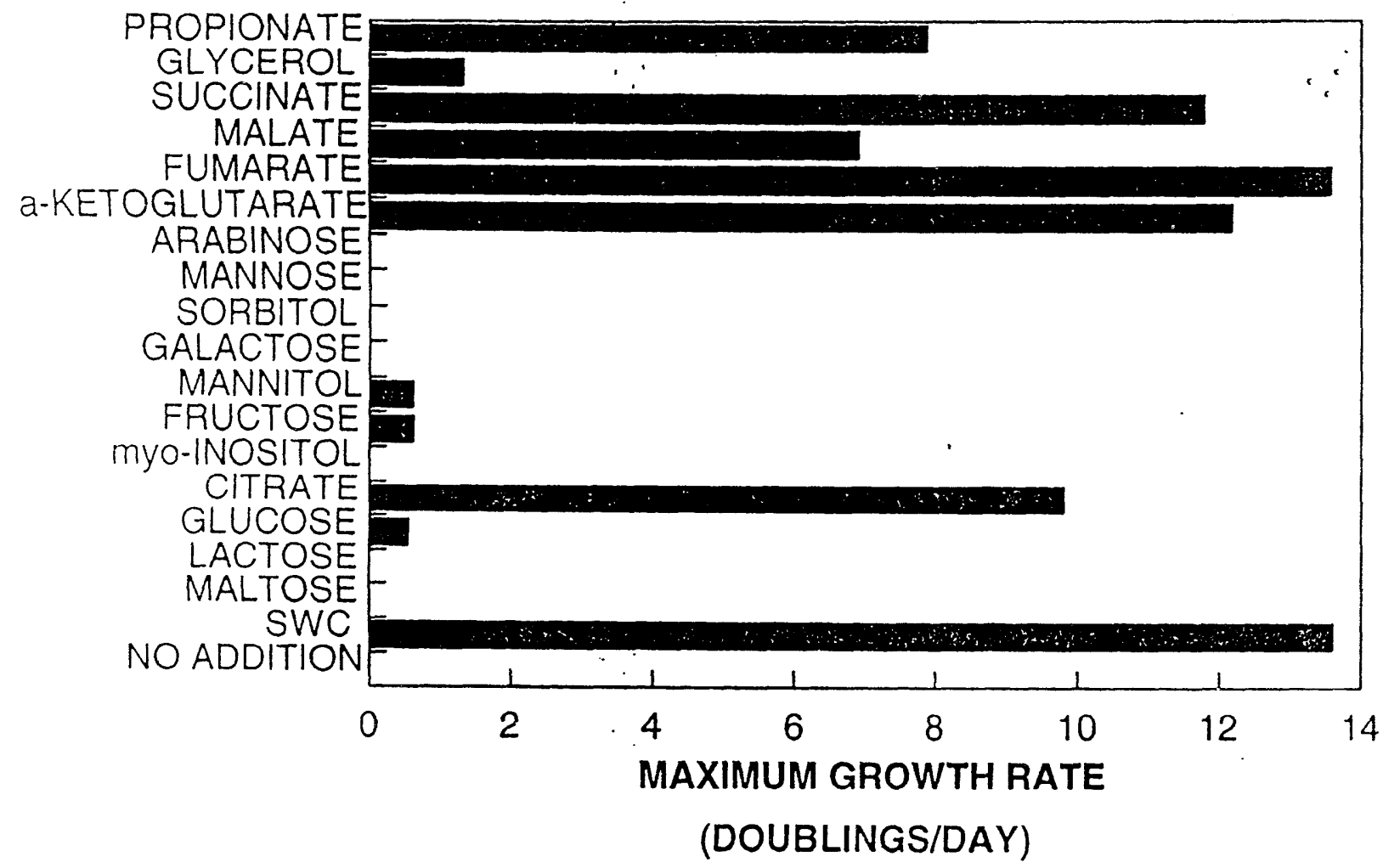

Figure 1. Maximum growth rates of the bacterium $p$. stutzeri in ASW-based media each containing one carbon/energy source. A culture with no carbon/energy source and SWC medium were included as controlc 


\section{NITROGEN DEPLETION / WITHOUT BUFFER}

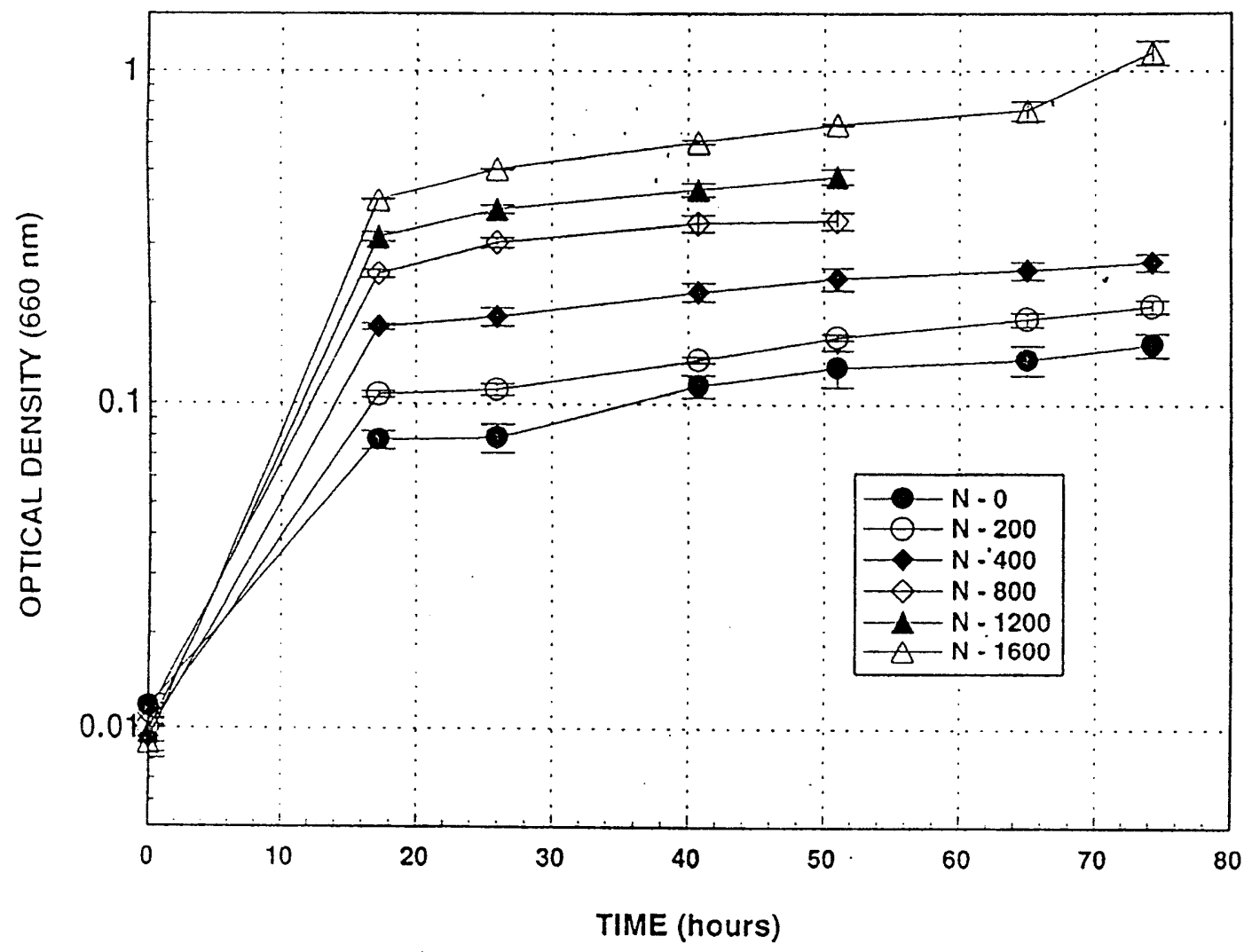

$\boldsymbol{F}$ igure 2. Growth curves for the bacterium $P$. stutzeri. Cultures were grown under nutrient replete conditions except for the level of nitrogen. Each curve represents a different nitrogen

concentration: $0,200,400,800,1200$, and 1600 uM. No buffer was added to the cultures. 


\section{PHOSPHORUS DEPLETION / WITHOUT BUFFER}

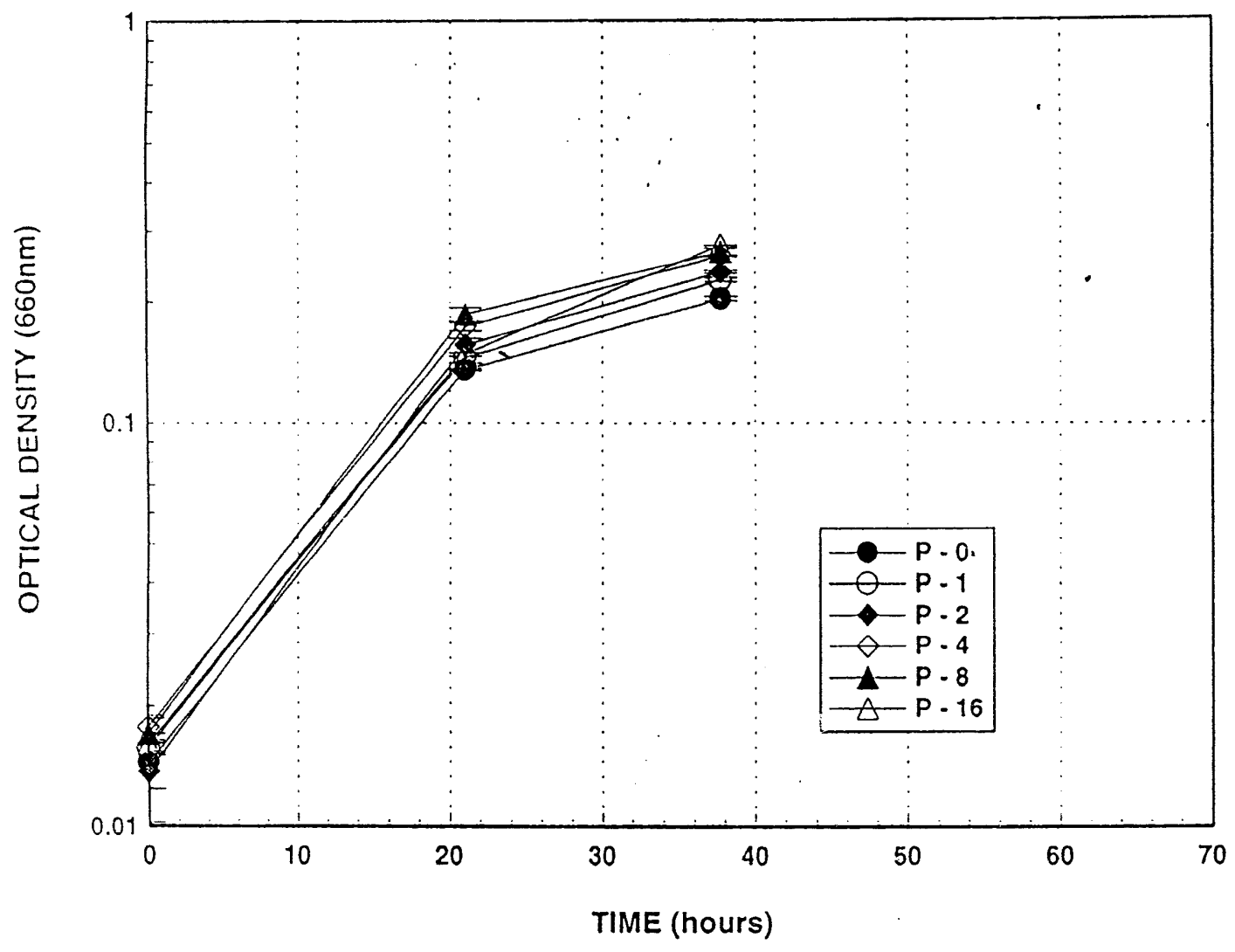

Figure 3. Growth curves for the bacterium P.stutzeri. Cultures

were grown under nutrient replete conditions except for the level

of phosphorus. Each curve represents a different phosphorus

concentration: $0,1,2,4,8$, and 16 uM. No buffer was added to

the cultures. 


\section{EFFECT OF HEPES BUFFER ON BACTERIAL GROWTH}

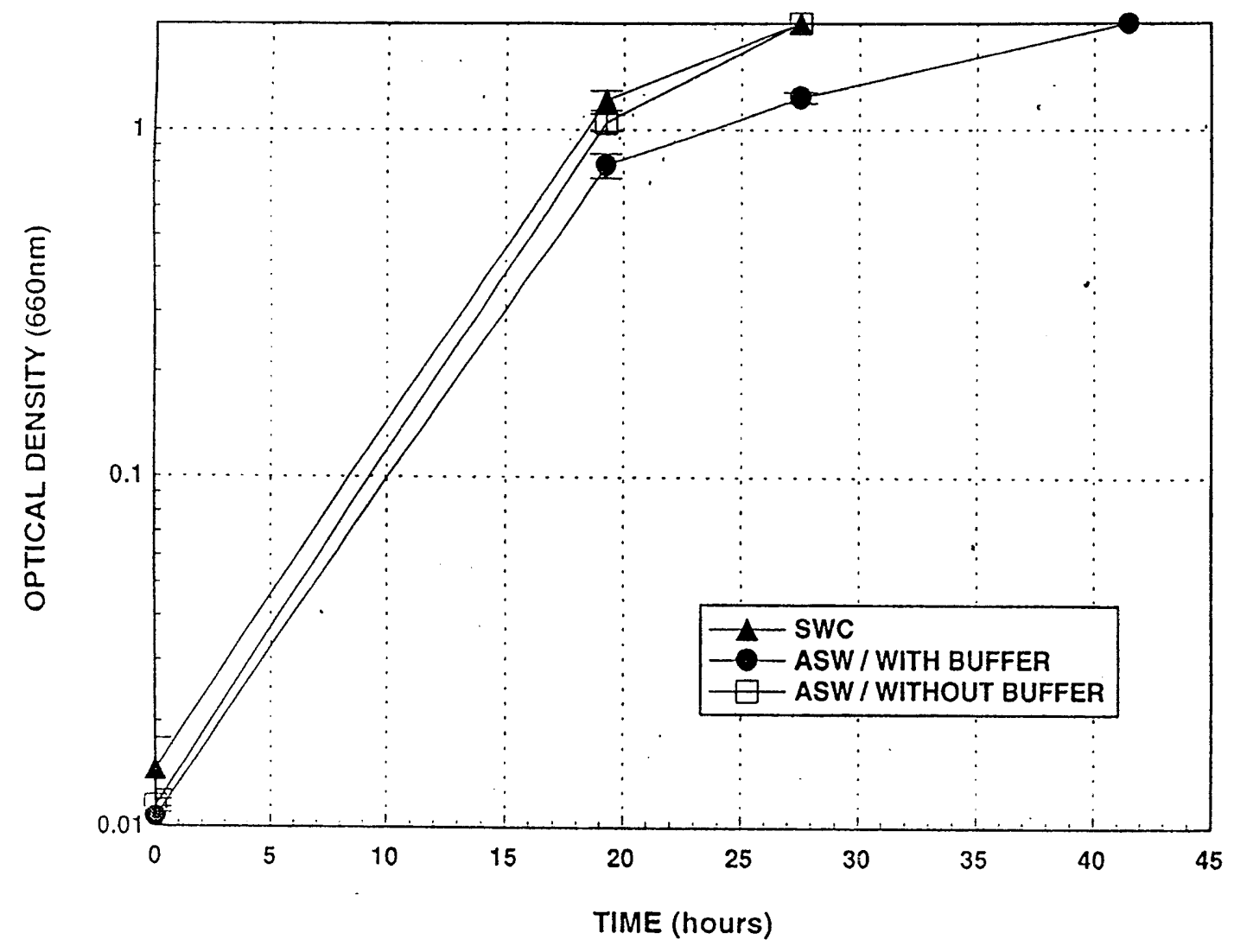

Figuro 4. Growth curves for the bacterium $P$. stutzeri. This experiment compared growth in ASW with and without $50 \mathrm{mM}$ Hepes buffer(pH 7.4). An SWC culture was included as a control. 


\section{NITROGEN DEPLETION / WITH BUFFER}

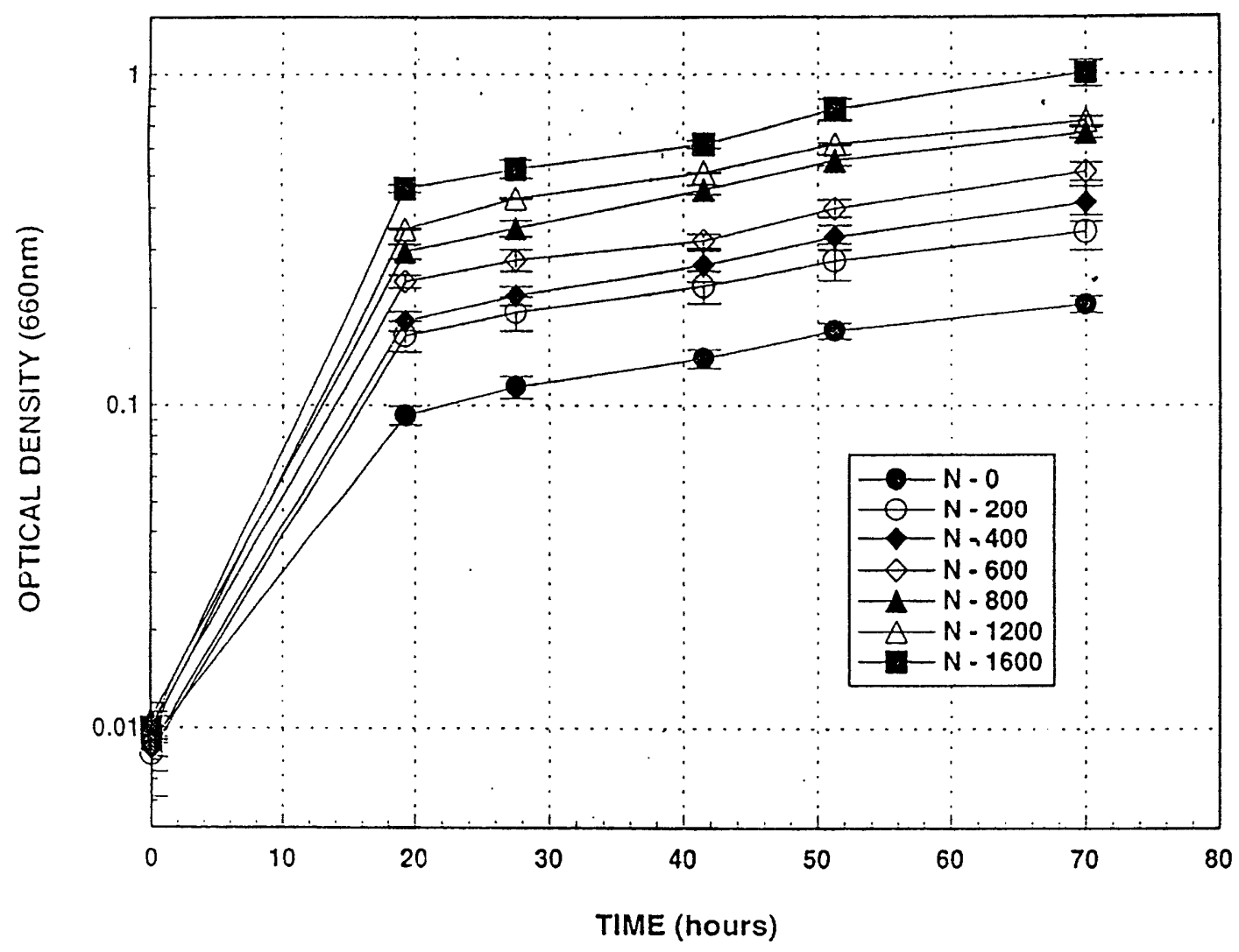

Figure 5. Growth curves for the bacterium $P$. stutzeri. Cultures were grown under nutrient replete conditions except for the level of nitrogen. Each curve represents a different nitrogen

concentration: $0,200,400,600,800,1200$, and $1600 \mathrm{um} .50 \mathrm{mM}$

hepes buffer $\left(\mathrm{pH}^{7.4}\right)$ was added to all cultures. 


\section{PHOSPHORUS DEPLETION / WITH BUFFER}

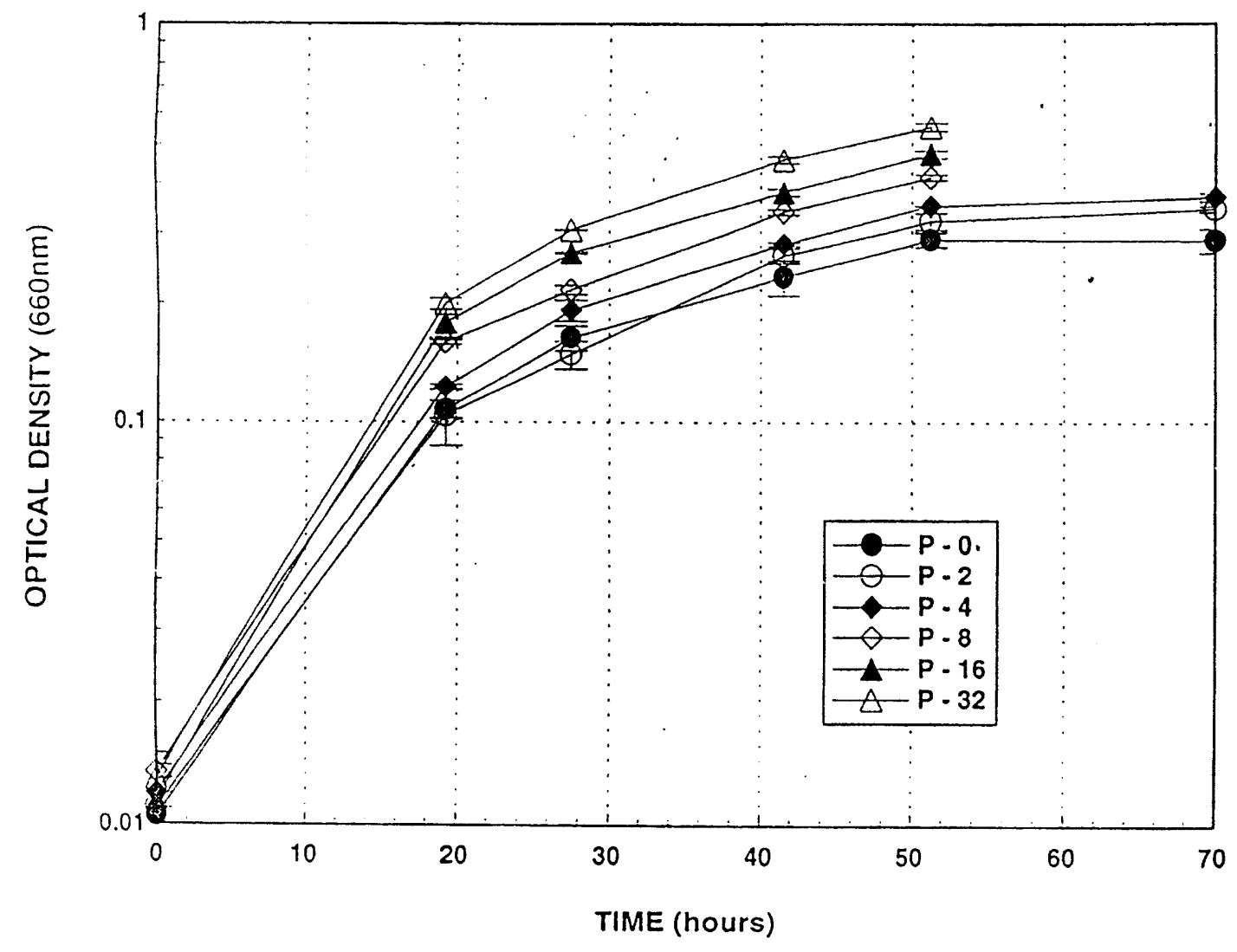

Figure 6. Growth curves for the bacterium $P$. stutzeri. Cultures

were grown under nutrient replete conditions except for the level

of phosphorus. Each curve represents a different phosphorus

concentration: $0,2,4,8,16$, and 32 uM. $50 \mathrm{mM}$ Hepes buffer (pH

$7.4)$ was added to all cultures. 


\section{TOXIN PRODUCTION EXPERIMENT}

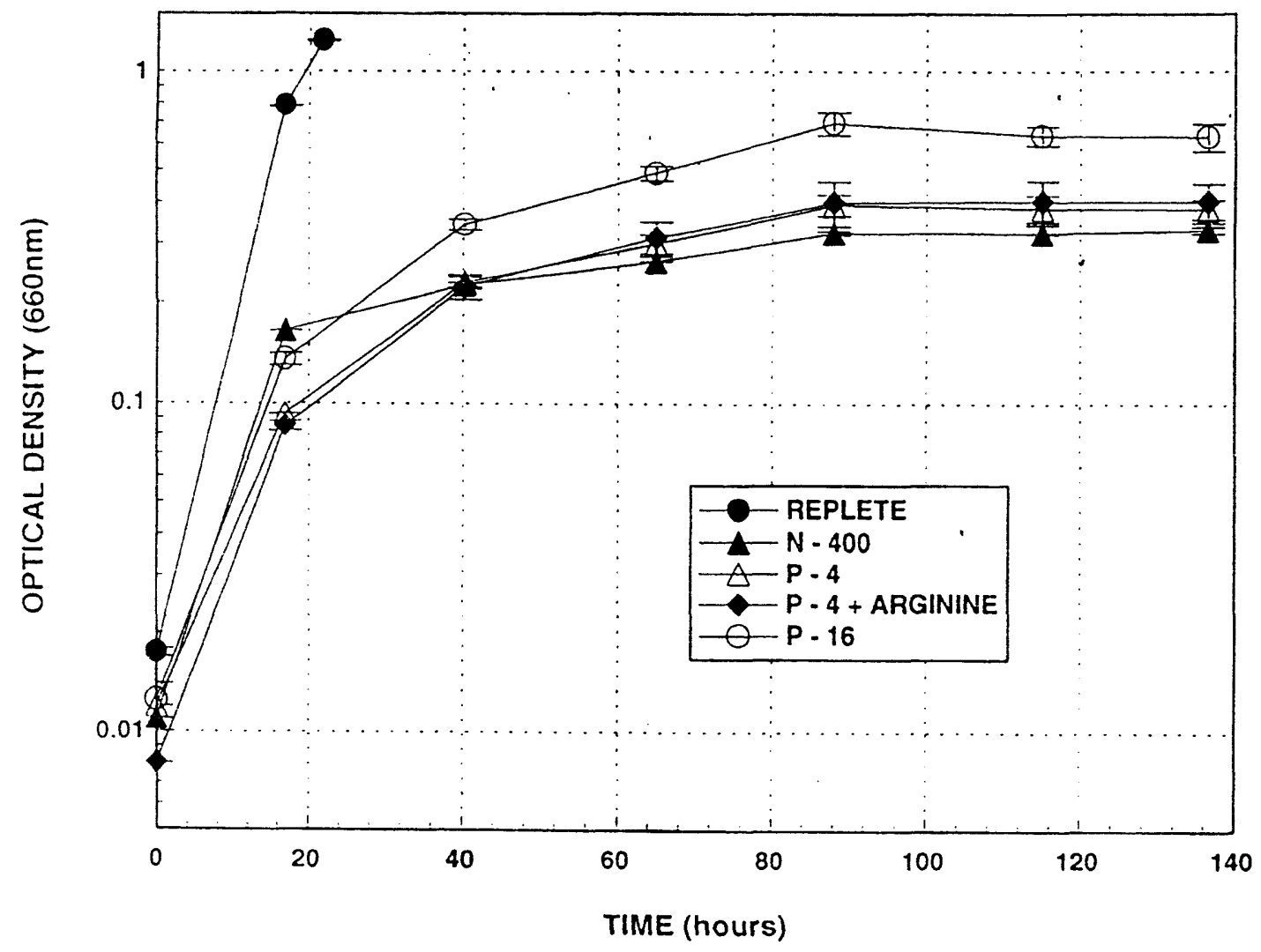

Figure 7. Growth curves for large scale cultures of the bacterium $P$. stutzeri. One culture was grown under nutrient replete conditions to serve as a control. The remalning four cultures were grown into either nitrogen or phosphorus depletion. Each curve represents a culture with a different concentration of a growth-limiting nutrient. The concentrations of deplete nutrient were as follows: $400 u M N, 4$ M P, 4UM P + 50uM Arginine, and 16uM P. 


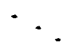

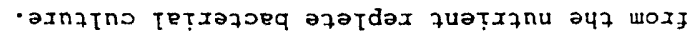

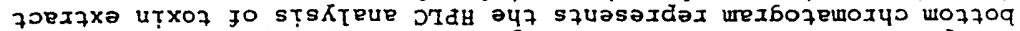

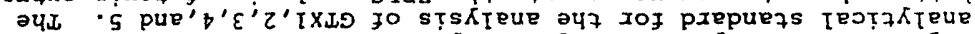

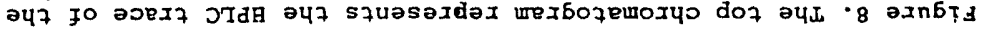
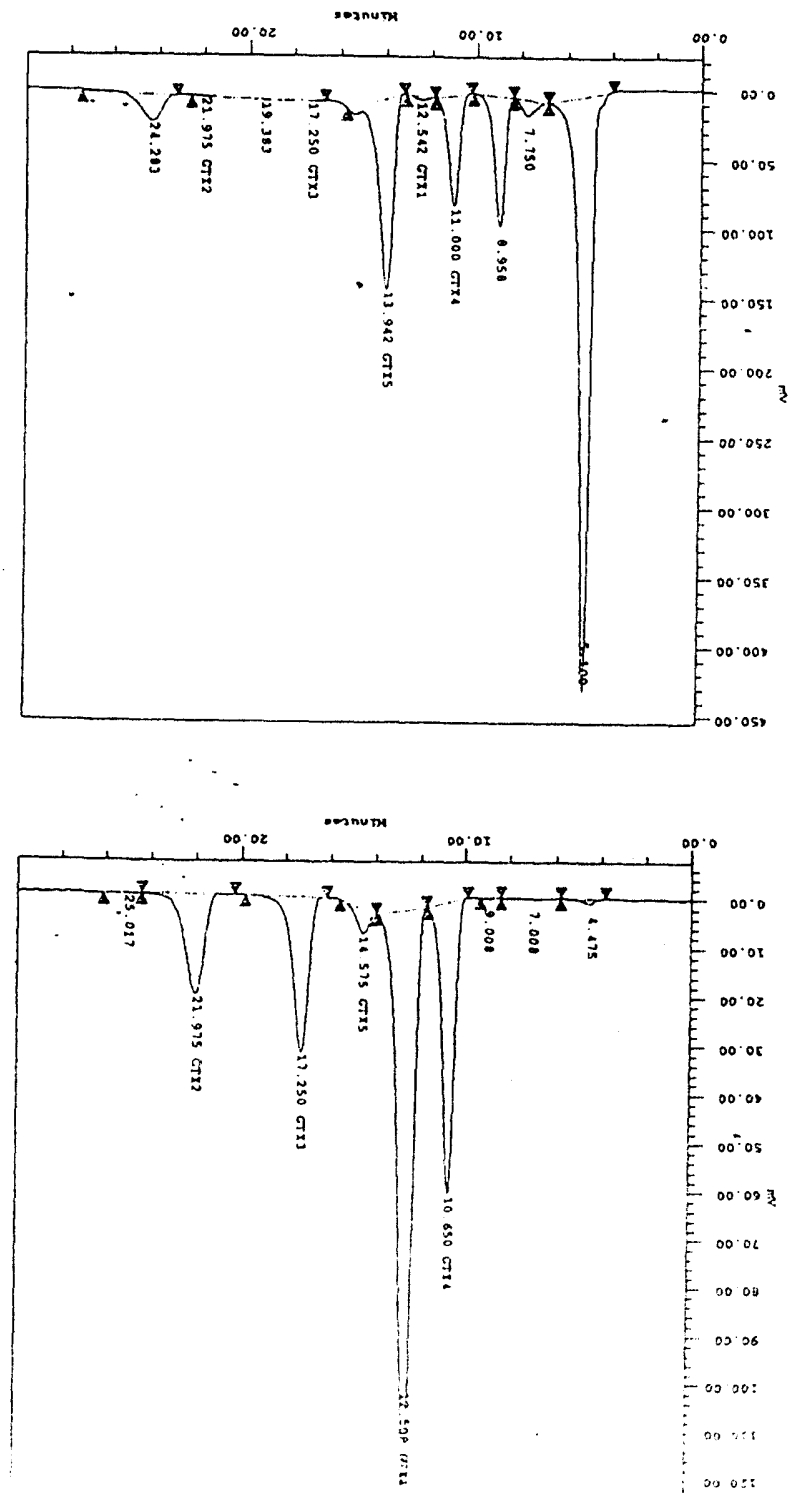


\title{
GROWTH INHIBITION IN GH4C1 CELLS: EFFECTS OF MTX AND TGF $\alpha$
}

\author{
R. Blaine McCleskey \\ Supervisor: Dr. Fran Van Dolah \\ Marine Biotoxin Program \\ National Marine Fisheries Service \\ Charleston, SC 29412 \\ and
}

Marine Biomedical and Environmental Sciences Program MUSC

Charleston, SC 29412

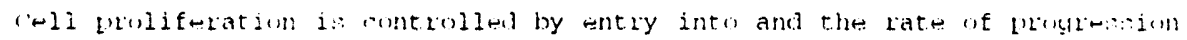

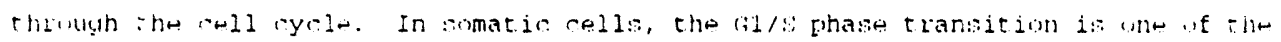

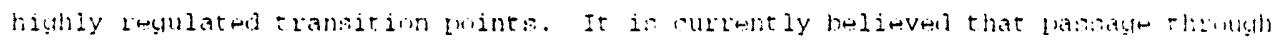

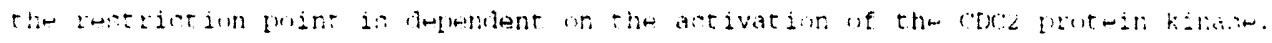

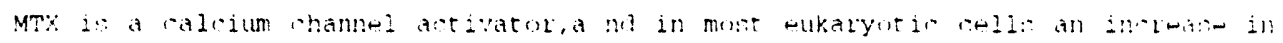

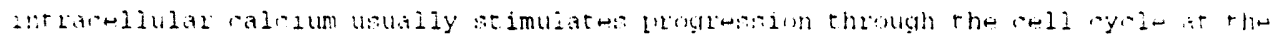

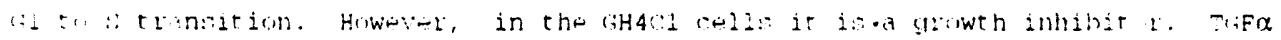

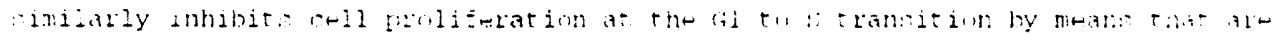

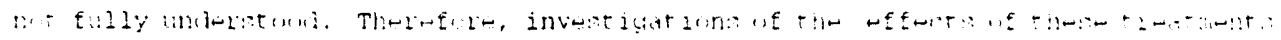

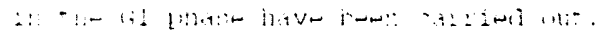




\section{INTRODOCTION}

Cell proliferation is controlled by the entry into and rate of progression through the cell cycle. The cell cycle consists of four major phases: G1, S, G2, and $M$. The $G 1$ phase is a time of intensive biochemical activity. The cell increases in size as its enzymes, ribosomes, mitochondria and other intercellular molecules and structures also increase in number. In early Gl, the cell may opt to differentiate and enter $G 0$ where the ceil is in mitotic arrest. Entrance back into $G 1$ represents reentry into the proliferative state. Just prior to the Gl/S transition, the cell passes through the restriction point that commits it to replicate its DNA and allows it to continue on with the cell cycle. The key process of DNA replication occurs during the $S$ phase of the cell cycle, a period in which many of the histones and other DNA. proteins are also synthesized. During the G2 phase, the final preparations for cell division occur. The newly repicated chromosomes begin to conderise which is necessary for the separation of the chromosomes that will occur in mitosis. In the $\mathrm{M}$ phase, the condensed chromosomes are arranged so that each new cell gets a full complement, one of each, forming what is known ds the spindie. This process is divided zrto four phases: Prophase, metaphase, anaphase, and telophase. Einälly, cytokinesis, the division oz the yoplasm forming two daugher ceils, takes place.

In somatiz qells, the GLS prase zansition z the most tagny

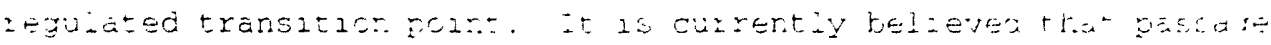


through the restriction point is dependent on the activation of cell cycle regulatory protein kinases, CDC2 and/or CDK2. Treatments which stimulate or inhibit progression through the restriction point ultimately alter the activity of CDC2 and/or CDK2 prior to the GI/S transition; therefore, either activating or inhibiting the activity of cell cycle regulatory protein kinases. Calcium is an intracellular signal which has been demonstrated in most cell types to activate progression through the G1/S transition. In a few cell types calcium acts as an inhibitor at the Gl/S transition; however, the signalling mechanism by which calcium modulates the G1/S transition is not well understood.

The GH4Cl cells utilized in this experiment are inhibited from progression through GI/S by agents which activate calcium signalling. In this study, we conducted some initial investigations to determine where in the G1 phase Maitotoxin, a calcium channel activator, inhibits cell cycle progression using flow cytometry and measurement of CDC2 and CDK2 activity.

\section{EXPERIMENTAI PROCEDURES}

\section{Methods}

Cell culture - GH4Cl cells were maintained at $37^{\circ} \mathrm{C}$ in F10+ medium (Hams F10 nutrient mixture supplemented with $2.5 \%$ fetal bovine serum and $15 \%$ horse serum in the absence of antibiotics. The celis were routinely passaged at weekly intervais to maincain their exporentzal growth, for à maxirum of 10 passages. In craer to 
harvest cells, stock ciltures were treated with $0.02 \%$ EDTA-PBS to detach cells from the dishes.

Cell synchronization - Cells were plated at a concentration of 0.5 $\times 106$ cells per $100 \mathrm{~mm}$ dish with $8 \mathrm{ml}$ of $\mathrm{F} 10$ medium (serum free) and then were incubated for at least 36 hours at $37^{\circ} \mathrm{C}$ (this caused the cells to be blocked in early Gl). The cells were then released by removal of the serum free medium and subsequent addition of $8 \mathrm{ml}$ of the F10+ medium. Synchronized cells were compared to asynchronized cell using flow cytometry.

Cell cycle analysis - Synchronized cells were released and were allowed to incubate for 22-24 hours with no treatments, $3 \mathrm{ng} / \mathrm{ml}$ MTX, or $10 \mathrm{ng} / \mathrm{ml} \mathrm{TGF}-\alpha$ which were added at various times. At the end of the incubation period, the cells were harvested and fixed with $-20^{\circ} \mathrm{C}$ methanol. Cells were then pelleted by centrifugation at $1000 \times 9$ for $5 \mathrm{~min}$, and resuspended in PBS containing $0.5 \%$ Tween 20. $1 \mathrm{mg} / \mathrm{ml}$ heat treated RNase and $10 \mathrm{ug} / \mathrm{ml}$ propidium iodide (PI) for 15 min. Cell cycle distribution was analyzed on a coulter Epics 753 flow cytometer using a $5 \mathrm{~W}$ Argon laser at $488 \mathrm{~nm}$ excitation and $635 \mathrm{~nm}$ emission wavelengths. Cell aggregates were eliminated by gating all histograms within the linear range using a peak-area cytogram for fI fluorescence. Cell cycle distribution was analyzed using the "Multicycle" software program (Phoenix Flow ScEtware, San Diego, (A).

Havone Kinase Issay - Histone dirase activity was measured oy the 
method of Van Dolah/Ramsdell. Synchronized cells were released in F10+ and allowed to incubate for 36 hours with no treatment, 3 $\mathrm{ng} / \mathrm{ml} \mathrm{MTX}, 10 \mathrm{ng} / \mathrm{ml} \mathrm{TGF}-\alpha$, or $300 \mathrm{uM}$ minosine. At the end of the incubation period, ceils were harvested, pelleted by centrifuging at $1000 \times \mathrm{g}$ for $5 \mathrm{~min}$, and then the supernatant was removed. Lysates were then prepared by addition of 100 ul lysis buffer [50 $\mathrm{mM}$ Hepes, $\mathrm{pH} 7.4,0.1 \%$ Triton $\mathrm{x} 100,150 \mathrm{mM} \mathrm{NaCl}, 1 \mathrm{mM}$ EDTA, $1 \mathrm{mM}$ PMSF, $50 \mathrm{mM} \mathrm{NaF}, 80 \mathrm{mM}$ b-glycerophosphate, $0.1 \mathrm{mM} \mathrm{Na} \mathrm{VO}^{4}, 1 \mathrm{ug} / \mathrm{ml}$ leupeptin, aprotinin 1:100 stock]. Lysates were then vortexed vigorously and incubated on ice for 15 minutes. Histone kinase activity specific to $\mathrm{CDC} 2$ or $\mathrm{CDK} 2$ kinase was immunoprecipitated from $150 \mathrm{ug}$ protein from each lysate. For immunoprecipitation, 1 ug antibody was incubated with $30 \mathrm{ul}$ I.gG Sorb for 1 hour at $4^{\circ} \mathrm{C}+\mathrm{n}$ 30 ul lysis buffer. The capsules were pelleted, rinsed twice with $50 \mathrm{mM}$ Hepes, $\mathrm{pH} 7.4,150 \mathrm{mM} \mathrm{NaCl}$, and $0.1 \%$ Triton X100, and then 150 ug lysate added and incubated for 3 hours on a rotator at $4^{\circ} \mathrm{C}$. The capsules were again washed twice with $50 \mathrm{mM}$ Hepes, $\mathrm{pH} 7.4,1 \mathrm{mM}$ dithiothreitol and then combined with a reaction mixture containing $40 \mathrm{ug} \mathrm{Histone} \mathrm{H1,} 50 \mathrm{UM}$ ATP, $10 \mathrm{mM} \mathrm{UCi}$ of gamma ['P]-P.TP. Samples were incubated 15 minutes at room temperature and the reaction. stopped by addition of sample buffer for SDS/PAGE and heating for 5 mirutes at $95 \mathrm{C}$. Lysates were then separated electrophoretically on 250 SDS polyacrylamide gels and relative histone kinase activity determined by autoradiography. 


\section{RESOLTS}

GHAC1 cells synchronization in G1

GH4C1 cells grown in F10 (serum free) medium for one length of the cell cycle (36 hours) arrested in early G1.

\section{GH4C1 cells released from a F10 block}

Adding serum $(\mathrm{F} 10+)$ to the medium of serum starved cells that were synchronized in Gl allowed the cells to progress through the cell cycle in a synchronized fashion. It took 18-22 hours for cells release from a serum free block to reach $S$ phase.

\section{Both TGF $\alpha$ and MTX inhibit GHAC1 cell proliferation}

The addition of $10 \mathrm{ng} / \mathrm{ml}$ of MTX and $10 \mathrm{nM}$ TGF $\alpha$ at different times to synchronized cells which were released from a serum free (F10) block and then harvested at 22 hours determined the reiative times MTX and TGF $\alpha$ block cell cycle progression. At 15 hours, TGF $\alpha$ began to lose its ability to block cells in GI phase. MTX was somewhat later, and began to lose its ability to prevent s-phase entry at 18 hours.

MTX treated G1 cells block where CDC2 kinase is already activated There was low CDC2 kinase activity in serum starved ce:-s, cells in $S$ phase had some what higher histone kinase activity. Cells treated with TGF $\alpha$ had approximately the same amount of histone kinase activicy as the controls. MTX appeared to pcssess a much higher histone kinase activity. 


\section{DISCUSSION}

GH4Cl cells grown in a serum free medium arrest in early Gl. Addition of serum back to the cells allows the cells to proceed through the cell cycle in a synchronized fashion. Cells that have been released from a serum free block in early G1 take between 18 and 22 hours to reach $\mathrm{S}$ phase.

In a preliminary experiment, TGF $\alpha$ treated GH4C1 cells lose their ability to block $S$ phase entry at about 15 hours after the serum addition. However, MTX lost its ability to block at about 18 hours. Also in a preliminary experiment, MTX had more CDC2 activity than TGF $\alpha$. From previous experiments done at the lab, it has been determined that TGF $\alpha$ blocks at the restriction point. From these experiments, it appears that MTX blocks later than TGF $\alpha$, and thus blocks after the restriction point.

It is important to point out that these are only preliminary results, and further experiments need to be performed before any definite conclusions can be made. 


\section{REFERENCES}

1. Van Dolah. F. and Ramsdell, J. (1992) Marine Biomedical and Environmental Sciences.

2. Cobrinik, D., Dowdy, S., Hinds, P., and Mittnacht, S. (1992) Tibs 17.

3. Buchkvich, K., Duffy, L., and Harlow, E. (1989) Cell 58, 10971105.

4. Cooper, J., and Whyte, P. (1989) Cell 58, 1009-1011.

5. Whitaker, M. and Patel, R. (1990) Developement 108, 525-542.

6. Enoch, T. and Nurse, P. (1990) Ce11 60, 665-673. 
Figure 1. a. Synchronized GH4C1 cells grown in serum free (E10) medium for 36 hours. Flow cytometry was then used for the cell cycle analysis. $90.8 \%$ of the cells are accumulated in G1.

Figure 1. b. Cell cycle analysis of unsynchronized cells. GH4C1 cells were grown in serum containing medium (F10+) and flow cytometry was used to determine cell cycle distribution. $50.7 \%$ of the cells were in G1, $38.2 \%$ were in S, and $11.1 \%$ were in G2 and $M$.

Figure 2. An experiment run previously which demonstrates the time it the cells to progress into $S$ phase from a serum free block. At time 0 greater that $90 \%$ of the cells were in G1, and at 12 and 18 hours after addition of serum virtually none of the cells had entered S phase. However, between 18 and 24 hours after serum addition, nearly $50 \%$ of the cells had entered $S$ phase.

Figure 3. Time for GH4C1 cells to reach $S$ phase from a Serum free block. Until 18 hours, essentially no cells had entered s-phase, and between 18 and 22 hours after serum addition approximately $30 \%$ of the cells had entered S-phase.

Figure 4. Relative times that MTX and TGF $\alpha$ blocked cell cycle progression. Addition of serum to serum starved cells ailowed the cell to progress through G1, then there was addition of $10 \mathrm{ug} / \mathrm{ml}$ MTX. or $10 \mathrm{nM} \mathrm{TGE} \alpha$ at different times after serum addition, ard the $c=1 \mathrm{~s}$ were allowed to grow to 22 hours before being narvested. $=$ : cycle analysis was ther. used to determine when the ceils enteves 3 - 
phase.

Figure 5. CDC2 kinase activity in control cells at 22 hours after serum addition, cells treated with MTX, TGF $\alpha$, mimosine, and cells that remained in serum free medium. The serum free cells had no CDC2 activity where the control and the mimosine had about the same amount of activity. The TGF $\alpha$ had slight CDC2 activity, although there was a bit of degregation in this lane and the MTX had even more activity than the TGF $\alpha$. 
Figure 1
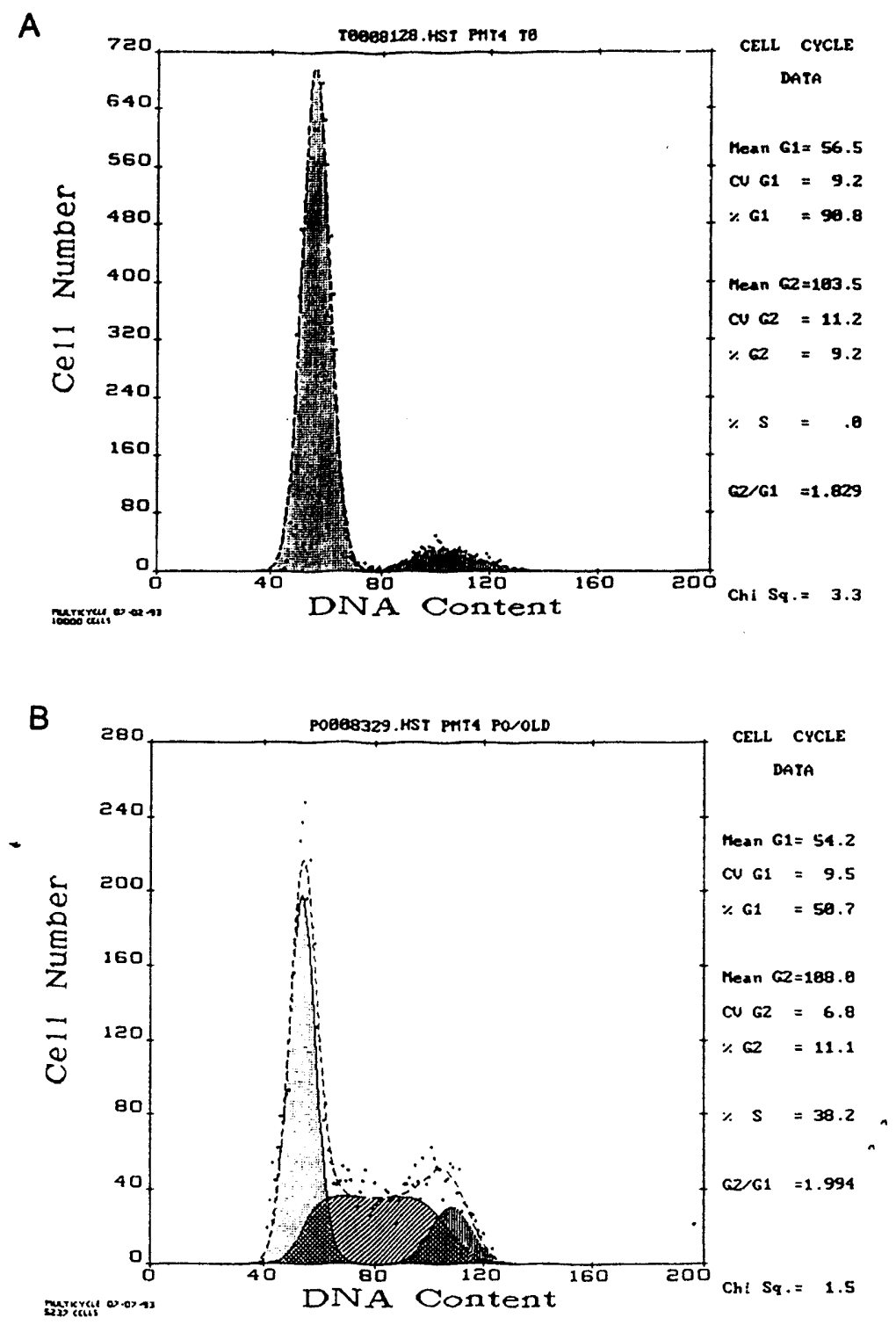
Figure 2

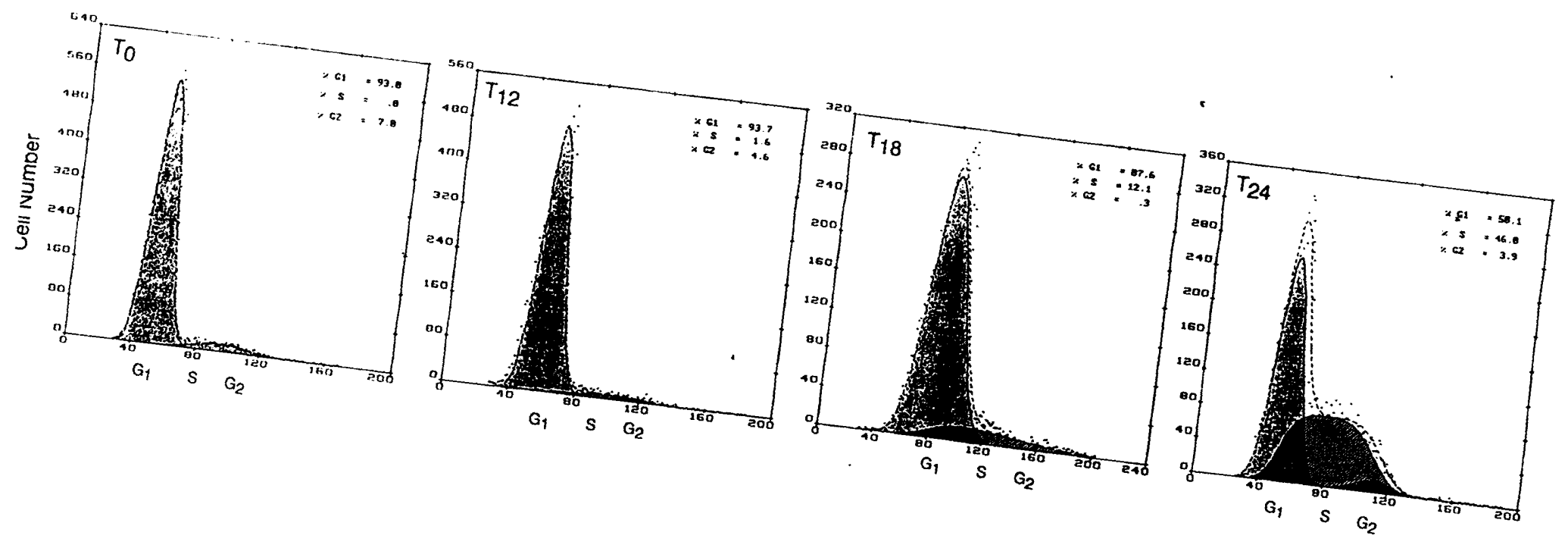


Figure 3

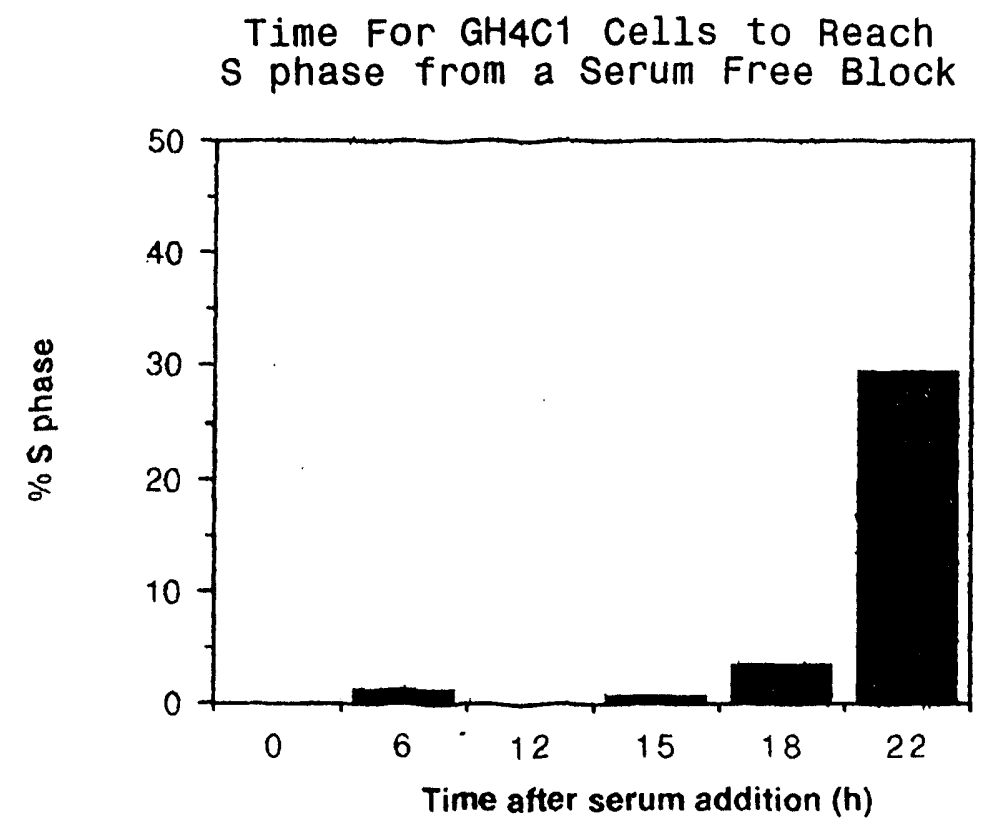


Figure 4

Time to MTX and TGF- $\alpha$ Block

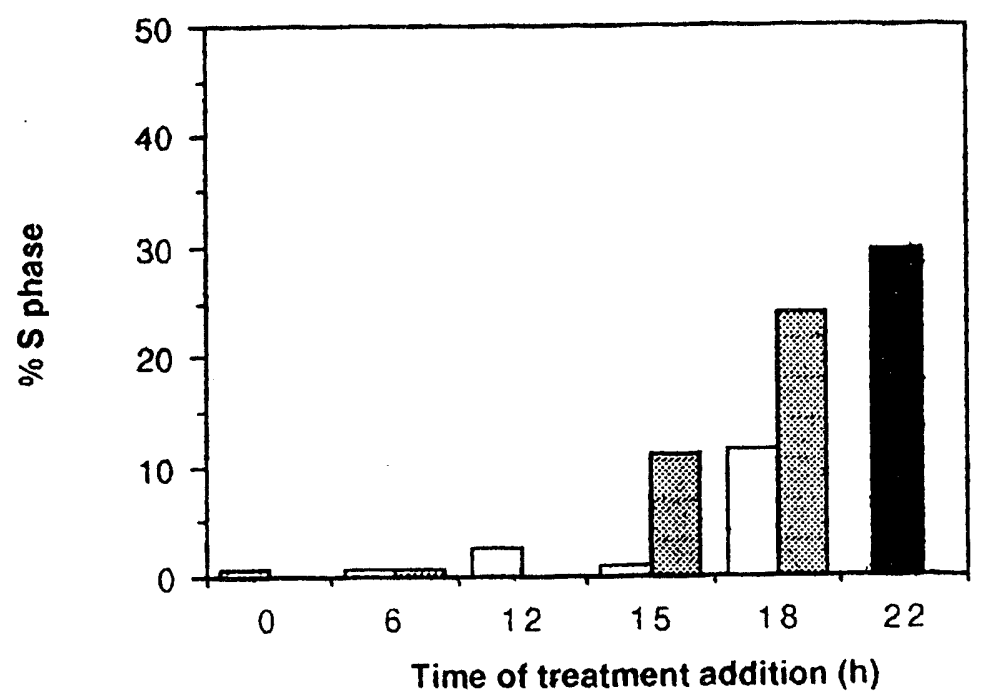

TGF - $a$

MTX

Untreated Cells 
Figure 5 CDC2 ACTIVITY

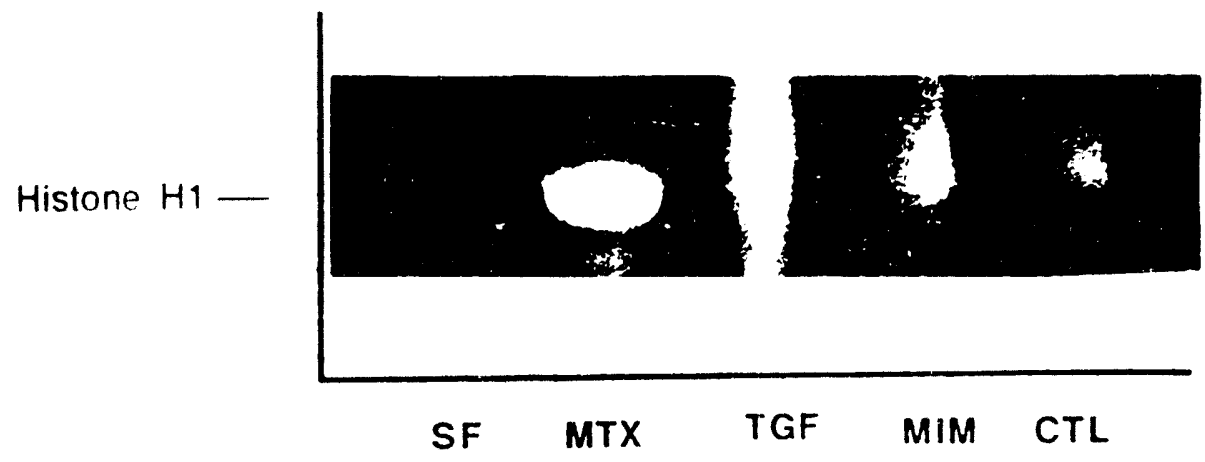




\section{An Epidemiological Study of Leukemia in South Carolina}

\section{Background}

Over the past several years, numerous health studies have been carried out on populations living near nuclear facilities. The principle finding of many of these reports is an increase in martality from leukemia between birth and age 24 (1-6). Although the reason for this apparent increase has been disputed, it is biologically plausible that proximity to radiation releasing facilities is a contributing factor, as it has been demonstrated that radiation produces differing responses in different age sroups $(7,8)$. Leukemia also lends itself well to an epidemiological study because it has a relatively short latency period between exposure and onset, allowing adverse conditions to be detected within a reasonable amount of time. My research project has been a study of leukemia in the 0-24 age group, focusing particularly on the counties on the southwestern side of the state that borders the Savannah River, where the Savannah River Plant is located. Built in Edgefield County by the Atomic Energy Commission in the early 1950's, the Savannah River Site occupies 312 square miles and has been the center of tritium production activity in the United States $(9,10)$. Tritium is produced through the irradiation of lithium, and as an unwanted byproduct in the reactors at the plant $(10)$. The main possible sources of environmental contamination are direct release of radionuclides into the river, and seepage from underground holding tanks that enters the river via streams. Slightly elevated levels of tritium have been detected downriver at treatment plants where the river is the main source of drinking water (11). It may be noted that the plant has maintained environmental monitoring and reported releases have been kept well below the recommendations of the International Commission on Radiological Protection $(9,11,12)$.

Tritium is a radioactive isotope of hydrogen and is considered $a$ health hazard $(10,13-20)$. The main avenue of exposure to man is through ingestion, and possible routes include water vapor, drinking water, fish from polluted waters, contaminated milk, and others $(11,21,22)$. Ingested tritium has a biological half life of $5-15$ days in man $(23,24)$.

\section{Methods}

The main focus of this report is on the thirteen counties covered by the Savannan River Region Health Information System ISPPHIS: This area embodies the South Carolina side of the eavaniar. Fiver Regicn and ircludes the following counties (see mapl: Fiker. Allendale. Beaifort. Eerkeley, Bamberg, Barnwell, Charleston. Colleton, trorchester. Edgefield, Hampton, Jasper, and rrangerise

Morality stat:etice fuom death certificates was the primary aurce ct date used, suppianentod with incidence rates (25). All rates ate expressed as the mutier of people affected per 100,000

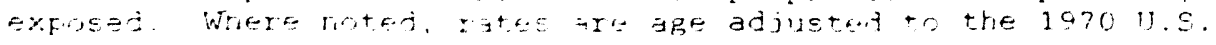


standard population to minimize skewing due to age variance between populations. State and county population statistics for the most recent years were available or projected from the 1990 census information, while population data for past years was provided by the American Cancer Society. Due to the absence of some very recent data in useable form, some rates have been projected and are noted as such.

\section{Limitations}

The limitations inherent in reliance on mortality rates are primarily caused by potential incorrect reporting of cause of death, particularly in the earlier years when health care was not as developed; therefore, the more recent data is generally considered to be more reliable. Also, greater success in treatment has increased the Eive year survival rate for leukemia to over $50 \%$ in the younger age groups, making mortality a smaller part of the overall picture. Incidence rates can be underreported where quality control is poor, or in areas without $100 \%$ cooperation of hospitals. Since incidence information is processed where the patient seeks treatment, geographical rates may be slightly misleading for patients who travel out of the county or state. (An effort has been made in this study to minimize this problem by including cases from the Georgia cancer registry with South Carolina addresses). Lastly, low numbers in some categories, as recorded in the corresponding charts, in the age specific rates present results within these categories with low statistical power, requiring caution in interpretation.

\section{Results}

Mortality rates from the SRRHIS Region over the thirty-five year period from 1953-1987 were compared to South Carolina and U.S. rates (fig 1). Over that span, both the state and SRRHIS rates were below that of the U.S., with no significant difference between South Carolina and the SRRHIS region. The SRRHIS rate was then recalculated subtracting the rates from the Trident Health Region (Berkeley. Charleston and Dorchester counties), and Colleton. These are the four furthest counties from the Savannah River Site and are somewhat different from the other nine counties in the SRRHIS region in racial distribution and urbanization. The resulting rate from the remaining counties was found to be slightly lower than the others (fig 2 ).

The same comparisons for the years 1983-1991 (fig 3 ) indicated that the SRRHIS region was noticeably lower than the state and national rates, while subtracting the Trident area resulted in a decrease to only slightly more than half of the national figure. A breakdown into approximate ten year intervals demonstrates that neither the SRRHIS region as a whole, nor the area comprised of the non-Trident onnties his ever been significantly above the rest of South Carolina, and the non Trident counties have always followed the trend of being at of below the Trident counties (fig 4 ).

To eliminate the possible skewng of statistas by racial distribution, the data was divijed into subcategories based on race and seforate rates were determined for whites and nonwhites 
(Eigs 5-7). The pattern in both racial groups was quite similar, with high resemblance to the overall formation. The characteristic higher rate in whites was also present.

When incidence rates from 1991 (the only year that South Carolina data is currently available) were plotted against the U.S. rate ( $\mathrm{fig} 8$ ), the SRRHIS region was substantially lower, supporting mortality figures from the same year, which were more than $50 \%$ below the national mortality rate. The incidence rates were then broken down into five year age specific rates to determine if they were distributed normally (fig 9). All of the SRRHIS rates were uniformly below the U.S. rates for these categories with the exception of the 20-24 age group, which showed a slight elevation. SRRHIS region mortality rates for this age group matched with overall state rates over a 35 year interval showed some temporal variation, which is possibly due to random chance, while the totals for the length of the time period were basically identical (fig 10). Rates divided into racial categories were lower in the SRRHIS region for whites, but higher for nonwhites (fig 11). Also worthy of note is the fact that the normal trend for a substantially higher rate of leukemia in whites is not reflected here, but is slightly reversed. When the SRRHIS region was divided into those counties that actually border the river and those that don't (fig 12), the bordering counties consistently had higher rates than the non-bordering, with the relative difference increasing over time to a peak in 1983-1987 of a rate that was nearly three times higher in the bordering counties. Rates for whites and nonwhites demonstrate that the trend is exaggerated in whites, but reversed in nonwhites (fig 13).

\section{Conclusions}

Neither overall rates nor race specific rates indicate any abnormal leukemia risks associated with the Savannah River. The rates are actually lower in the counties nearest the river, which may be due in part to lower overall urbanization. Parallel patterns in racial sub-groupings reinforce this, indicating a minimum of skewing from racial distribution. Incidence rates, were also lower in the SRRHIS region than the U.S. For every age ategory except 20-24; however, mortality rates for this group were not elevated over state or national rates. Figures in counties bordering the river were shown to be somewhat higher than those in non-bordering counties, but the considerable difference in race specific rates, in the absence of a biologically plausible explanation, indicates that this may be due to chance distribution. Making inferences on this phenomenon will reguide the aralysis of incidence data from future vears, as wel: as demoristrable causation. 
Counties and State Health Districts of SC.

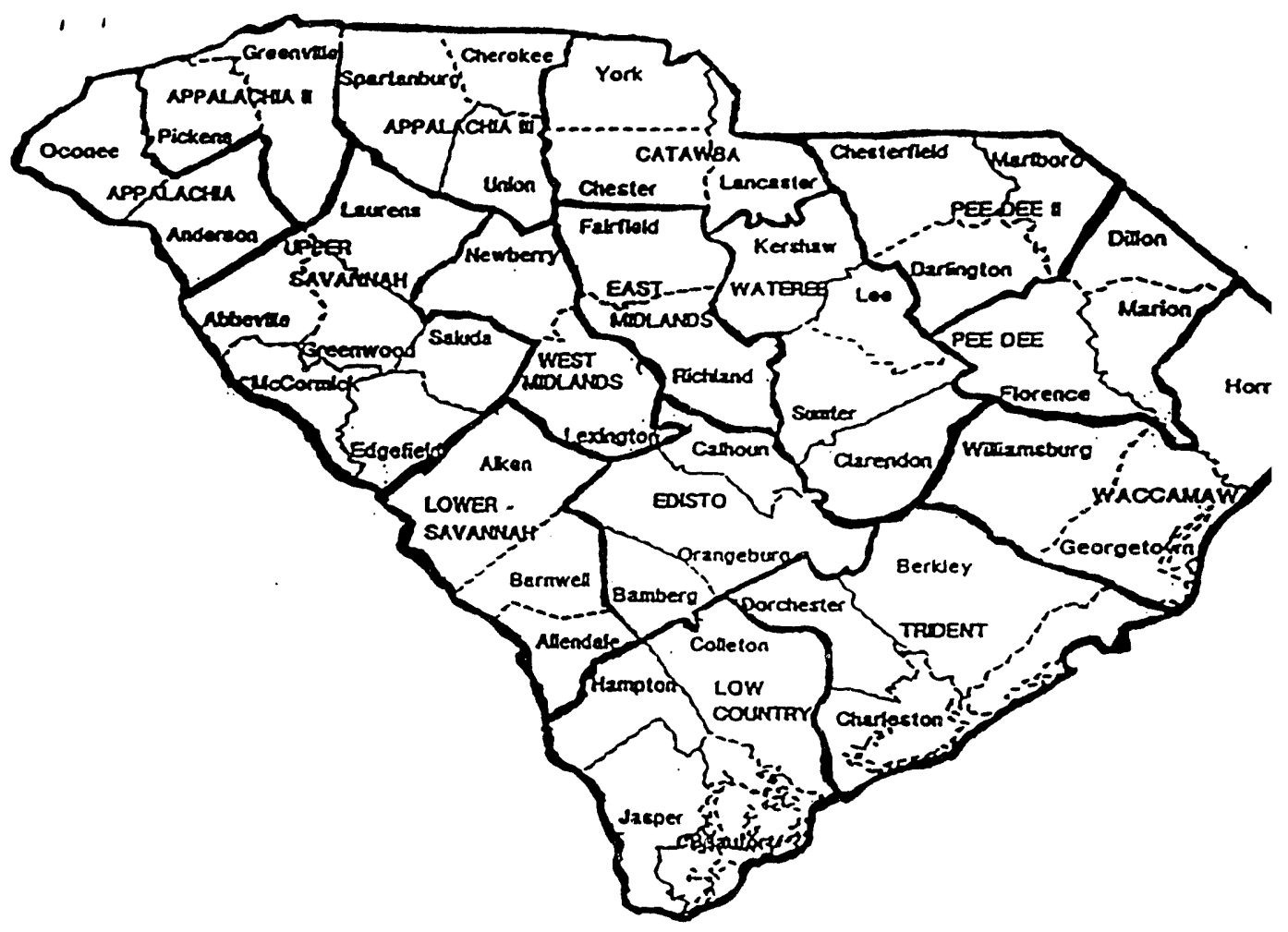

Health Districts:

Counties:

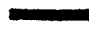


Fiqure 1

\section{Mortality 1953-1987 \\ Age: 0-24}

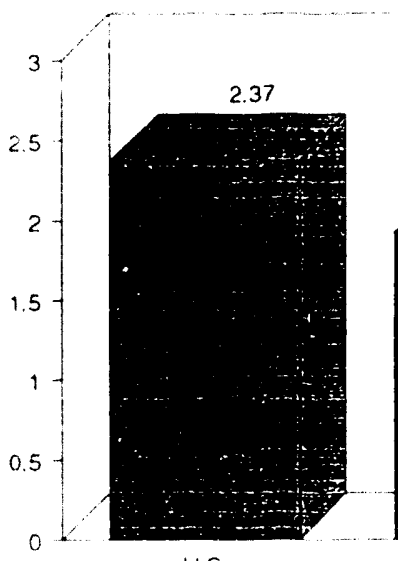

US

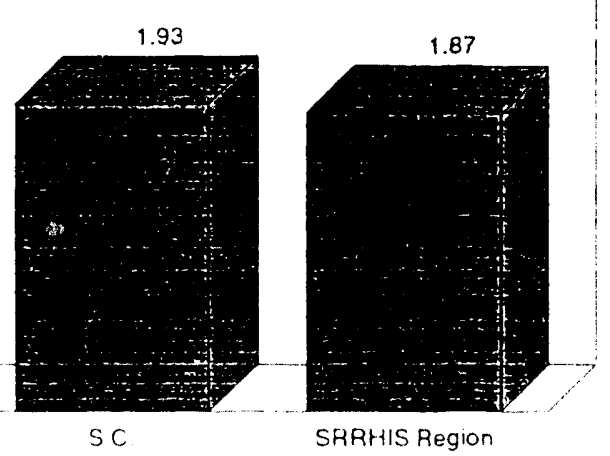

SRRHIIS Region

Hales are aoge adjusled

Figure?

Mortality 1953-1987

Age: 0-24
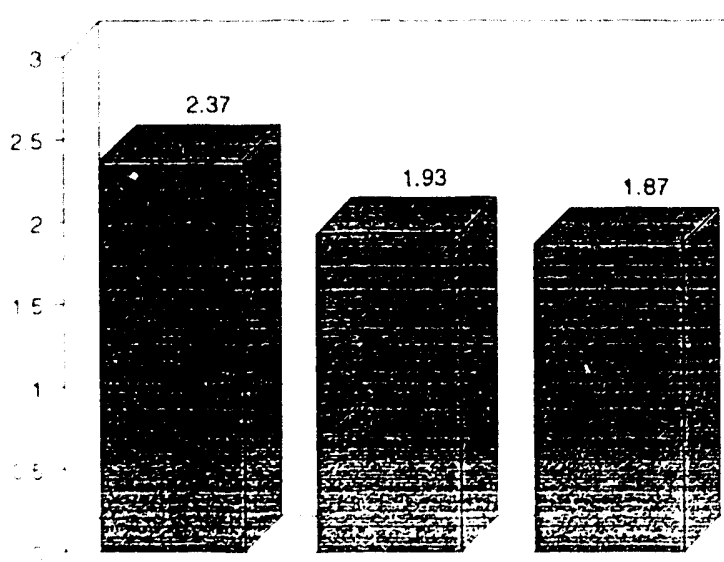

1.7

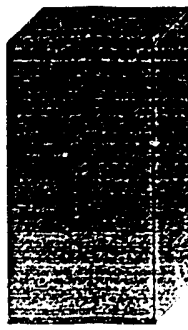


Figure 3

Mortality 1983-1991

Age: 0-24

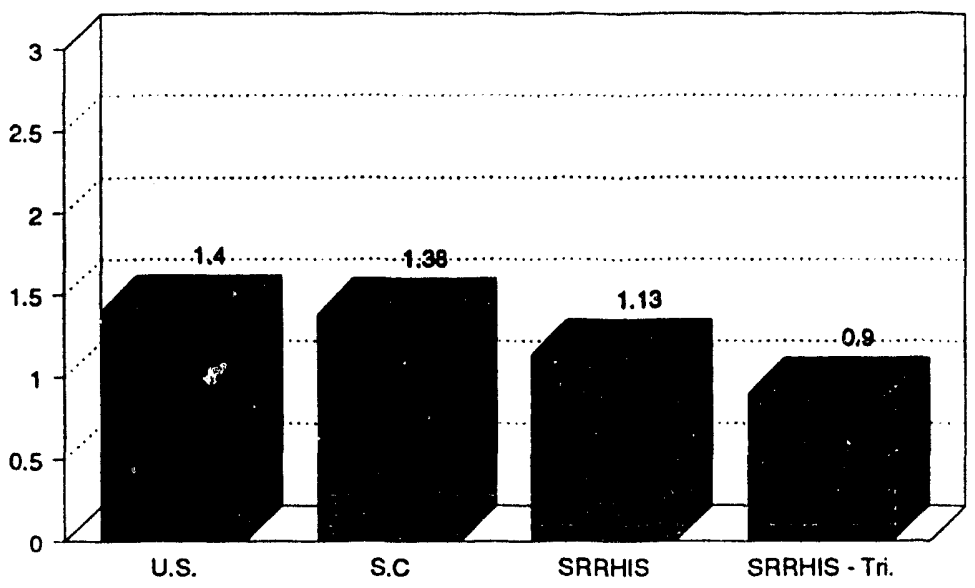

Hates are age adjusted, U.S. rate is projected

Figure 4

\section{Trends in Mortality}

Age: 0-24

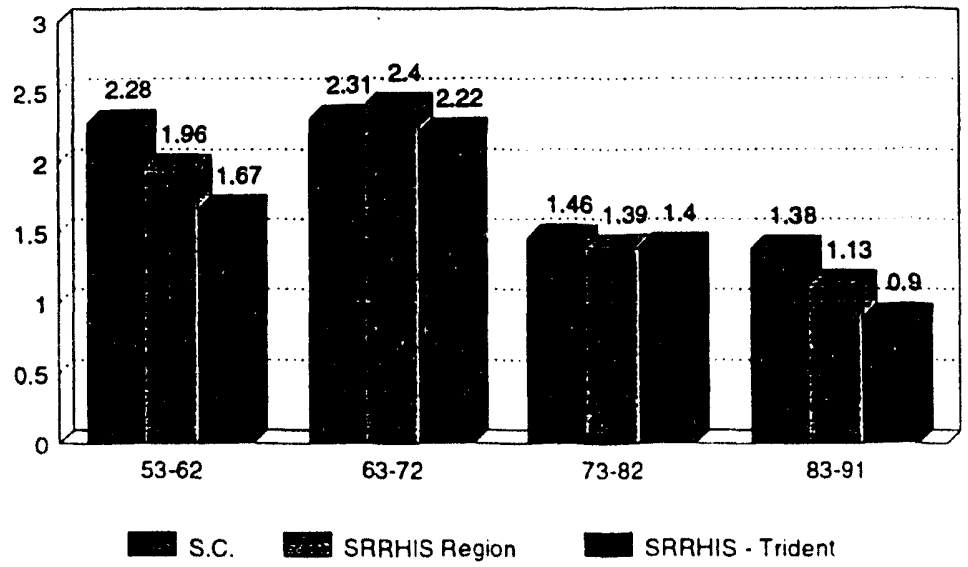


Figure 5

Mortality 1953-1987

Age: 0-24 Race: White

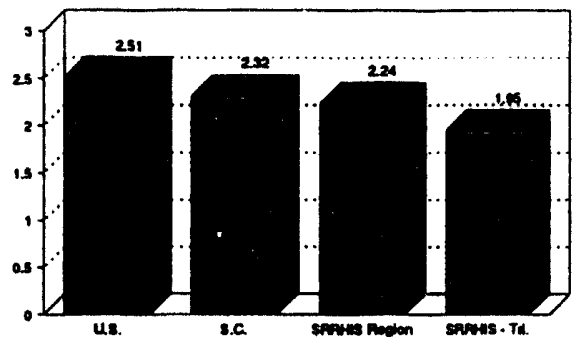

Figue 6 Mortality 1953-1987

Age: 0-24 Race: Nonwhite

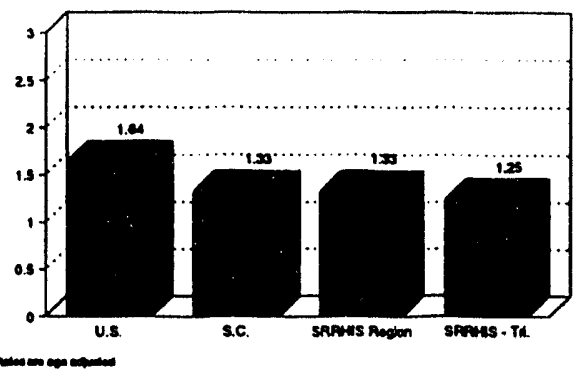

\section{Mortality By Race 1953-1987 Age: 0-24}

Figure 7

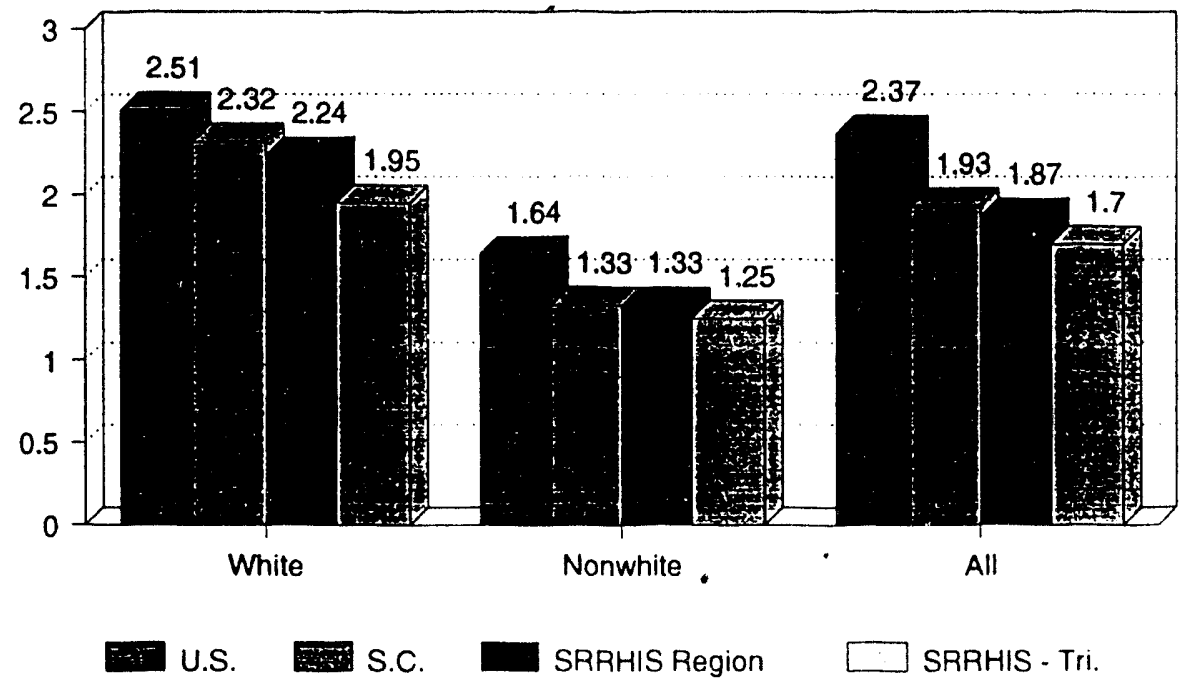

- Rates are age adjusted 


\section{Incidence and Mortality \\ Figure 8 \\ Age: 0-24}

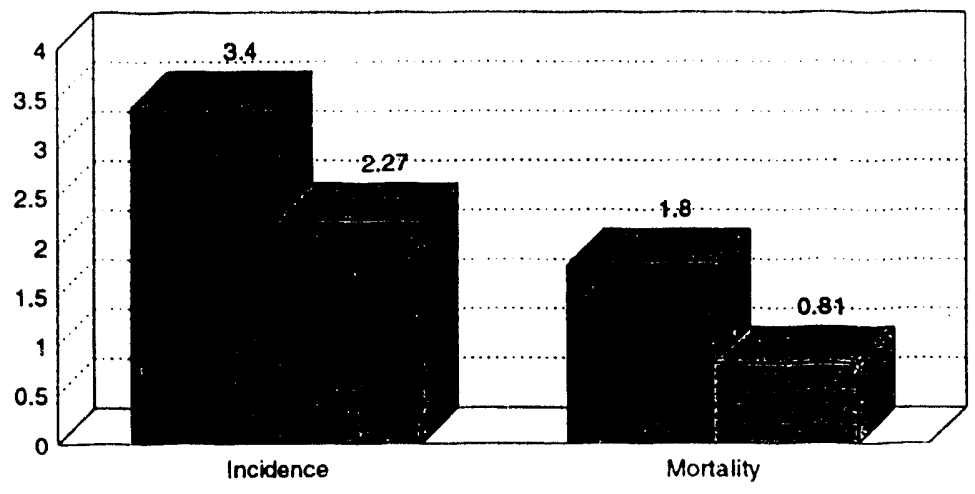

U.S. $\quad$ SRRHIS Region

Rates are age adjusted, U.S. rates are projected

\section{Incidence Rates By Age Group}

Figure 9

1991 Cases: 12

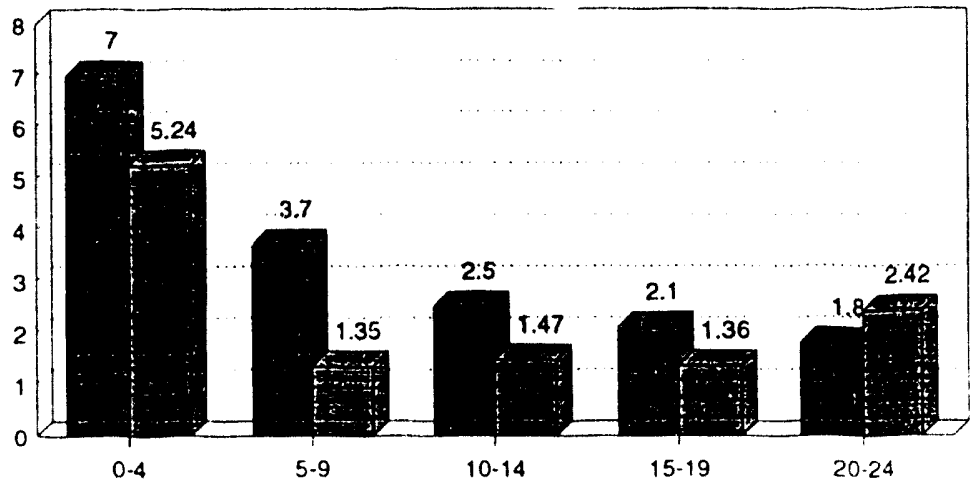

$\rightarrow$ U.S. SRAHIS Region 
Figure 10

Age Specific Comparisons Age: 20-24 Race: All

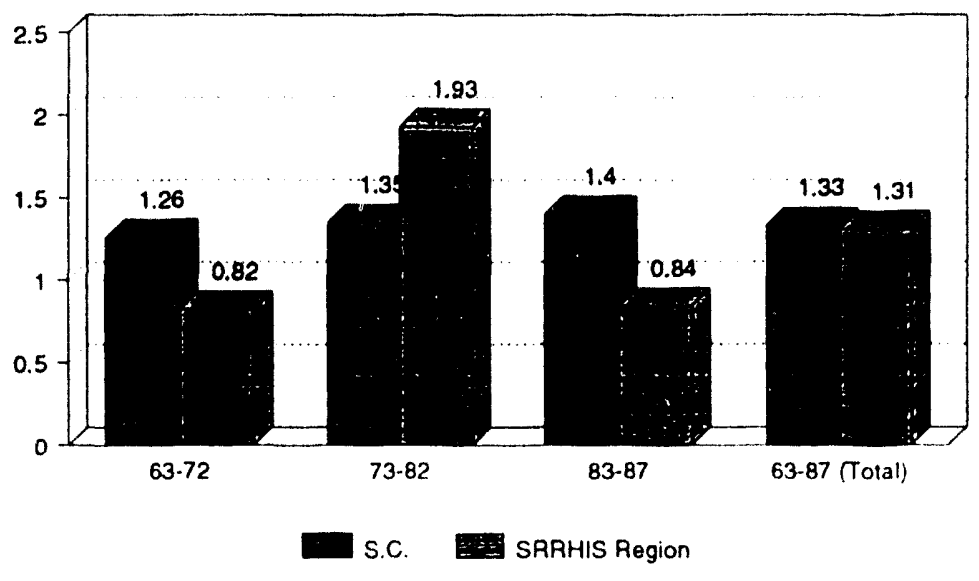

Tolal cases 24

Figure 11

Age Specific Comparisons Age: 20-24 Yrs: 1963-1987

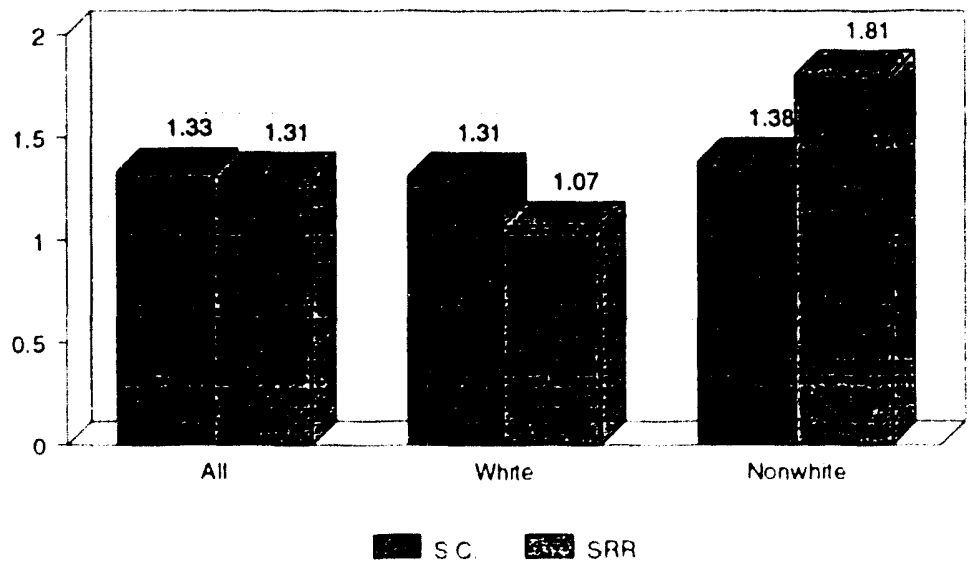


Figure 12 Age Specific Comparisons Age: 20-24

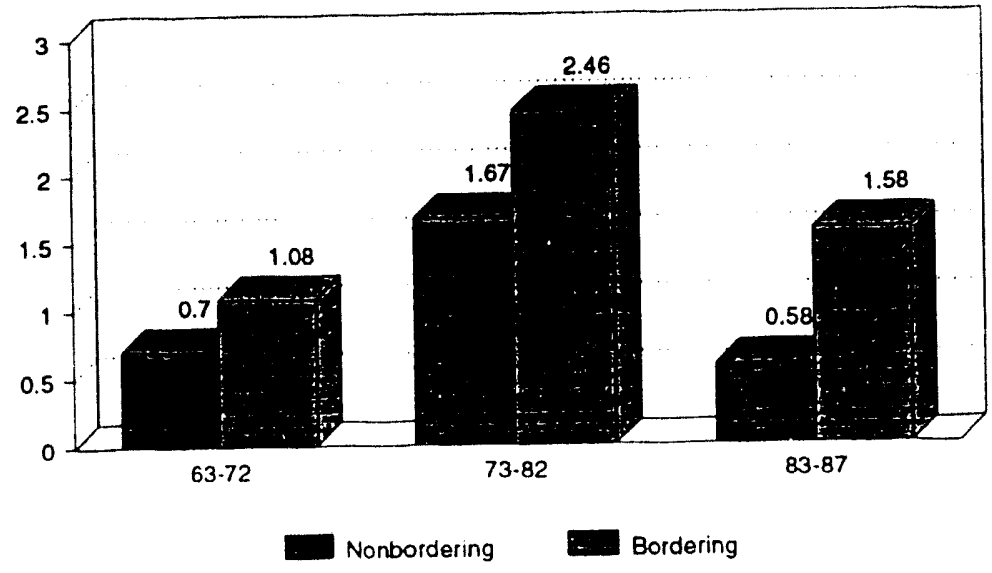

Number of cases: 24

Figure 13 Age Specific Comparisons Age: $20-24$

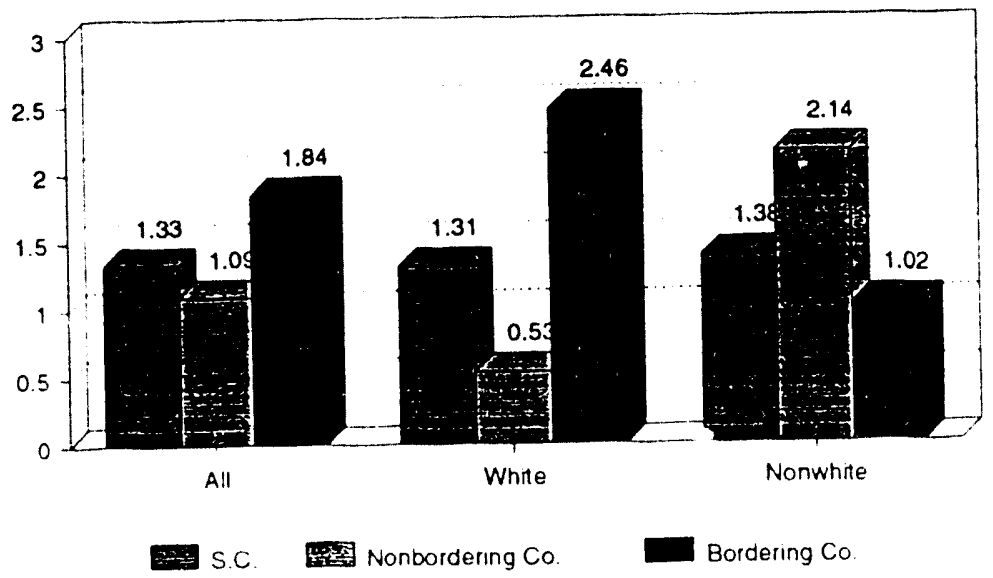

Tolal cases 24 


\section{References}

1. Cook-Mozaffari, P.J., S.C. Darby, R. Doll, D. Forman, M.C. Pike, and $T$. Vincent. Geographical variation in mortality from leukaemia and other cancers in England and Wales in relation to proximity to nuclear installations, 1969-78. Br. J. Cancer (1989); 59: 476-485.

2. Forman, D., P.J. Cook-Mozaffari, S. Darby, G. Davey, I. Stratton, R. Doll, and M. Pike. Cancer near nuclear installations. Nature (1987); 329: 499-505.

3. Shleien, B., A.J. Ruttenber, and M. Sage. Epidemiologic studies of cancer in populations near nuclear facilities. Health Physics (1991); 61: 699-713.

4. Grosche, B. Childhood Leukemia in the vicinity of nuclear power plants in Germany. (Obtained from author).

5. Urquhart, J. Leukemia and nuclear power in Britain. In: Jones, R.R., and R. Southwood, eds. Radiation and health. John Wesley and Sons, 1987.

6. Stather, J.W., J. Dionian, J. Brown, T.P. Fell, and C.R. Muirhead. Assessing risks of childhood leukemia in Seascale. In: Jones, R.R., and R. Southwood, eds, Radiation and health. John Wesley and Sons, 1987.

7. Etnier, E.L., and J. Till. Significance of incorporating age-dependent data into population dose estimates. Health Physics (1979); 37: 774-777.

8. Adams, $N$. Dependence on age at intake of committed dose equivalents from radionuclides. Phys. Med. Biol. (1981); 26: $1019-1034$.

9. Evans, A.G., W.L. Marter, and W.C. Reinig. Guides limiting the release of radionuclides from the Savannah River Plant. Health Physics (1968); 15: 57-65.

10. Reinig, W.C., and E.L. Albenesius. Control of tritium health hazards at the Savannah River Plant. Industrial Hygiene Journal (1963); May-June.

11: United States Dept. of Energy. 1991 Savannah River Site Environmental Report.

12. The International Commission on Radiological Protection. Recommendations of the International Commission on Radiological Protection. Publication 26. New York: Pergamon Press, 1977.

13. Evans. A.G. New dose estimates from chronic tritium exposures. Health Physics (1969); 16: 57-63.

14. Carsten. A.L. Tritium in the environment. In: Advances in Radiation Biology: Volume 8. Academic Press: 1979.

15. Cahili, D.F., arid C.L. Yuile. Tritium: some effects of continuous exposure in utero on mammalian development. Radiation Fiesearch $(1970) ; 44: 727-737$.

16. Vennart. J. Fadiotoxicology of tritium and $14 \mathrm{C}$ compounds. Health Frysics (1969): 16: $429-440$.

17. Feinendegen, L.E. Effects of tritium on the human organism. 
J. Belge de Radiologie (1958); 58: 147-155.

18. International Atomic Energy Agency. Radiation induced cancer. Vienna: 1969.

19. Jones, R.R., and R. Southwood, eds. Radiation and health: the biological effects of low-level exposure to ionizing radiation. New York: John Wiley and Sons, 1987.

20. Sanders, C.L., and R.L. Kathren. Ionizing radiation: tumorigenic and tumoricidal effects. Columbus: Batelle Press, 1983.

21. Osborne, R.V. Absorption of tritiated water vapor by people. Health Physics (1966); 12: 1527-1537.

22. Grainger, C.R. Tritium and health. J.R.S.H. (1988); 6: 203204.

23. Butler, H.L., and J.H. Leroy. Observation of biological half-life of tritium. Health Physics (1965); 11: 283-285.

24. Croach, J.W. Theoretical radiation dose to the human system from assimilated tritium. Health Physics (1973); 24: 17-22.

25. Mortality statistics were provided by the National Cancer Institute, the American Cancer Society, The Cancer Information Service, and the South Carolina Department of Health and Environmental Control. Incidence data was provided be the Savannah River Region Health Information System cancer registry.

\section{Additional References}

Bridges, A.B. Short term screening tests for carcinogens. Nature (1976); 195-200.

Cairns, J. The origin of human cancers. Nature (1981); 289: $353-357$.

Cook-Mozaffari, P., S. Darby, and R. Doll. Cancer near potential sites of nuclear installations. The Lancet (1989); Nov.: 1145-1147.

Crump, K.S., N.G. Tie-Hua, and R.G. Cuddihy. Cancer incidence patterns in the Denver metropolitan area in relation to the Rocky Flats Plant. Amer. J. of Epidem. (1987); 126: $127-135$.

Darby, S.C., and R. Doll. Radiation and exposure rate. Nature (1990); 344: 824 .

DeRouen, T.A., and J.E. Diem. The New Or.leans drinking water controversy. A.J.P.H. (1975); 65: 1060-1062.

Doll. R. Strategy for detection of cancer hazards to man. Nature (1977); 265: $589-596$.

Doll. R. An epidemicilozical perspective of the tiology of cancer. Cancer kesearch (1978); 38: 3573-3583.

Doll. R., and F. Fets. The causes of carcer: quartitative eztimates of avcijakie risks cf cancer in tre united States today. JYCI (1981;; 66: 1293-1265.

Grosen, D.S., and L.E. Hopwod. Eiological eftects of radiation. SEg. Ed., New Yorr: Acadenic Press, 2979. 
Higginson, J., and C.S. Muir. Environmental carcinogenesis: misconceptions and limitations to cancer control. JNCI (1979); 63: 1291-1298.

Hoel, D.G., N.L. Kaplan, and M.W. Anderson. Implication cf nonlinear kinetics on risk estimation in carcinogenesis. Science; 219: 1032-1036.

Hoover, R., T.J. Mason, F.W. McKay, and J.F. Fraumeni, Jr. Cancer by county: new resource for etiological clues. Science; 19: 1005-1007.

Irlweck, K., and D.K. Teherani. Tritium concentration in urine and blood of Austrian residents. Health Physics (1976); 30: 407-409.

Lambert, B.E., and R.J. Clifton. Radiation doses resulting from the administration of tritiated folic acid and tritiated water to the rat. $\mathrm{Br}$. J. Radiol. (1967); 40: 56-61.

Moghissi, A.A., M.W. Carter, and E.W. Bretthauer. Further studies on the long-term evaluation of the biological half-life of tritium. Health Physics (1972); 23: 805-806.

Osbourne, R.V. Permissible levels of tritium in man and the environment. Rad. Res. (1972); 50: 197-211.

Peto, R. Distorting the epidemiology of cancer: the need for a more balanced overview. Nature (1980); 284: 297-300.

Sutherland, J.V. Case analysis: Health hazards of plutonium release from the Rocky Flats Plant. In: Health effects of low-level radiation. W.R. Hendee, ed. Appleton-CenturyCrafts, 1968 .

Upton, A.C. Evolving perspectives on the biology and mechanisms of carcinogenesis. Leuk. Res. (1986); 10: $727-734$.

Wynder, E.L., and G.B. Gori. Contribution of the environment to cancer incidence: an epidemiological exercise. J. Nat. Can. Inst. (1977); 4: 825-832. 


\title{
PHARMACOKINETICS-MATHEMATICAL VS. PHYSIOLOGICAL A SYSTEM SCIENCE APPROACH
}

\author{
Department of Biometry and Fpidemiology \\ Medical University of South Carolina \\ Charleston, SC 29425 \\ Mentors: Dr. Eberhard Voit, Dr. Hong Zhang, Dr Zhen Zhang
}

By: Beverly Charlotte Smith

\section{Introduction}

Physiologically-based pharmacokinetic (PB-PK) modeling and simulation have been an integral part of environmental exposure analysis and health risk assessment. PB-PK models rely heavily on known anatomical, physiological facts for the development of model structure and the determination of model parameters. Compared to the traditional mathematically-based multi-compartment pharmacokinetic models, the PBPK models often have a higher order of complexity in terms of the number of variables and parameters, although they are used to model the same set of dose response data.

In the previous work by Drs. Z. Zhang, H: Zhang, and E. Voit, they derived a set of necessary conditions under which tissue regions in a PB-PK model can be "lumped" together without affecting the computation of the remaining part of the model. For a flow-limited PB-PK model if there is no more tissue region that can be further lumped together, the PB-PK model becomes a "minimum system." It was proved theoretically that such a minimum system and its mathematically-based counterpart model have the same level of complexity and are two possibly different "realizations" of the same system.

The goal for my summer research program is to use computer numerical simulation to experimentally verity the above two theoretical results, namely, for flow-limited PB-PK models, (1) the lumping of tissue regions using the derived necessary condition will not affect the computation of the remaining part of the model; and (2) for the same set of dose response data. a reduced mınimal PB-PK model is equivalent to that of a mathematically based model. 


\section{Methods}

1) Develop a PB-PK model with multiple tissue regions based on data from published literature. The model is so designed that parameters of some of the regions satisfy the derived necessary conditions for region lumping.

2) Conduct numeric simulation to verify that lumping tissue regions under the conditions does not affect the computation of the remaining tissues/organs in a reduced PB-PK model.

3) Use a known PB-PK model to generate a set of test data. A mathematically-based pharmacokinetic model is developed based on the test data and the graph of the data.

4) Derive the system transfer functions for both the mathematically-based model and a reduced model of the original model used to generate the test data. Show the similarity between the two system transfer functions.

5) Conduct numeric simulation to experimentally verify the results in 4).

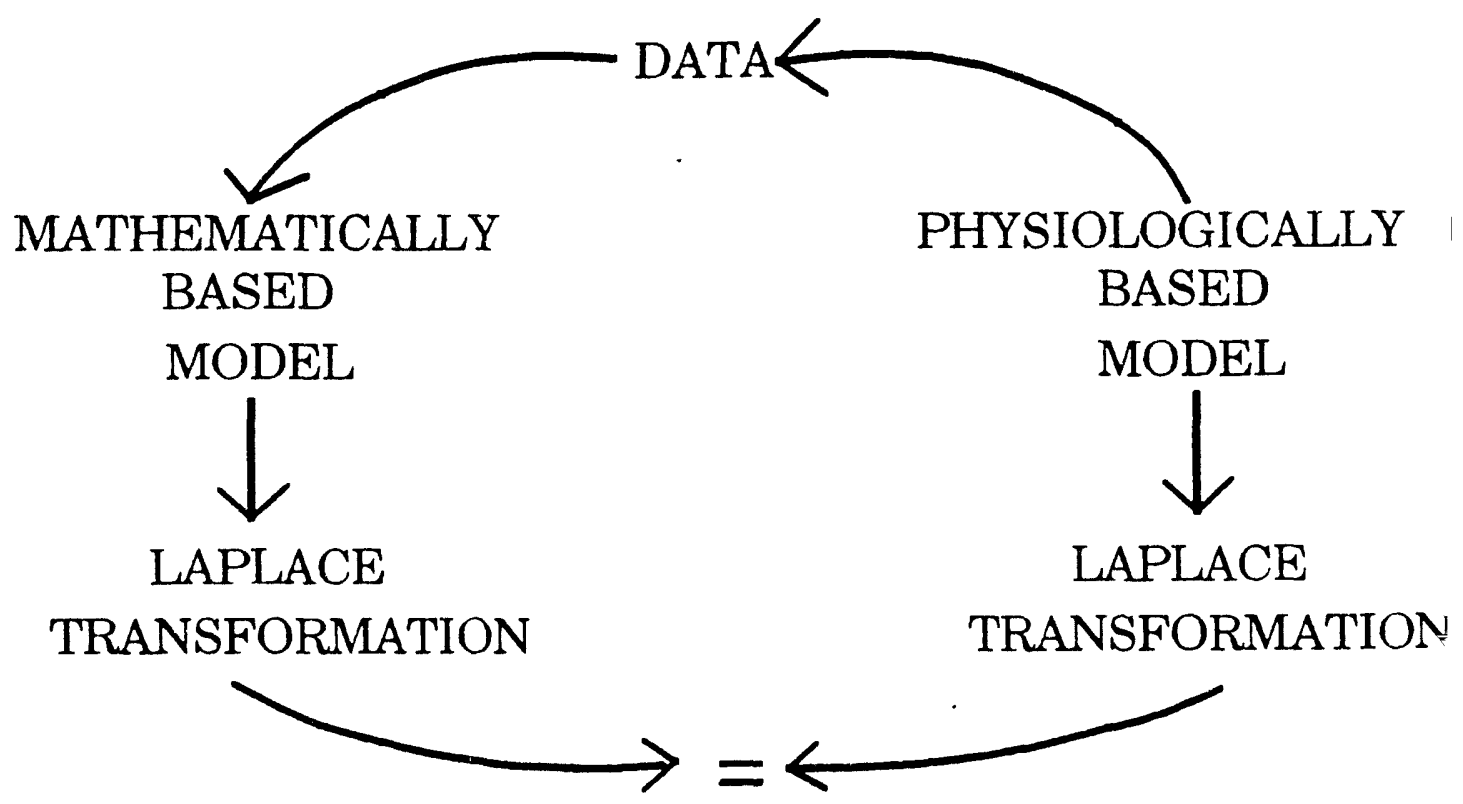




\section{Results}

The physiologically based model produced by my theoretical data set included the blood pool and three compartments: liver, kidney, and muscle. Each compartment has, associated with itself, several variables. The four most important variables in my study were $R$, the partition coefficient; $Q$, the flow rate of the metabolite within the compartment; $V$, the compartment volume; and $C$, the concentration of metabolite in the compartment. In this system two of the compartments satisfied the lumping condition

$$
Q_{k} /\left(R_{k}^{*} V_{k}\right)=Q_{m} /\left(R_{m}^{*} V_{m}\right)
$$

and could, therefore, be lumped or combined to form a minimal system, a system in which no compartments satisfy the lumping condition. The lumped compartment I called "tissue".

This compartment was given an $R_{1}, Q_{1}$, and $V_{1}$ by combining those values of the unlumped compartments in the following manner

$$
\begin{gathered}
Q_{i}=\sum Q_{i} \\
V_{1}=\sum V_{i} \\
R_{t}=\left(\Sigma\left(V_{1}^{*} R_{i}\right)\right) /\left(\sum V_{i}\right)
\end{gathered}
$$

To obtain graphs of the concentrations in each compartment relative to time, differential equations are employed. The formula for any compartment $i$ is

$$
V_{i}^{*}(\delta C / d t)=Q_{1}^{*}\left(C_{p}-C_{i} / R_{i}\right)
$$

where $C_{p}$ is the blood pool concentration. The formula for the blood pool is

$$
V_{p}^{*}\left(\delta C_{p} / d t\right)=\left(\Sigma\left(Q_{1} * C / R_{i}\right)\right)-\left(\left(\sum Q_{i}\right) * C_{p}\right)
$$

where $p$ denotes the blood pool, and i denotes a compartment.

In order to show that the two compartment system was equivalent to the three compartment system, I compared the graphs of the blood pool concentration. The two graphs overlay each other exactly.

The Laplace transformation is a formula used to demonstrate that two or more systems are equivalent regardless of how they appear. The final equations of each system involved should be equal even though they reached such a function by different means. The equation of the transpose is

$$
b(s i-A) c
$$

where $b$ is the row matrix $\left[\begin{array}{lllll}1 & 0 & 0 & \ldots\end{array}\right]$ : $s$ is the laplace operator: 1 , the identity matrix; 
$A$, the coefficient matrix of the differential equations; and $c$, the transpose of $b$.

Depending on the size of your coefficient matrix, this equation can be very complicated. A simpler method is to simply recognize that

$$
b(s \mid-A) c=\operatorname{det}(\text { minor of }(s \mid-A)) / \operatorname{det}(s \mid-A)
$$

In order to create a mathematically based model, I graphed the natural log of the blood pool concentration from the minimal physiologically based system. The blood pool was chosen because that is the only data a study can accurately find. The chemical concentrations in organs and tissues is difficult, if not impossible, to measure. The laplace transformation is viewed slightly differently when working with mathematically based models because there are no differential equations from which to draw data. The disposition, $d$, is defined as

$$
\begin{aligned}
& \Pi_{i}\left(s+E_{i}\right) / \Pi_{1}\left(s+\lambda_{i}\right) \\
& j \in\{1 . . n\} ; i \in\{2 . . n\}
\end{aligned}
$$

where $n$ is the number of compartments in the minimal system (including blood pool); $s$ is, again, the laplace operator; $E$ is the exit rate constant; and $\lambda$ is the disposition rate constant. The disposition rate constant is determined by the slopes of the lines from which the logarithmic plot is formed.

$$
\lambda=-2.303^{*} \mathrm{~m}
$$

where $m$ is the slope. The exit rate constants are determined by the $\lambda$ 's and the $y$ intercepts $\left(A_{1}\right)$.

$$
A / A_{1+1}=\left(\lambda_{1}-E_{i+1}\right) /\left(E_{i+1}-\lambda_{i+1}\right)
$$

With the knowledge of these formulas and the appropriate $\lambda$ 's and $E$ 's from the physiologically based model, lines can be plotted on the plasma graph by computer aided linear regression. The formula for such a line is

$$
y_{1}=a_{1}+b_{1} x_{1}
$$

The $y_{1}$ and $x$ can be figured from the plot. The as, the $y$ intercept, and the $b_{1}$, the slope, can be solved with a series of points or nodes.

Since it is critical that the mathematically based laplace transformation be as close to the physiologically based transform as possible, it is necessary to work backwards. From the physiologically based laplace transform it is known that

$$
\begin{array}{ll}
i_{1}=9.098 & \\
i_{2}=1.219 & E_{2}=6 \\
i_{3}=0.000 & E_{i}=1
\end{array}
$$


The first line was to yield $\lambda_{1}$. By formula \#\#\#, the slope of such a line would have to be -\#\#\#. By choosing appropriate starting and ending nodes on the plasma curve, a tangent with a slope of -3.23 (approximately accurate) was found. Thus $\lambda 1$ was \#\#\#\#. Each line was derived in this manner. The y-intercepts $\left(A_{1}, A_{2}, A_{3}\right)$ could then be estimated and solutions $E_{2}$ and $E_{3}$ found. The mathematical laplace created was

$$
[(s+3.46) *(s+0.118)] /[(s+5.44) *(s+0.209) *(s+0.019)]
$$

This transform is relatively close to the physiologically based one.

In order to get a better view of how close the mathematically based model was to the physiologically based model, the inverse laplace of each function was graphically compared.

The inverse laplace function is

$$
f(t)=0.372^{*} e^{\cdot\left(t^{*} .44\right)}+0.296^{*} e^{-\left(t^{* 0.209)}\right.}+0.333^{*} e^{-(1 * 0.019)}
$$

for the mathematically based model and

$$
f(t)=0.35^{*} e^{-\left(t^{*} \cdot 098\right)}+0.109^{*} e^{-(1 \cdot 1.219)}+0.541^{*} e^{-\left(10^{*} 0\right)}
$$

for the physiologically based model.

\section{Discussion}

Overall, as I had originally asserted, the mathematically based pharmacokinetic model produces the same result as the physiologically based model. I was very surprised at how close to equivalent the models were. Although I expected such results, I also expected a large experimental error. I must assume the small error that I found was due to the method I used to choose the starting and ending nodes by which I derived the mathematical model. I simply eyeballed where I felt the lines should fall. In future tests of the equivalence between mathematically based models and physiologically based models, a better method of the node-choosing should be implored, and real data should be used rather than the experimental data I produced.

Although this experiment shows that the two modelling methods are mathematically equivalent, they are not equivalent in their usefulness. The Physiologically based model is used for extrapolation between species. It has also become a promising tool in environmental health risk assessment. The mathematically based model is only useful within a single species for interpolation and limited extrapolation. It is important that both methods be preserved for their different purposes. 


\section{Toluene Toxicity : Metabolism by Isolated Rat Hepatocytes \\ Amy Weaver and JoEllyn McMillan, Ph.D. \\ Pharmacology Department; Medical University of South Carolina \\ Summer Undergraduate Research Program}

Toluene is a popular organic solvent used worldwide in industrial settings. It is found extensively as a component in gasoline and refinery oils, as an ingredient in paint thinners and adhesives, and as an intermediate in the synthesis of many organic chemicals (Donald et al. 1991). Because of its widespread use it has become the most abundant aromatic hydrocarbon contaminant at many waste sites. At DOE sites it is present in soil at levels up to 1,000 times and in water up to 10 times higher than that of the EPA's proposed maximum contaminant level in drinking water (Riley et al., 1992).

Acute toluene toxicity is characterized by its central nervous system effects, which has led to the abuse of toluene for its intoxicating effects, i.e. "glue-sniffing" (Chapman et al., 1990). Chronic effects of exposure to toluene have been observed in the central nervous system, liver, heart and kidneys of experimental animals and humans. Recent studies have implicated it as an embryotoxin and fetotoxin and a potential immunotoxin. In addition, toluene exposure has been shown to result in an increased number of micronuclei within polychromatic erythrocytes obtained from mouse femoral bone marrow, and this response could be increased by pre-treatment of the mice with hepatic cytochrome P-450 inducers (Chapman et al., 1990).

Toluene is metabolized by the hepatic cytochrome $\mathrm{P} 450$ system to several oxidative products. Oxidation of the aromatic ring is thought to result in formation of a reactive intermediate(s) that binds covalently to biomolecules; covalent binding to a key protein(s) may lead to manifestation of toluene toxicity (Nakajima et al., 1992).

In these studies, we wanted to examine the metabolism of toluene by rat hepatocytes and hypothesized that benzyl alcohol would be the major metabolite formed.

\section{MATERIALS AND METHODS}

Animals. Male Long Evans rats weighing $200-300) \mathrm{g}$. were used in Toluene treated rat hepatocyte experiments. All rats were maintained on pelleted feed and water. 
Isoiation of hepatocytes. Hepatocytes were isolated according to the Collagenase Perfusion Method (McMillan et al., 1992).

Incubation and Assays The metabolism of Toluene was determined by measuring the rate of formation of benzaldehyde, benzoic acid, benzyl alcohol, hippuric acid, and o- and p-cresol. $1 \mathrm{mM}$ Toluene was added to the hepatocytes. Vials containing $1 \mathrm{ml}$ of cells $\left(8 \times 10^{6}\right.$ cells $\left./ \mathrm{ml}\right)$ were placed in a shaking water bath at $37.0^{\circ} \mathrm{C}$ for 2 hours. The hepatocytes were quick frozen to stop the reaction and then stored in the freezer. The scintillation vials were then taken out of the freezer, placed at room temperature, and allowed to thaw. The hepatocytes were centrifuged to separate out the proteins, and $20 \mu$ of the supernatant was injected onto a high-performance liquid chromatography system (HPLC, Waters Associate Chromatography Pump) with UV detector (Waters 481). The conditions were as follows : a Resolve reverse phase $\mathrm{C}-18$ radial compression module; mobile phase $1,6 \%$ methanol : $94 \% 0.01 \mathrm{M}$ potassium phosphate at $\mathrm{pH} 3.5$; mobile phase II, $50 \%$ methanol : $50 \% 0.01 \mathrm{M}$ potassium phosphate at $\mathrm{pH} 3.5$ and a flow rate of $2.0 \mathrm{~mL} / \mathrm{min}$; wavelength $254 \mathrm{~nm}$.

$\beta$-glucuronidase To determine the extent of glucuronic acid formation, the major conjugate of benzyl alcohol in the hepatocytes, incubation with B-glucuronidase solution was used. Incubation with B-glucuronidase was carried out by centrifuging out the proteins, adding 4 volumes of ethanol for 1 volume of hepatocytes, and drying down the solution in an evaporator. The residue was then resuspended in $200 \mu \mathrm{l}$ of water. $200 \mu \mathrm{l}$ of the B-glucuronidase solution which was (a 1:10 dilution of $\mathrm{B}$-glucuronidase with $1 \mathrm{M}$ Sodium Acetate at $\mathrm{pH} \mathrm{5.2)}$ was added to the resuspended solution. The solution was allowed to incubate in a water bath at $37.0^{\circ} \mathrm{C}$ for 16 hours. At the end of 16 hours, TCA was added to stop the reaction. The proteins were centrifuged out, and $20 \mu \mathrm{l}$ of the supernatant was injected onto the HPLC.

\section{RESULTS}

Toluene metabolism in rat hepatocytes. Benzaldehyde, benzyl alcohol, hippuric acid, o- and pcresol were not found in toluene treated hepatocytes. Benzoic acid was the main metabolite observed in the toluene treated hepatocytes; it had a retention time of 40) minutes (Fig. 1). 


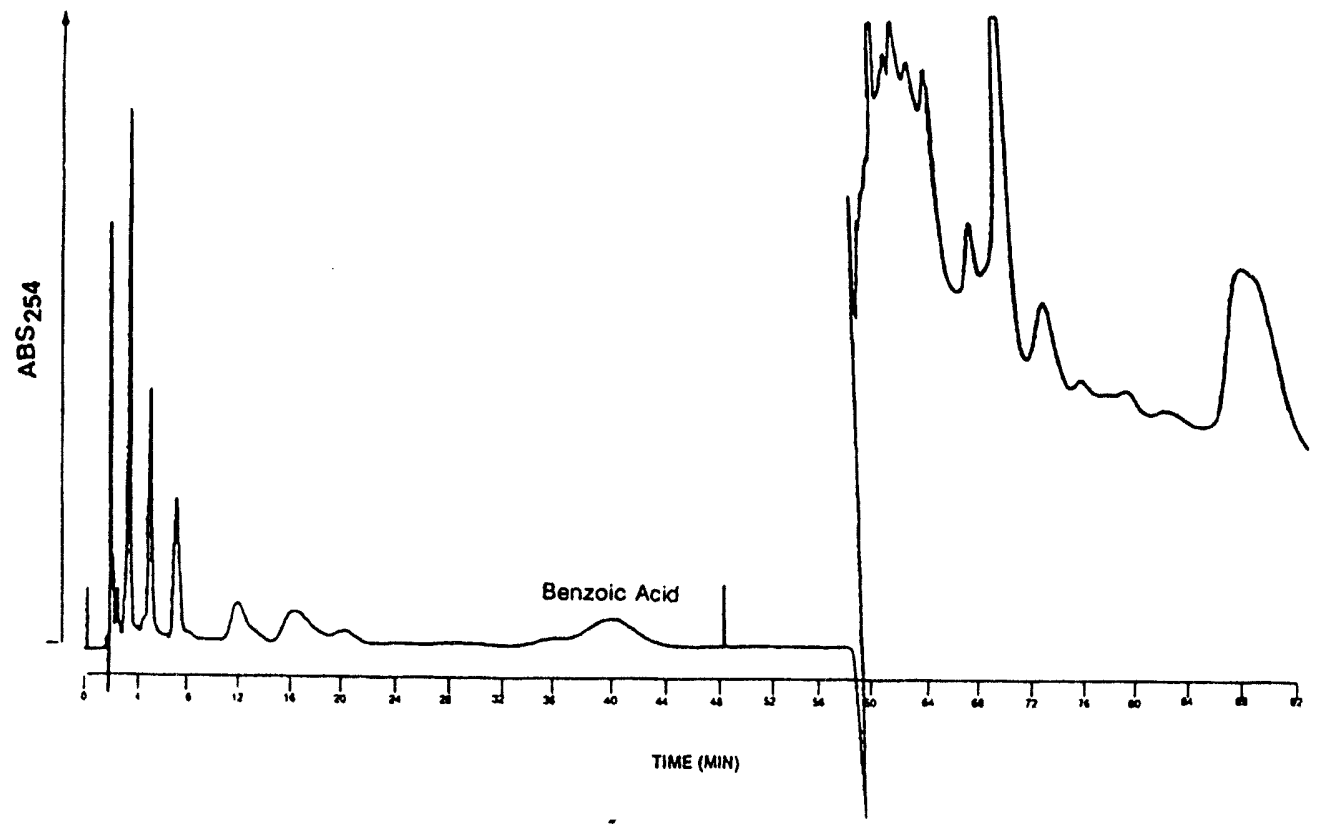

Fig.1. An HPLC Chromatogram of Toluene treated rat bepatocyres at the 2 bour time point. The only metabolite detected was benzoic acid witb a retention time of 40 minutes. At 48 minutes, the mobile phase was switcbed from Mobile Phase I to mobile phase II. Un-metabolized wiluene had a retention time of 60 minutes.

$\beta$-Glucuronidase digest of Toluene treated rat hepatocytes. To determine the presence of glucuronic acid conjugates, B-glucuronidase digest was used. B-Glucuronidase digest should cause a significant increase in the benzyl alcohol peak and a significant decrease in the glucuronide conjugate. A significant increase was observed at the retention time of benzyl alcohol, 20 minutes, but no significant decrease in any peak was observed when B-glucuronidase was incubated alone; the increase at 20 minutes proved to be a contaminant in the B-glucuronidase solution (Fig. 2). 


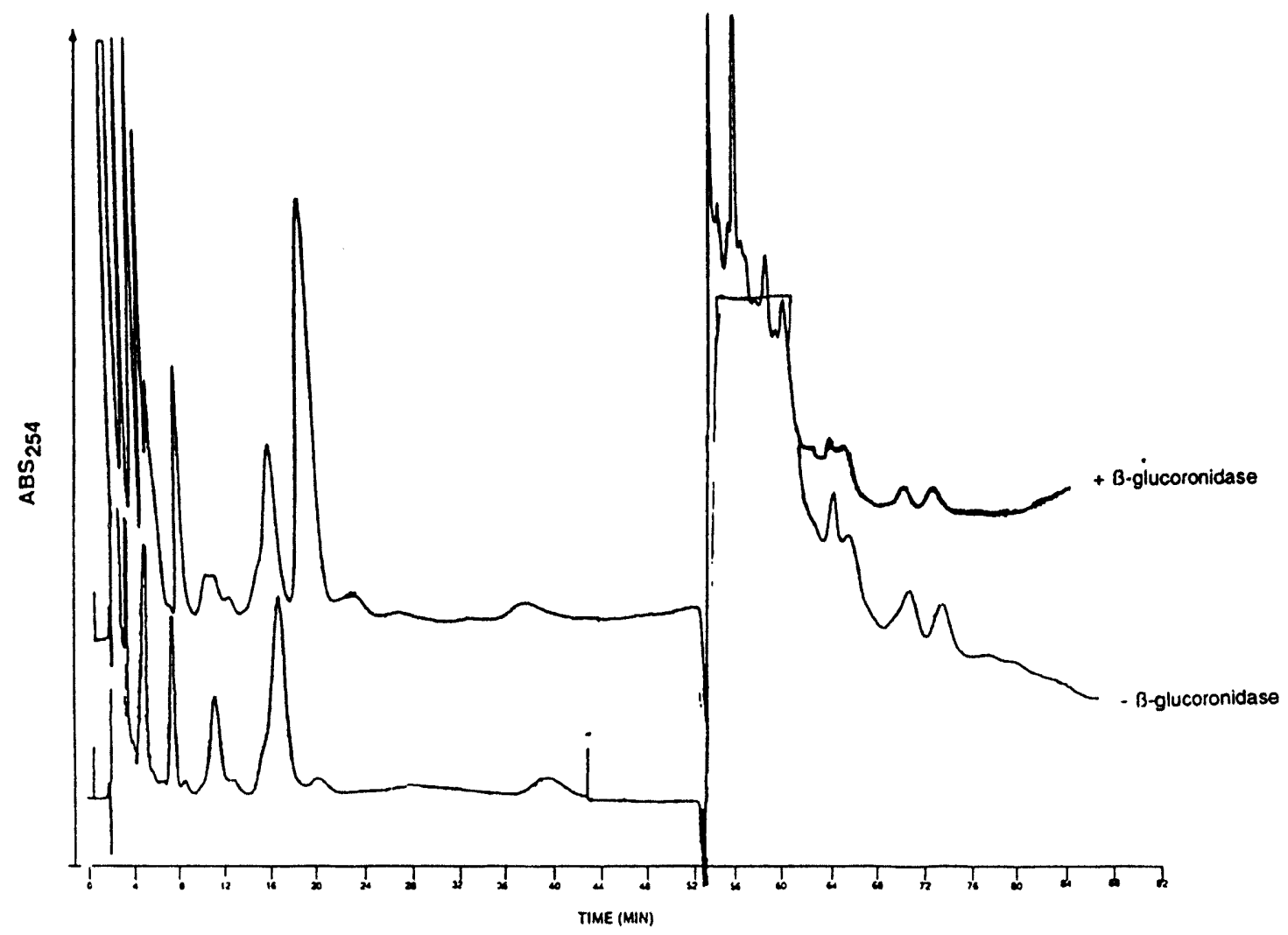

FIG.2. An HPLC Chromatogram of Toluene treated rat bepatocytes with and without B-glucuronidase digest at 16 bours. An inzrease is observed in the peak eluting at 20 minutes. A benzoic acid peak was observed again at 40 minutes. At 48 minutes, the mobile phase was switched from Mobile Pbase I to Mobile Pbase II. Un-metabolized toluene had a retention time of 60 minutes.

Metabolism of Benzyl Alcohol. Since there were no peaks corresponding to the retention time of benzyl alcohol at 20 minutes, which was hypothesized to be the major metabolite of toluene, an incubation with benzyl alcohol being added to the hepatocytes instead of toluene was carried. No peaks of benzyl alcohol or its glucuronic acid could be seen. Only a peak of benzoic acid could be seen at the corresponding retention time of 40 minutes (Fig. 3). 


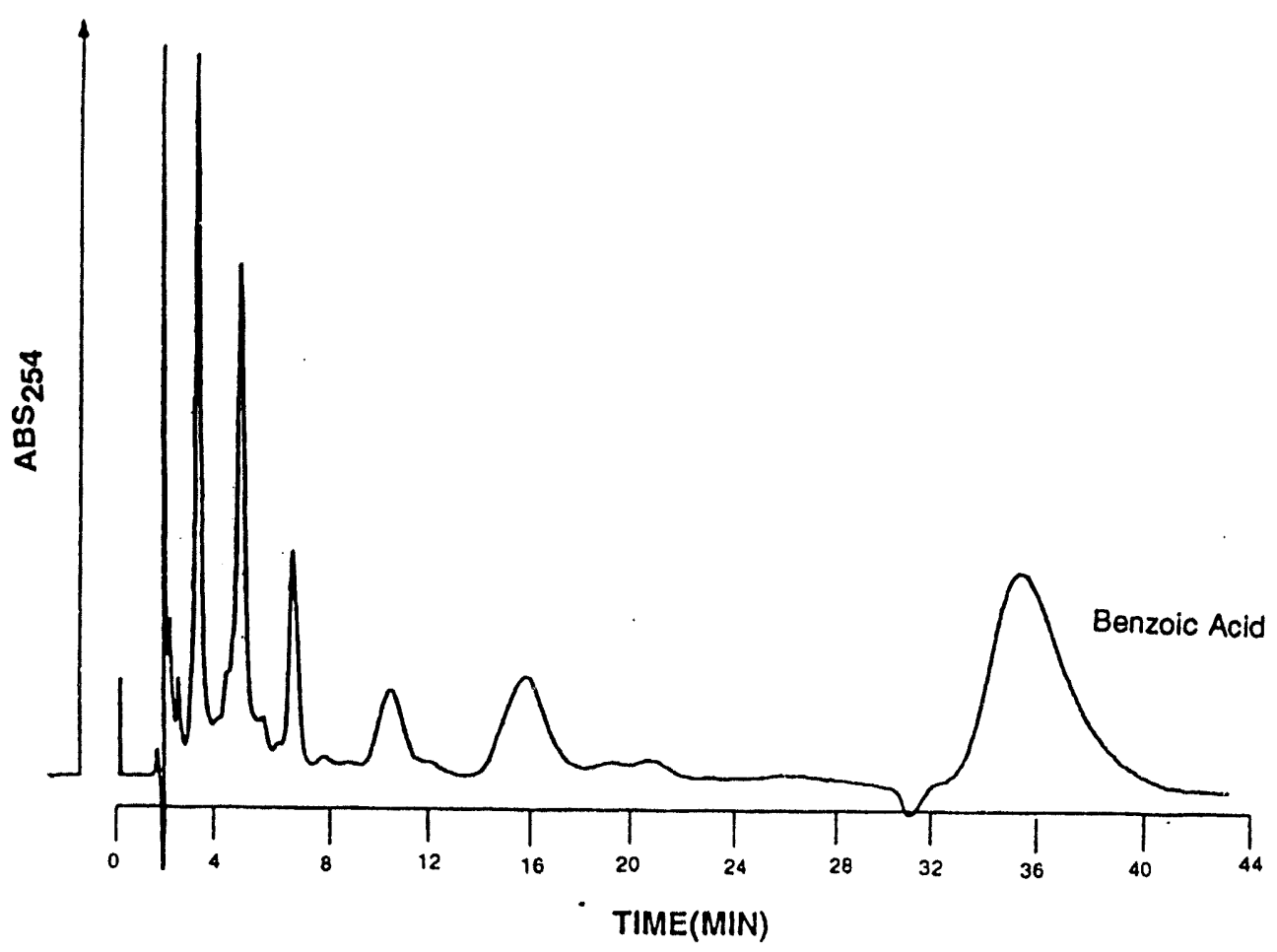

FIG. 3. An HPLC Chromatogram of Benzyl Alcobol treated bepatocyres at 2 bours. A peak corresponding to the 40 minute retention time of benzoic acid could be observed. A peak of benzyl alcohol could not be seen at its retention time of 20 minutes.

$\beta$-Glucuronidase digest with Benzyl Alcohol treated rat hepatocytes. B-Glucuronidase of benzyl alcohol was done to see if the glucuronic acid conjugate could be seen. Once again digestion with B-glucuronidase should show an increase in one peak height and a decrease in another. A significant increase was observed at the retention time of benzyl alcohol, 20 minutes, but no significant decrease could be seen. However, this significant increase in peak height proved to be a contaminant, as mentioned before, upon incubation of B-glucuronidase alone (Fig. 4). 


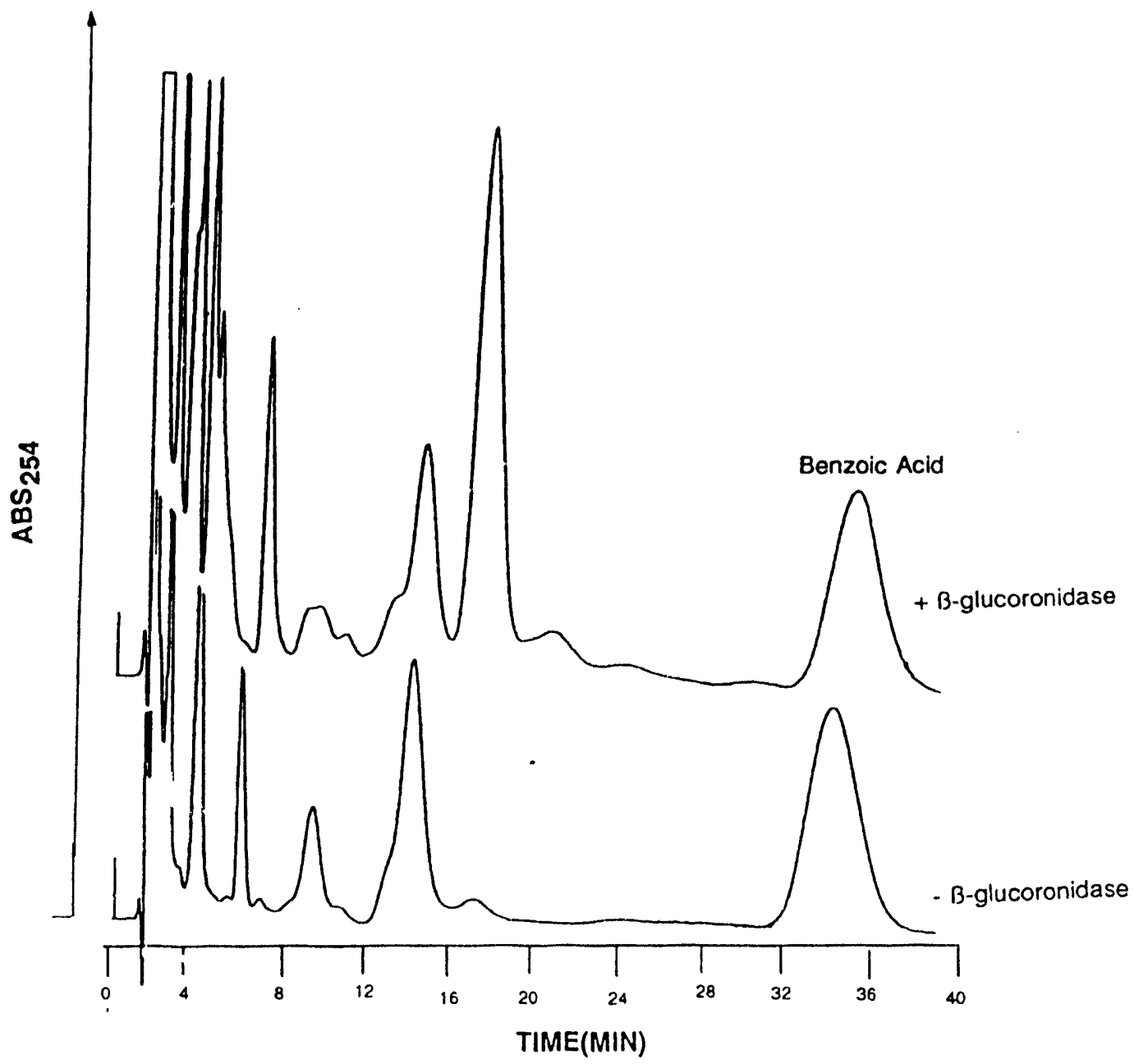

FiG. 4. An HPLC Chromatogram of Benzyl AJcohol treated rat bepatocytes with and without B-glucuronidase digest at 16 bours. An increase in peak height is observed again at 20 minutes. Again, the benzoic acid peak is seen at 40 minutes.

Quantitative Study of Toluene Metabolism. Benzoic acid was injected onto the HPLC at various concentrations to determine quantitatively how much benzoic acid was being formed from toluene. The concentration of benzoic acid formed in the hepatocytes was $(0.43 \mu \mathrm{M}$ (Fig. 5). 


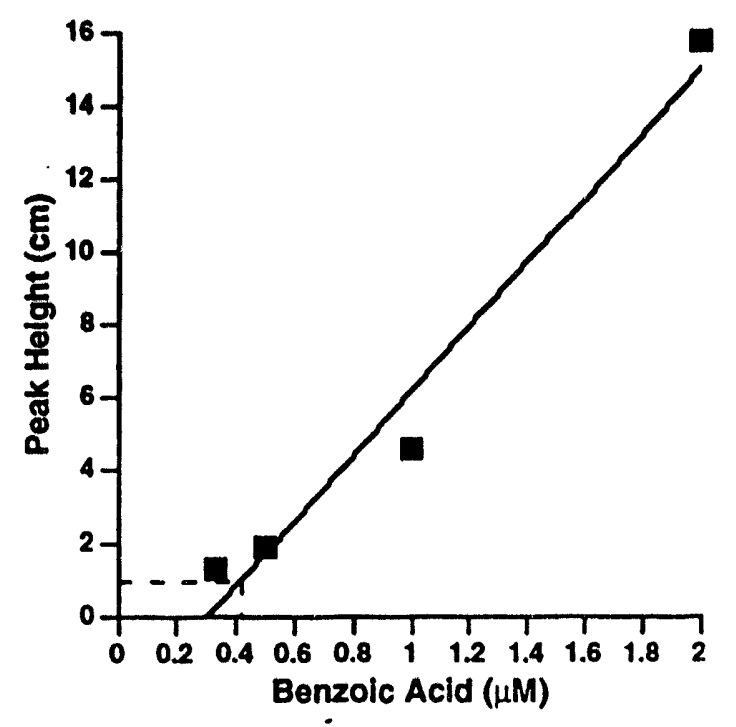

Fig. 5. Concentration vs. Peak Height for Benzoic Acid. The dashed line represents the concentration of Benzoic Acid in the rat hepatocytes after toluene treatment.

\section{DISCUSSION}

Results of HPLC analysis show that benzoic acid was the major metabolite formed from toluene in rat hepatocytes. The hypothesized major metabolite, benzyl alcohol, could not be seen. This could be due to one of two possibilities: either toluene was being metabolized to benzoic acid so quickly that benzyl alcohol could not be observed or toluene was being metabolized directly to benzyl alcohol glucuronic acid. The latter could be determined by B-glucuronidase digest, but failed to show benzyl alcohol release. This failure was due to the contaminant found on incubation of B-glucuronidase in a later experiment. However, the idea that benzoic acid was being formed 
very quickly was further supported by a HPLC analysis on a sample treated with benzyl alcohol taken as a zero time point. For the time it took to quick freeze the sample, benzoic acid was already being formed.

Our results support the findings of Chapman et al. (1990). Chapman et al. found that benzyl alcohol was the major metabolite in microsomes while benzoic acid was the major metabolite in liver slices. Our results show that benzoic acid is the major metabolite in whole cell samples or liver hepatocytes. The enzymes alcohol and aldehyde dehydrogenase would carry out the conversion of benzyl alcohol to benzoic acid. These enzymes are soluble enzymes and would not be present in a microsomal suspension. In intact cells benzyl alcohol would be further metabolized to benzoic acid, whereas in microsomes only benzyl alcohol would be formed. Our findings indicate that rat hepatocytes can be used in studies if toluene toxicity.

\section{References}

Chapman, Dennis E., Moore, Tracy J., Michener, Sandra R., and Powis, Garth. (1990).

Metabolism and Covalent Binding of [ ${ }^{14} \mathrm{C}$ ]Toluene by Human and Rat Liver Microsomal Fractions and Liver Slices. Drug Metabolism and Disposition. 18, 929-936.

Donald, James M., Hooper, Kim, and Hopenhayn-Rich, Claudia. (1991).Reproductive and Developmental Toxicity of Toluene: A Review. Environmental Health Perspectives. 94, 237 244.

McMillan, JoEllyn M., and Jollow, David J. (1992). Galactosamine Hepatotoxicity: Effect of Galactosamine on Glutathione Resynthesis in Rat Primary Hepatocyte Cultures. Toxicology and Applied Pharmacology. 115, 234.240.

Nakajima, Tamic; Wang, Rui-Sheng; Katakura, Yohko; Kishi, Reiko; Elovaara, Eivor; Park, Sang S.; Gelboin, Harry V.; and Vainio, Harri. (1992). Sex-, Age-, and Pregnancy-Induced Changes in the Metabolism of Toluene and Trichloroethylene in Rat Liver in Relation to the Regulation of Cytochrome P450llEI and P4501IC1 I Content. The Joumal of Pharmacology and Experimental Therapeutics. 261:3,869-874. 
Riley, R.G., and Zachara, J.M. (1992). Chemical Contaminants on DOE Lands and Selection of Contaminant Mixtures for Subsurface Science Research. U.S. Department of Energy. DOE/ER-0547T, $i$-xiii and 1-77.

THIS PUBLICATION IS SUPPORTED BY FUNDS FROM THE U.S. DEPARTMENT OF ENERGY GRANT DE-FG01-92EW50625 AND THE MEDICAL UNIVERSITY OF SOUTH CAROLINA'S ENVIRONMENTAL HAZARDS ASSESSMENT PROGRAM. 

